\title{
FALLAMIENTO NEOTECTÓNICO DE LA PENÍNSULA DE NICOYA Y SU RELACIÓN CON EL ESCAPE TECTÓNICO DEL ANTEARCO CENTROAMERICANO
}

\author{
NEOTECTONIC FAULTING OF THE NICOYA PENINSULAAND ITS RELATION \\ WITH THE TECTONIC ESCAPE OF THE CENTRALAMERICAN FOREARC SLIVER
}

\author{
Walter Montero $^{2 *} \&$ Percy Denyer ${ }^{1,2}$ \\ ${ }^{1}$ Escuela Centroamericana de Geología, Universidad de Costa Rica, Apdo. \\ 214-2060, Ciudad Universitaria Rodrigo Facio, Costa Rica \\ ${ }^{2}$ Centro de Investigaciones en Ciencias Geológicas (CICG), Universidad de Costa Rica \\ *Autor para contacto: wmontero@geologia.ucr.ac.cr
}

(Recibido: 9/03/2011; aceptado: 28/11/2011)

\begin{abstract}
A neotectonic array of faults has been determined in the Nicoya peninsula. In the central and NW sectors of the peninsula, blocks restricted by N-S trending dextral slip faults predominates. ENE sinistral slip faults and E-W oblique sinistral-reverse and NW pure reverse faults are confined to the dextral fault blocks. The previous spatial relationships between the different faults are explained by the north translation of this sector of the peninsula and the transrotation occurring inside the blocks. Sinistral and dextral slip faults with apparent similar relevance, and subordinate reverse faults have been mapped in the southern Nicoya peninsula. $\mathrm{N}$ and less probably E translational movements are inferred in this sector. The neotectonic faulting of the Nicoya peninsula is associated with the Cocos Ridge collision with the central and southern Costa Rica convergent margin, causing the tectonic escape to the NW of the Central American forearc sliver, parallel to the Middle America trench.

Key words: Neotectonics, morphotectonics, seismotectonics, Nicoya, Costa Rica.

RESUMEN: Se ha determinado un arreglo de fallas neotectónicas dentro de la península de Nicoya. En la parte central y NW de la península predominan bloques limitados por fallas de desplazamiento de rumbo dextral con rumbo N-S, dentro de los cuales se reconocen fallas sinestrales de rumbo ENE, oblicuas sinestrales-inversas con rumbo E-W e inversas de rumbo NW. Las anteriores relaciones espaciales entre los diversos tipos de fallas se explican por traslación al $\mathrm{N}$ de este sector de la península y la transrotación que ocurre dentro de los bloques. Las fallas cartografiadas en la zona $\mathrm{S}$ de la península se han interpretado como sinestrales y dextrales con una relevancia aparentemente similar, además se han definido fallas inversas subordinadas. Movimientos translacionales al $\mathrm{N}$ y menos probable al E se infieren en la misma. El arreglo de fallas neotectónicas de la península de Nicoya es asociado con la colisión de la cordillera del Coco bajo el margen convergente del centro y S de Costa Rica, el cual origina el escape tectónico del bloque del Antearco Centroamericano hacia el NW, paralelo a la fosa Mesoamericana.

Palabras clave: Neotectónica, morfotectónica, sismotectónica, Nicoya, Costa Rica.
\end{abstract}




\section{INTRODUCCIÓN}

La interacción de levantamientos oceánicos en zonas de convergencia de placas provoca diversos efectos tectónicos en la placa cabalgante, incluyendo la generación de fallas tanto compresivas como de desplazamiento horizontal. Un ejemplo bastante estudiado en la literatura es donde colisiona el levantamiento d'Entrecasteaux con el arco de islas de la Nueva Hébridas, en el pacífico occidental (Collot et al., 1985; Taylor et al., 2005). En el NW de Costa Rica se presenta una situación tectónica similar, dado que bajo el sector central-S de la península de Nicoya, la placa Coco subduce bajo la placa Caribe, una corteza rugosa formada en la paleo-dorsal Coco-Nazca y la serranía submarina de Fisher, mientras que hacia el SE de la península se subducen varios levantamientos submarinos incluyendo la cordillera del Coco, la cual origina un proceso tipo colisión con el S de Costa Rica (Fig. 1; Montero, 1994; Kolarsky et al., 1995; LaFemina et al., 2009). Por lo anterior, resulta relevante estudiar los efectos tectónicos que las anteriores batimetrías submarinas causan en el antearco NW de Costa Rica.

Estudios recientes han determinado que como consecuencia de la subducción de la serranía de Fisher, bajo la parte $\mathrm{S}$ de la península de Nicoya, ha ocurrido una rotación holócenica alrededor de un eje horizontal en la misma (Gardner et al., 2001), levantamientos verticales (Fisher et al., 1998), y fallamiento neotectónico (Marshall et al., 2008; Montero \& Denyer, 2008). En este estudio ampliamos los estudios anteriores reportando la existencia de un arreglo de fallas neotectónicas, distribuido dentro de la península de Nicoya, el cual ha sido identificado mediante análisis morfotectónico y complementado con datos geológicos y sismológicos. El estudio ha permitido reconocer dos dominios, el primero de tipo translacional al N, localizado en la región centralNW de la península y representando por fallas principales de movimiento dextral N-S y fallas sinestrales de rumbo ENE a inversas NW, estas dos últimas limitadas por las dextrales. La anterior distribución de fallas es explicada mediante un modelo de transrotación. Al segundo dominio, localizado en la región $\mathrm{S}$ la península, no se le ha determinado un movimiento translacional predominante e incluye fallas de desplazamiento de rumbo dextrales de rumbo N-S y sinestrales ENE. Asimismo, se han definido fallas de movimientos oblicuos sinestrales-inversos e inversas de rumbo cercano al E-W.

Para explicar la deformación neotectónica anterior, se discuten dos modelos: 1 . La convergencia oblicua entre las placas Coco y Caribe y el movimiento resultante del bloque del Antearco Centroamericano al NW a una tasa de unos $8 \mathrm{~mm} /$ año (Norabuena et al., 2004) y 2. La indentación tectónica causada por los levantamientos de Fisher y del Coco con el margen pacífico de Costa Rica y en particular con la península de Nicoya y el escape tectónico al NW de la península de Nicoya a una tasa de $8 \mathrm{~mm} /$ año (Montero, 1994; La Femina et al., 2009).

\section{MARCO TECTÓNICO}

Costa Rica se encuentra localizada en el borde $\mathrm{W}$ de la placa Caribe y de la microplaca de Panamá, bajo las cuales se subduce la placa Coco a lo largo de la fosa Mesoamericana, con una tasa de convergencia de $8 \mathrm{~cm} /$ año frente al NW de Costa Rica (DeMets et al., 2010; Fig. 1). La geometría de la zona de subducción cambia a lo largo de Costa Rica, desde una zona sísmica que alcanza los 200 $\mathrm{km}$ de profundidad en el NW, disminuyendo su profundidad a unos $120 \mathrm{~km}$ bajo el centro del país (Protti et al., 1995), y a unos $70 \mathrm{~km}$ de profundidad bajo el SE de Costa Rica (Arroyo, 2001). Estos cambios en la zona sísmica Wadati-Benioff han sido relacionados con la batimetría submarina y la edad de la placa oceánica del Coco, que se introduce bajo el territorio costarricense (Fig. 1; Kolarsky et al., 1995; Protti et al., 1995).

Bajo el NW de la península de Nicoya se subduce una litósfera oceánica formada en la dorsal del Pacífico E (DPE), la cual se caracteriza por mostrar un piso oceánico de morfología relativamente suave, con una edad de 24 Ma frente a la fosa, el cual ha sido denominado como el segmento liso de la placa Coco (Fig. 1; von Huene et al. 1995, 2000; Barckhausen et al., 2001). Bajo la costa SW de la península de Nicoya se subduce el 


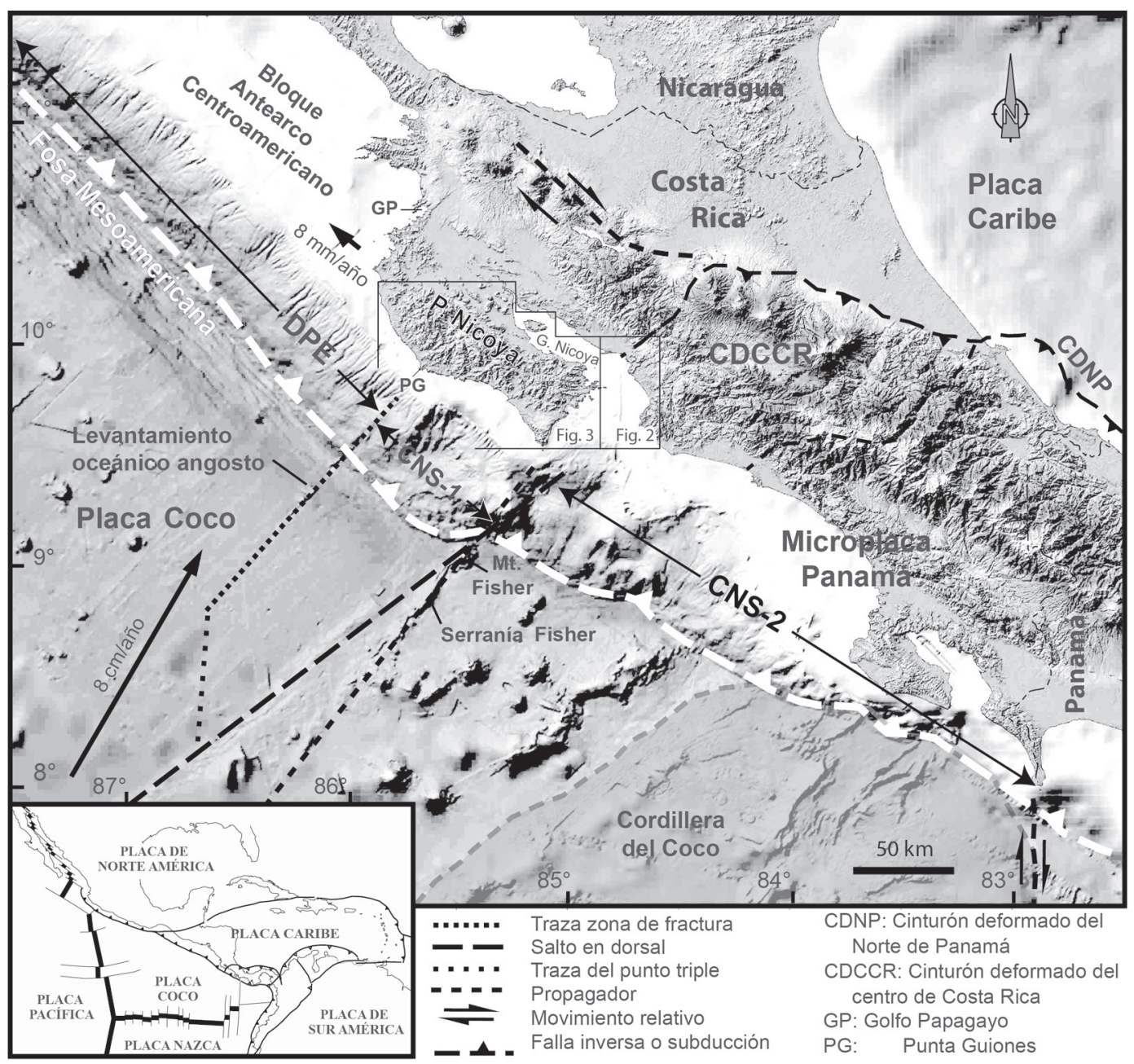

Fig. 1: Batimetría del fondo oceánico del lado pacífico de Costa Rica y modelo de elevación digital del país. Los límites tectónicos dentro de la placa Coco son mostrados de acuerdo con Barckhausen et al. (2001). Se observan entre otros, la serranía de Fisher y la cordillera del Coco (definido entre las líneas a trazos gris claro). DPE, CNS-1, CN-2 son respectivamente, la cortezas subducidas bajo la placa cabalgante Caribe formadas en la dorsal del Pacífico E y en el primer y en el segundo centro de dispersión entre las placas Coco y Nazca. Un levantamiento oceánico angosto separa las cortezas DPE y CNS-1. Los rectángulos en gris muestran las áreas cubiertas por las figuras 2 y 3 . Las flechas con los valores de $9 \mathrm{~cm} /$ año y de $8 \mathrm{~mm} /$ año muestran respectivamente, las velocidades del vector de movimiento relativo entre las placas Coco-Caribe y la del bloque del Antearco Centroamericano, que es paralelo a la fosa Mesoamericana. El modelo de sombras se hizo con base en datos SRTM (USGS, 2004) y el modelo batimétrico con la base de datos del Marine Geoscience Data System de Lamont-Doherty Earth Observatory de la Universidad de Columbia y von Huene et al. (1995).

primer precursor de la corteza oceánica formada en la dorsal entre las placas Coco y Nazca, denominada CNS-1 y que tiene una edad entre 22,5 y 22,0 Ma (Barckhausen et al., 2001). El límite entre ambos tipos de cortezas oceánicas es una serranía oceánica angosta, que está siendo subducido bajo punta Guiones (Fig. 1). La corteza que se subduce bajo el centro-SE de Costa Rica fue for- mada en un centro de dispersión de edad intermedia denominado CNS-2 (19 Ma al NW y de $15 \mathrm{Ma}$ al SE) (Barckhausen et al., 2001). Esta corteza se puede dividir en el segmento dominado por montes submarinos, localizado frente a la zona central de Costa Rica y por el segmento de la cordillera del Coco, que se subduce bajo el $\mathrm{S}$ de Costa Rica. El espesor de la corteza CNS-2, pasa de unos 11 
$\mathrm{km}$ al NW hasta más de $20 \mathrm{~km}$ de espesor bajo la cordillera submarina del Coco (Walther, 2003), por lo que al ser subducida origina un proceso tipo colisión con el S de Costa Rica (Montero, 1994; Kolarsky et al., 1995; LaFemina et al., 2009). El límite entre el segmento suave y el dominado por montes submarinos es la serranía de Fisher y el monte de Fisher (Fig. 1). La serranía de Fisher originalmente fue una zona de fractura, un "propagator", a lo largo del cual ocurrió vulcanismo durante el Mioceno, formando montes submarinos como el monte de Fisher (Barckhausen et al., 2001). Dado que su rumbo es paralelo al vector de convergencia Coco-Caribe, se ha subducido en la misma posición con respecto al margen costarricense durante por lo menos los últimos 1-2 Ma. La serranía de Fisher tiene un ancho en su base de alrededor de $10 \mathrm{~km}$ y un relieve de hasta más de 2 $\mathrm{km}$ de alto (Barckhausen et al., 2001).

La subducción de montañas submarinas y levantamientos oceánicos angostos bajo el margen continental provocan diversos efectos tectónicos sobre la placa cabalgante, de acuerdo con su morfología, tamaño, extensión y edad. Wells et al. (1988), Gardner et al. (1992, 2001), Fisher et al. (1994, 1998), Kolarsky et al. (1995), von Huene et al. (1995), Ranero \& von Huene (2000) y MacMillan et al. (2004), entre otros, estudiaron los efectos tectónicos causados por la subducción de diversas batimetrías submarinas en el antearco costarricense. Al SW de la península de Nicoya destacan la formación de surcos profundos $\mathrm{y}$ protuberancias dómicas en el piso submarino (Ranero \& von Huene 2000; von Huene et al., 1995). Asimismo, la rotación alrededor de un eje vertical del S de la península de Nicoya, ha sido asociado con la subducción de montañas submarinas o con la decapitación de las mismas durante la subducción (Gardner et al., 2001).

Los estudios geológicos y tectónicos realizados en la península de Nicoya han enfatizado primordialmente en el análisis pre-Miocénico (Dengo, 1962; Gursky, 1988; Chinchilla, 1999; Flores et al., 2003). Entre los trabajos regionales que involucran el análisis de la tectónica reciente tenemos el de Chinchilla (1999), quién definió una fase de exten- sión NNW-SSE en rocas plio-pleistocénicas y Hare \& Gardner (1985), quienes modelaron la deformación neotectónica de la superficie de erosión Cerro Azul, como un semi-domo fallado. Asimismo, Marshall et al. (2008) y Montero \& Denyer (2008) refieren evidencias de fallamiento neotectónico dentro de la península de Nicoya. Además, existen varios trabajos que han estudiado los levantamientos costeros los cuales han sido relacionados con los grandes terremotos interplaca Coco-Caribe (p.e. Marshall \& Anderson, 1995) y con la deformación causada por la subducción de montañas submarinas (p.e. Fisher et al., 1998; Gardner et al. 2001; Sak et al., 2009). Asimismo, los vectores de velocidad horizontal obtenidos de las estaciones GPS en la península de Nicoya (denominado bloque del Antearco Centroamericano, Fig. 1), han permitido establecer que esta tiene un movimiento horizontal paralelo a la fosa Mesoamericana, de $\sim 8 \mathrm{~mm} /$ año al NW, lo cual ha sido relacionado con convergencia oblicua (Norabuena et al., 2004) o con un escape tectónico debido a la colisión de la cordillera del Coco (Montero, 1994; LaFemina et al., 2009).

La geología de la península de Nicoya de Costa Rica es dominada por rocas predominantemente basálticas de afinidad oceánica del Jurásico-Cretácico (Denyer \& Alvarado, 2007; Denyer \& Gazel, 2009; Fig. 2). Sobre este basamento se depositaron sedimentos pelágicos, hemipelágicos y turbidíticos, durante el Cretácico tardío y el Paleógeno, en cuencas ubicadas del lado interno (golfo de Nicoya) y externo (SW) de la península. Rocas del Oligoceno solo se encuentran al $\mathrm{N}$ de punta Guiones y rocas del Mioceno-Plioceno solo se encuentran al $\mathrm{S}$ de la península y en la parte interna del golfo de Papagayo, donde afloran depósitos marinos neríticos del Mioceno Inferior al Plioceno (Figs. 1 y 2). Durante el Cuaternario se han depositado depósitos continentales, tanto en forma de aluviones de plano aluvial, como terrazas locales en valles estrechos y abanicos aluviales. En la margen oriental del golfo de Nicoya, la geología es dominada por la cobertura sedimentaria del Cretácico-Terciario, depósitos volcánicos del Neógeno y depósitos aluviales del Cuaternario. 


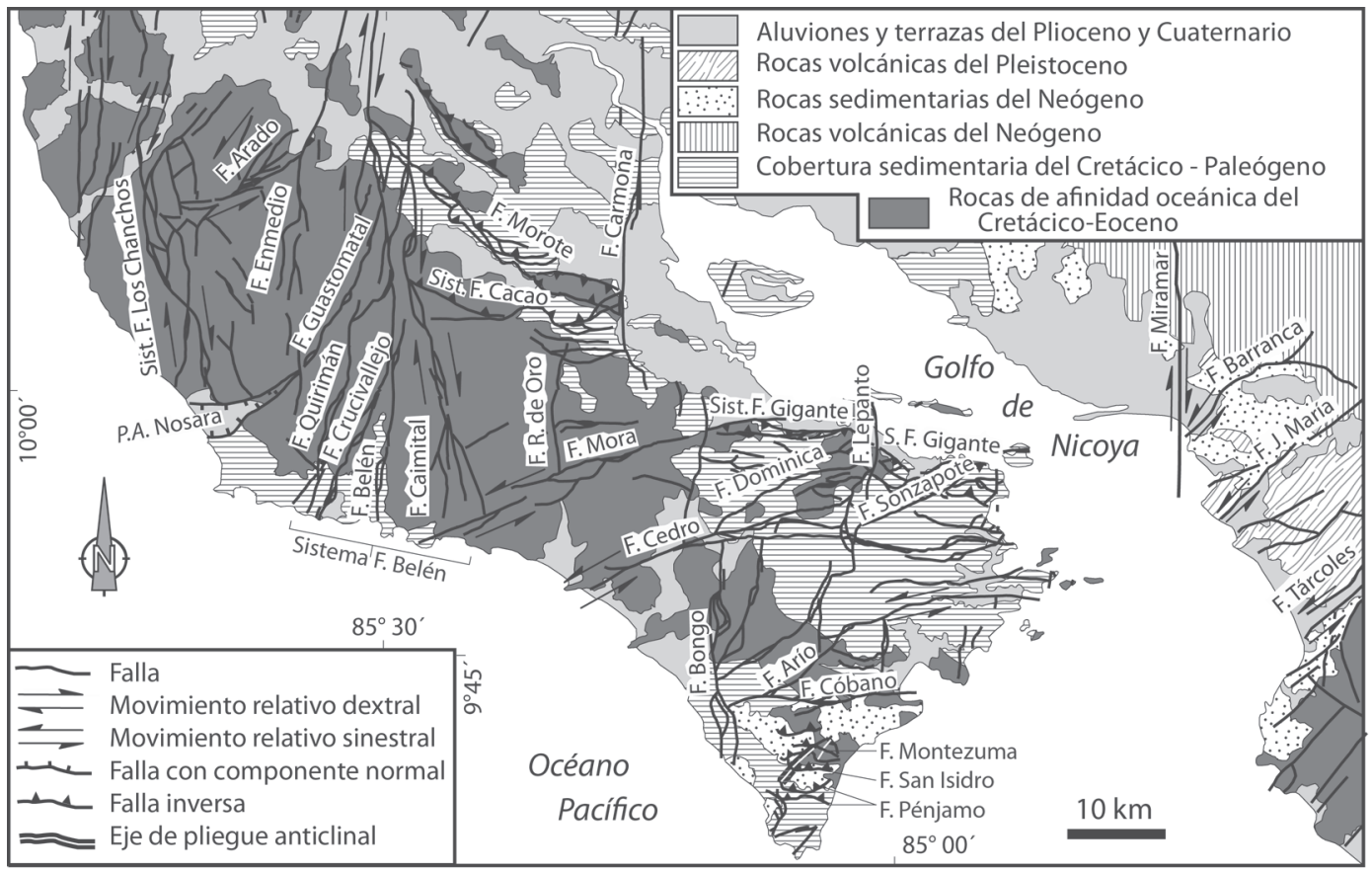

Fig. 2: Muestra en forma simplificada la geología y el sistema de fallas neotectónicas de la península de Nicoya y de la margen oriental del golfo de Nicoya (ubicación en figura 1). Predominan rocas de afinidad oceánica del Jurásico y Cretácico (Complejo de Nicoya) a lo largo del eje montañoso de la península y una cobertura sedimentaria del Cretácico al Paleógeno hacia los sectores costeros de la misma.

Un elemento geomórfico relevante en la península de Nicoya es la superficie de aplanamiento Cerro Azul (Hare \& Gardner, 1985; Fig. 3 ), la cual corresponde con una antigua superficie de erosión formada cerca del nivel del mar, durante un largo período de estabilidad tectónica, que pudo comprender el Mioceno Temprano al Medio (T. Gardner, comunicación escrita, 2011), que luego comenzó a ser levantada durante un período indeterminado hasta alturas de 700 m, lo cual renovó el ciclo geomórfico y el desarrollo de un nuevo patrón de drenaje. Como veremos, esta superficie ha sido deformada y desplazada por las fallas neotectónicas que han sido reconocidas en este estudio. Superficies de aplanamiento más recientes se localizan cerca de la costa pacífica a alturas comprendidas entre algunos metros sobre el nivel del mar hasta 100-200 m. Entre estas destaca la superficie de erosión de Cóbano, en el S de la península (Fig.
3), la cual se sugiere fue formada durante el ascenso del nivel del mar que culminó hace unos 120000 (Sak et al., 2009).

\section{DEFINICIONES Y METODOLOGÍA}

En este estudio se utiliza la definición amplia de deformaciones neotectónicas, como aquellas que empezaron en algún momento del Neógeno, por causa de un proceso tectónico determinado que perdura hoy día. Como veremos estas deformaciones se asocian con la subducción-colisión de la corteza engrosada CNS-2 bajo el centro-S de Costa Rica (incluye la cordillera del Coco). Dado que este evento tectónico pudo haber empezado desde $8 \mathrm{Ma}$ o tan solo desde hace $1 \mathrm{Ma}$ (ver discusión de inicio de la colisión en MacMillan et al., 2004) y dado que aún perdura, las deformaciones acumuladas que ha causado este proceso tectónico desde su inicio se consideran neotectónicas. 


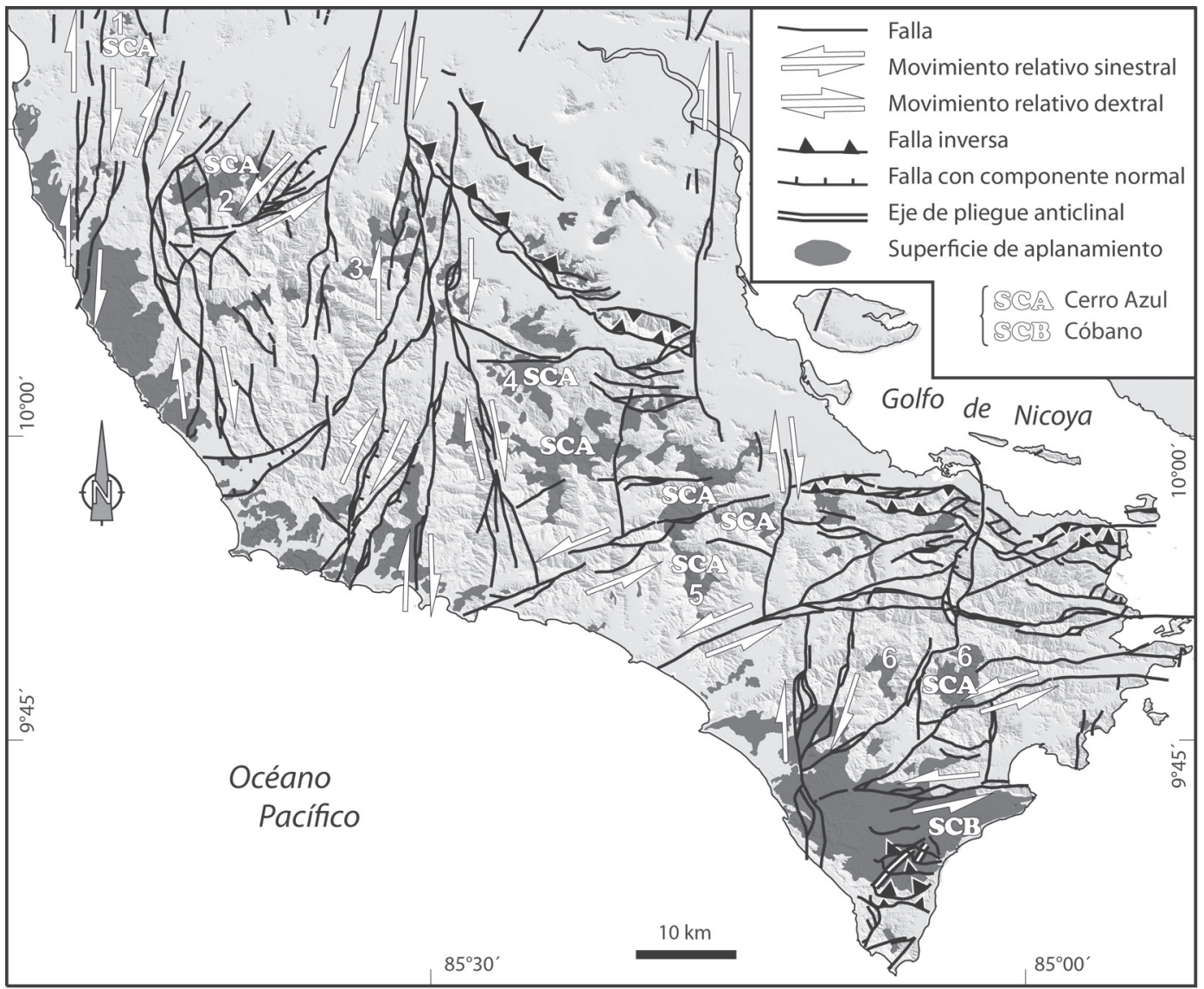

Fig. 3: A: Sobre un modelo de elevación digital se muestra simplificado el sistema de fallas neotectónico de la península de Nicoya y las superficies de aplanamiento (limitadas en gris). Los seis remanentes de la superficie Cerro Azul (SCA), reconocidos por Hare \& Gardner (1985), que se presentan a lo largo del eje montañoso son: 1. Finca Carrera Buena, 2. Montaña, 3. Esperanza, 4. San Isidro, 5. Cerro Azul y 6. Once Estrellas. En la parte S se localiza la superficie de aplanamiento de Cóbano (SCB), mientras que otras superficies de levantamiento se presentan a lo largo del sector costero externo. Ubicación en figura 1.

Un aspecto que merece resaltarse es que las interpretaciones morfotectónicas fueron realizadas en morfologías subyacidas por rocas predominantemente pre-Eocenas. Sin embargo, nuestros descripciones mostraran que la mayoría de las fallas neotectónicas reconocidas generalmente cortan, deforman o desplazan la superficie geomórfica neotectónica Cerro Azul (Hare \& Gardner, 1985) y las superficies de aplanamiento del sector litoral $\mathrm{W}$ de la península. Asimismo, las fallas de la parte $\mathrm{S}$ de la península, deforman la superficie de Cóbano. Dentro del texto se detallan igualmente casos en los que se interpretan o se infieren deformaciones neotectónicas en depósitos aluviales pleistocenos.
Para estudiar la deformación neotectónica, se analizaron fotografías aéreas, principalmente las fotos del proyecto TERRA (escala 1:40 000), y otras de diversas escalas adquiridas en el Instituto Geográfico Nacional (IGN). Esto se complementó con imágenes Landsat y de radar y un modelo de elevación digital del terreno hecho a partir de los mapas digitales del proyecto TERRA. Se hizo una verificación de campo que incluyó observaciones geomórficasy geológicas. Las fallas fueron reconocidas por sus características morfotectónicas y en su descripción se detallan algunas de las principales zonas donde se observaron geoformas y desplazamientos sugestivos de actividad 
neotectónica. La anterior información se complementó con un estudio de la actividad sísmica ocurrida a partir de 1992 y de profundidad menor a $15 \mathrm{~km}$, partiendo de la base de datos de la Red Sismológica Nacional (RSN, UCR-UCR) y otras que se detallan posteriormente.

\section{LA DEFORMACIÓN NEOTECTÓNICA DE LA PENÍNSULA DE NICOYA}

Se ha identificado un sistema de fallas neotectónicas dentro de la península de Nicoya, que comprende dos dominios, el primero ubicado en la zona central-NW de la península, es de tipo translacional hacia el $\mathrm{N}$, donde las fallas de movimiento dextral y rumbo aproximado N-S predomina sobre las fallas sinestrales de rumbos ENE y las fallas oblicuas inversas-sinestrales y las inversas E-W a NW, las cuales se encuentran delimitadas entre las fallas dextrales (Figs. 2 y 3). El segundo dominio ubicado en la región $\mathrm{S}$ de la península (Fig. 6), incluye fallas de desplazamiento sinestral y dextral, sin que se haya logrado determinar un movimiento translacional predominante. Fallas oblicuas inversas-sinestrales e inversas también han sido reconocidas y están subordinadas y limitadas por las primeras.

El límite entre ambos dominios es difuso hasta transicional, pero se considera que el segundo dominio inicia con la falla Cedro y se extiende al $\mathrm{S}$ de la misma. A continuación se describen diversas características geomórficas y estructurales de las principales fallas presentes dentro de cada dominio. En el cuadro 1 se resumen varias de sus principales características morfológicas y geométricas que distinguen a las diversas fallas reconocidas.

\section{EL DOMINIO TRANSLACIONAL DE LA REGIÓN CENTRAL-SEPTENTRIONAL DE LA PENÍNSULA DE NICOYA}

Comprende dos subdominios: el translacionalextensivo (Fig. 4) y el translacional-compresivo (Figs. 5 y 6). A continuación describimos cada uno.

\section{Subdominio translacional-extensivo}

Al N y NNW de Puerto Carrillo, los sistemas de fallas dextrales Los Chanchos y Belén, limitan un dominio de movimiento predominantemente dextral de rumbo $\mathrm{N}$ a NNE (Fig. 4). Las fallas sinestrales Arado y Nosara de rumbo ENE a E-W, se ubican dentro de este subdominio. Este conjunto de fallas imprime a este bloque un movimiento translacional al $\mathrm{N}$ y extensivo al E. A continuación se describen las principales fallas identificadas.

\section{Sistema de falla Los Chanchos}

Una falla de trazo similar a la de este trabajo fue reportada por Dengo (1962) con este nombre. Se localiza al NW de la península, iniciándose al $\mathrm{S}$ cerca de playa Ostional, a lo largo de dos trazas de rumbo cercano al N-S. Al N de playa Ostional, los ríos Rosario, Cuajiniquil, Chanchos, Verde y Tabaco muestran deflexiones al NW de su curso al cruzar la traza E de esta falla, lo cual refleja la naturaleza dextral del sistema de falla (Figs. 4 y 7). $\mathrm{Al} \mathrm{N}$ del río Cuajiniquil se presenta una zona transpresiva, limitada por dos trazas de falla, cada una evidenciada por escarpes facetados al NE (lado E) y al SW (lado W) (Figs. 7 y 8). Al cruzar el río Chanchos, ocurre un depósito aluvial, aguas arriba del cruce de la traza $\mathrm{W}$ de la falla, que se interpreta como un cuaternario represado, mientras que aguas abajo ocurre un desvío a la derecha del río y de sus depósitos aluviales (Fig. 7). Al N de la zona transpresiva, una doble traza de rumbo N-S limita el sector W del bloque Montaña de la superficie de aplanamiento Cerro Azul (Fig. 4).

$\mathrm{Al}$ cruzar el río Limones, el sistema de falla Los Chanchos se subdivide en dos trazas, donde la traza W tiene rumbo NNE, lo cual le da a la falla una componente normal, como lo evidencian varios escarpes alineados y facetados al W. La traza $\mathrm{E}$ de rumbo NE, tiene un escarpe principal facetado al NW, del lado $\mathrm{N}$ del bloque Montaña de la superficie Cerro Azul. Este relevo transtensivo de la falla Los Chanchos, se denomina Veintisiete de Abril. Más al $\mathrm{N}$, fuera del área de estudio, se considera que la falla Los Chanchos se une con el sistema de falla Belén. 


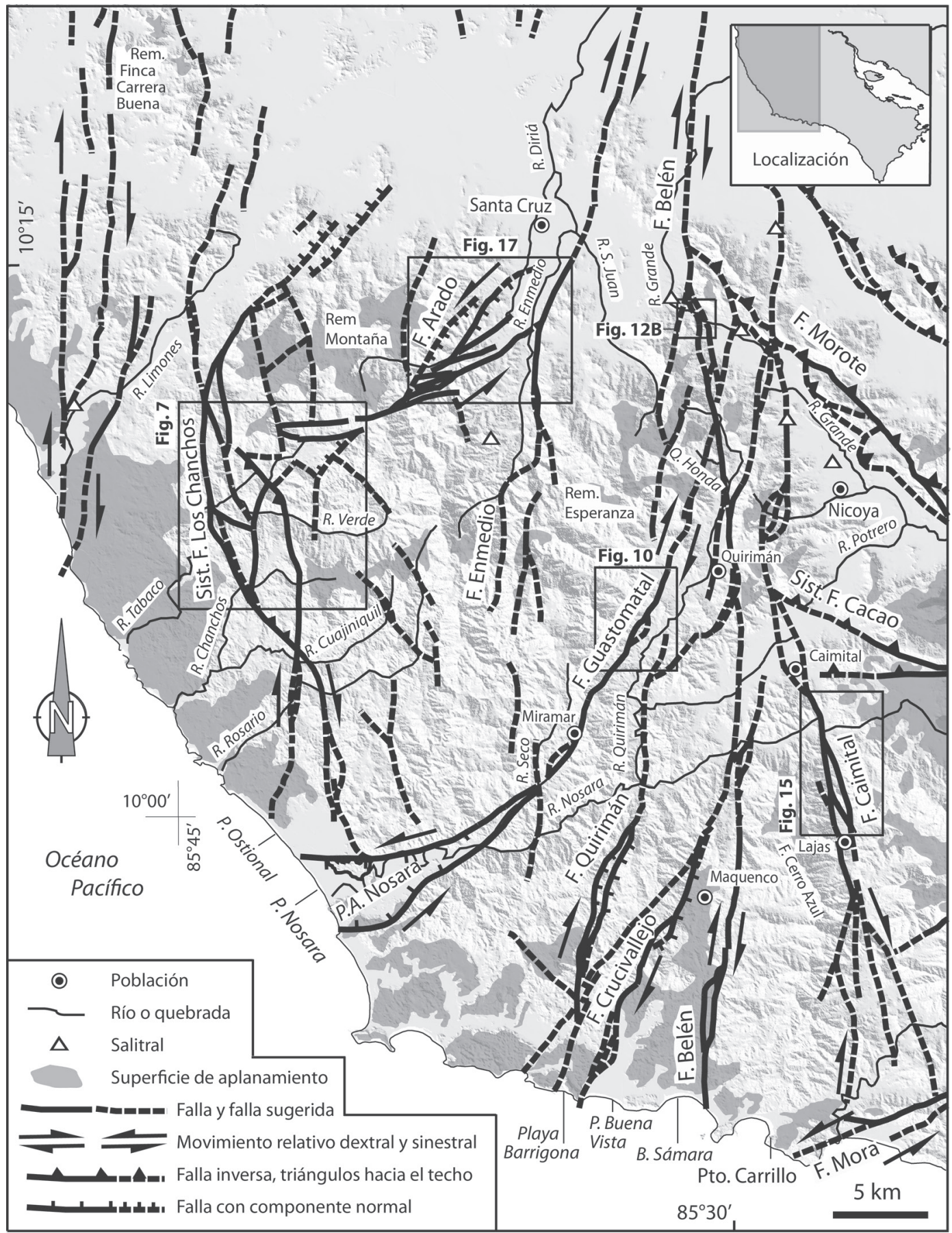

Fig. 4: Sobre un modelo de elevación digital se muestra el subdominio translacional-extensivo comprendido entre los sistemas dextrales Los Chanchos y Belén del NW de la península de Nicoya. Incluye diversos nombres geográficos mencionados en el texto. En rectángulos se muestran las figuras de detalle 7, 10, 12b, 15 y 17. 


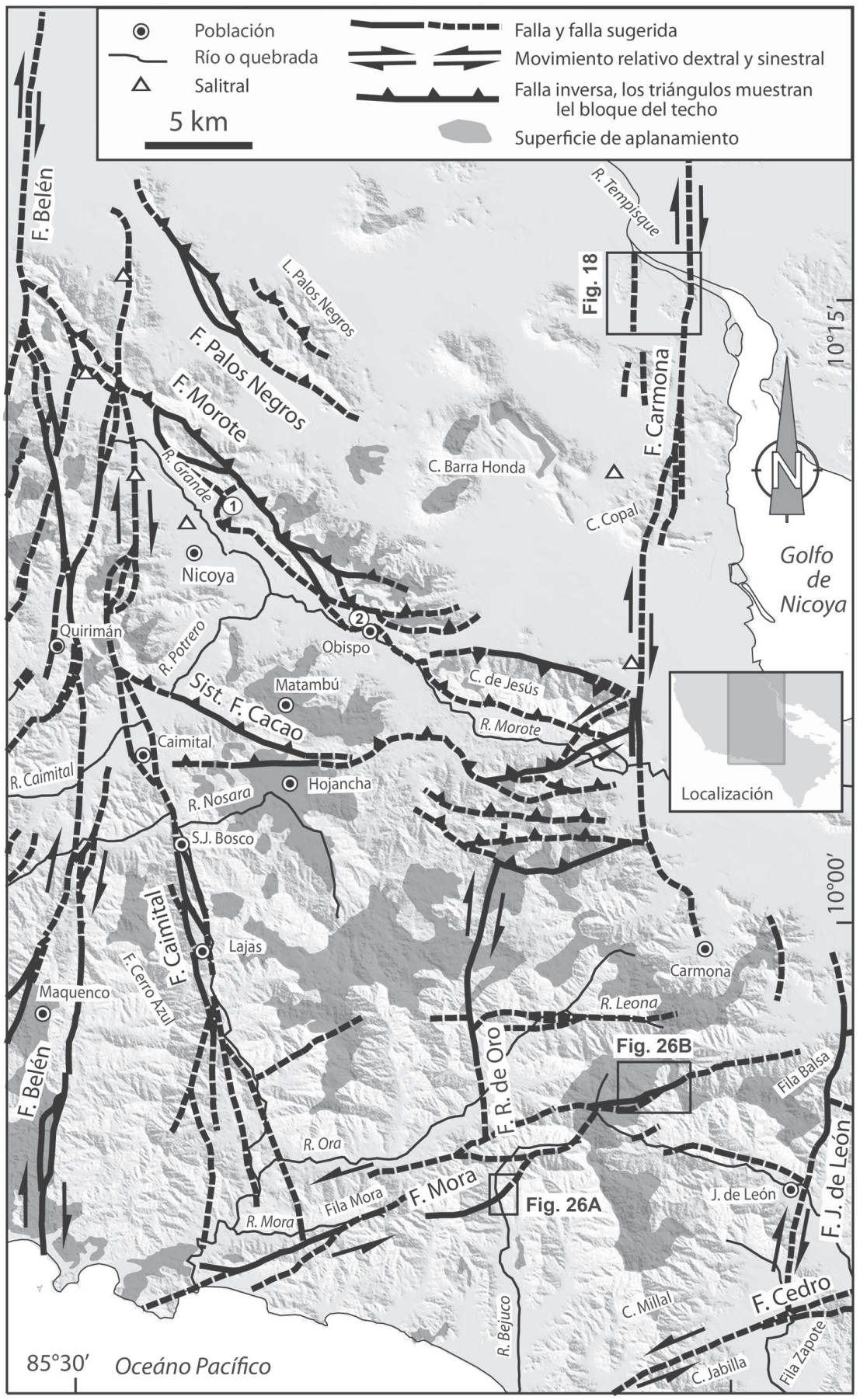

Fig. 5: Sobre un modelo de elevación digital se muestra el sector $\mathrm{W}$ del sub-dominio translacional-compresivo comprendido entre las fallas dextrales Belén-Caimital al W y la falla dextral Carmona, que se releva a la derecha con la falla Juan de León del lado E. Al S, el sub-dominio termina contra la falla sinistral Cedro. Incluye diversos nombres geográficos mencionados en el texto. Los rectángulos muestran las áreas de detalle de las figuras 26A y 26B. 

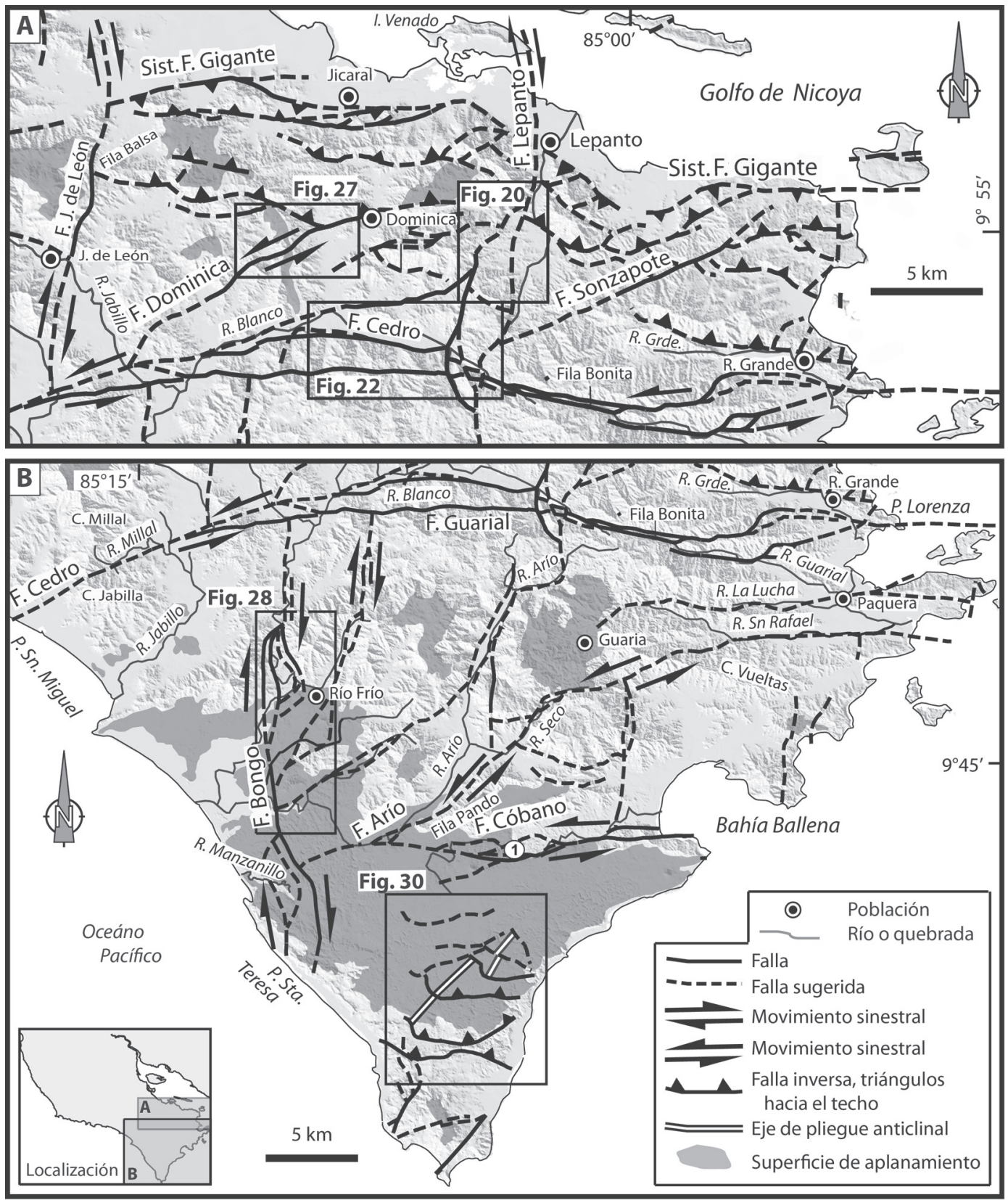

Fig. 6A: Sobre un modelo de elevación digital se muestra el sector central y E del sub-dominio translacional-compresivo comprendido entre las fallas dextrales Carmona-Juan de León al W y la falla dextral Lepanto y el del lado E de la última falla. Al S termina contra la falla Cedro. Los rectángulos encierran las áreas de detalle mostradas en las figuras 20, 22 y 27 . B. Se muestra el dominio del S de la península, que incluye las fallas ubicadas al S de la falla sinestral Cedro. Incluye diversos nombres geográficos mencionados en el texto. Los rectángulos encierran las áreas de detalle mostradas en las figuras 28 y 30. 


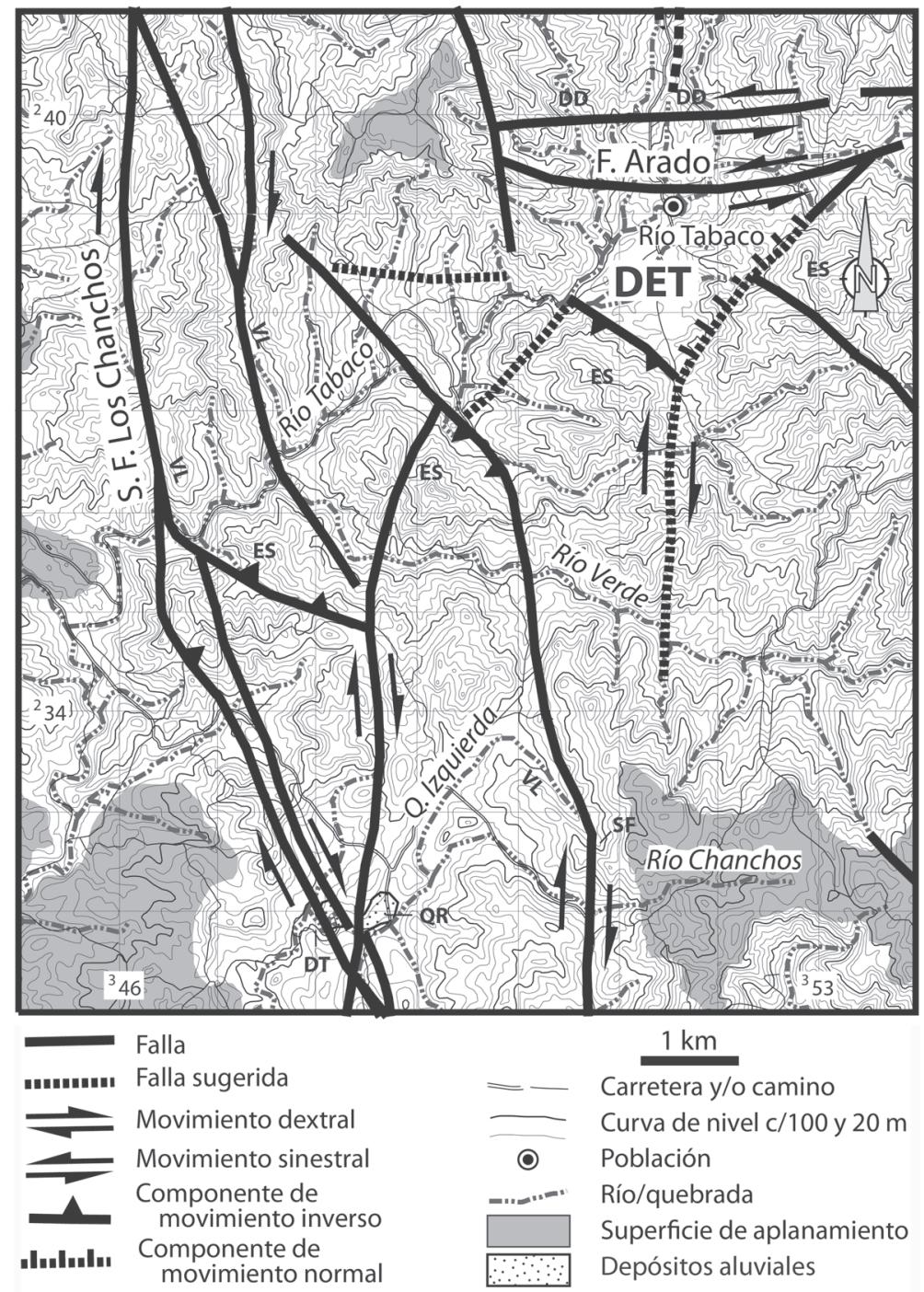

Fig. 7: Detalle de la zona transpresiva asociada con la falla dextral Los Chanchos y del sector transtensivo W de la falla sinestral Arado incluyendo la depresión de Tabaco (DET). Se observan deflecciones al N (dextrales) de los ríos Chanchos, Verde y Tabaco y de la quebrada Izquierda al cruzar las diversas trazas de la falla Los Chanchos. La traza W origina un represamiento aluvial aguas arriba (QR) y un desvío de terraza aluvial (DT) aguas debajo a lo largo del río Chanchos. Asimismo, se observan desvíos izquierdos (DD) asociados con la traza N de la falla Arado. ES, VL y SF son respectivamente escarpe de falla, valle lineal y silla de falla. Ubicación en figura 4.

\section{Sistema de falla Belén}

Es un sistema ancho de fallas, con trazas de rumbo NNW a NNE, que en su parte S tiene casi $20 \mathrm{~km}$ de ancho en dirección E-W, que van convergiendo hacia el $\mathrm{N}$, disminuyendo su ancho hasta unos $10 \mathrm{~km}$. Incluye varias trazas de falla, siendo las principales las fallas Enmedio, Guastomatal, Quirimán, Belén y Caimital (Fig. 4). El nombre de falla Enmedio fue originalmente 


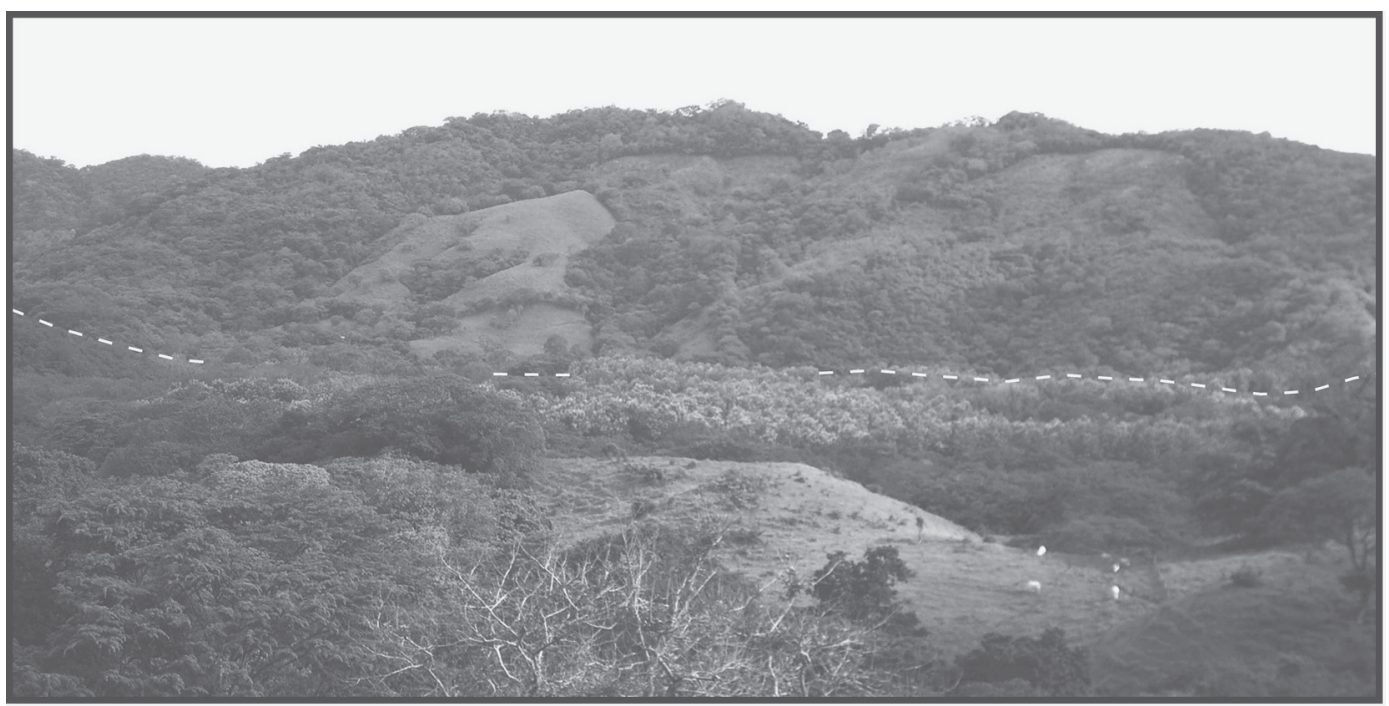

Fig. 8: Vista al SSW de escarpe de falla facetado al NE (línea blanca a trazos) asociado con límite E de la zona transpresiva de Los Chanchos. Al pie se localiza la depresión de Tabaco. El ganado pastando en el lado inferior derecho sirve de escala.

usado por Dengo (1962) para una traza similar a la de este estudio. Tiene un rumbo cercano al N-S y se ubica del lado W del sistema de falla (Fig. 4). Al S, parece converger con la falla Quirimán, mientras que al $\mathrm{N}$ alcanza la falla Belén, fuera del área de estudio. Su trazo es bastante discontinuo en diversos sectores, siendo más prominente sobre la margen derecha del río Enmedio, donde tiene un rumbo cercano al N-S.

El nombre de falla Guastomatal aparece en Dengo (1962) para una falla de trazo similar a la identificada en este estudio. Esta falla se inicia al E de la falla Enmedio. Al continuar al $\mathrm{N}$ pasa cerca de la localidad de Miramar, donde tiene un rumbo NNE y un trazo prominente al cruzar la zona montañosa (Figs. 4 y 9). Al cortar las estribaciones de la margen derecha del río Quirimán, los ríos afluentes Lajas y Zapote y la quebrada Caña Blanca, muestran amplios rellenos aluviales en la margen derecha y del lado E de la falla (Fig. 10). Estos depósitos pueden ser interpretados como paleo-desvíos derechos en los drenajes anteriores, como lo sugieren los niveles de terrazas con $r i$ sers de rumbo cercano al $\mathrm{S} 20^{\circ} \mathrm{W}$, observados en el lado $\mathrm{S}$ del río Lajas. La falla Guastomatal termina al N contra la falla Belén.

La falla Quirimán se inicia al $\mathrm{S}$ en playa Barrigona (Fig. 4). Al N corta y desplaza dextralmente una superficie de aplanamiento con una altura de hasta $80 \mathrm{~m}$. Más al N, al entrar en la zona montañosa, la falla se divide en dos trazas de rumbo NNE, mostrando escarpes facetados al E, continuos por unos $8 \mathrm{~km}$. La traza $\mathrm{W}$ tiene un escarpe prominente a lo largo del cual se bascula al W el bloque intermedio. Este sector de la falla se considera transtensivo. Continuando al $\mathrm{N}$, ambas trazas se unen y el rumbo de la falla cambia al N. Cerca de la localidad de Quirimán, la falla retoma un rumbo NNE y se acerca a la falla Guastomatal, también de rumbo NNE. Entre ambas fallas, que tienen escarpes facetados, se define un ancho valle aluvial anómalo dentro de una zona de topografía quebrada, lo cual sugiere una transtensión (Fig. 4). Al N, al unirse con la falla Belén, se observa desplazando terrazas aluviales (Fig. 11), ligeramente aguas arriba de la confluencia de la quebrada Honda con el río Quirimán.

La falla Belén tiene un trazo bastante rectilíneo y un rumbo cercano al N-S (Fig. 4). Se inicia al $\mathrm{S}$ en el sector E de la bahía Sámara, donde corta y desplaza una superficie de aplanamiento de unos $120 \mathrm{~m}$ de altura. La falla se evidencia por mostrar geoformas bastante bien conservadas (Cuadro $1 \mathrm{y}$ Fig. 12a). Al N de la unión de las fallas Quirimán 


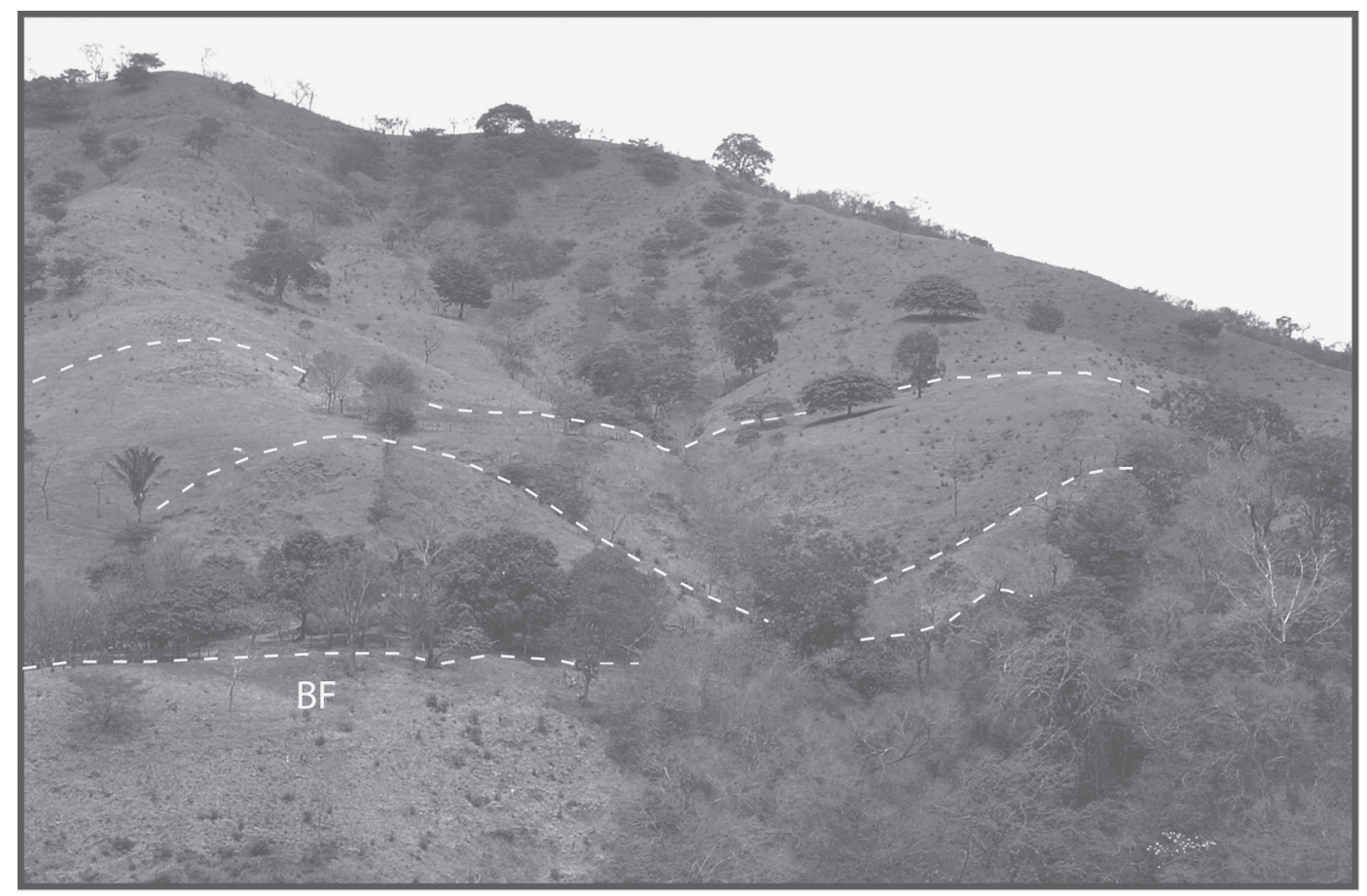

Fig. 9: Vista al E de la falla Guastomatal al cruzar la margen izquierda de la quebrada Aguas Frías cerca de la localidad de Miramar. La traza frontal muestra una berma de falla (BF), que representa un descanso en la topografía. Se sugieren otras trazas al E de la anterior (líneas blancas a trazos).

y Belén, el valle encajado antecedente del río Grande, es desplazado $\sim 0,5 \mathrm{~km}$ en forma dextral por la falla Belén (Fig. 12b). El sector $\mathrm{N}$ de la falla Belén se ubica en una zona cubierta con depósitos recientes, por lo que su trazo es inferido. $\mathrm{Al} \mathrm{N}$ se continúa fuera del área de estudio.

La falla Crucivallejo, de un rumbo NNE, se inicia al $\mathrm{S}$ en el extremo $\mathrm{W}$ de playa Buenavista y más al $\mathrm{N}$ dentro de la zona costera, corta y desplaza una superficie de aplanamiento de unos 80 $\mathrm{m}$ de altura. Al entrar en la zona montañosa muestra escarpes facetados al E continuos por unos 9 $\mathrm{km}$, indicando una componente de movimiento normal, la cual originó una zona aplanada y deprimida anómala de unos $6 \mathrm{~km}^{2}$ del lado del bloque descendente $\mathrm{E}$, donde se ubica la población de Maquenco (Figs. 4 y 13). Al N termina contra la falla Belén.

La falla Caimital, de rumbo predominante NNW, es la falla más oriental del dominio translacional. El tramo central de esta falla es muy similar a una falla cartografiada por Dengo
(1962). Al N, puede continuarse hasta terminar del lado E de la falla Belén y al S termina contra la falla Mora (Fig. 4). En su sector N, donde alcanza la falla Belén emanan varios salitrales. Esta falla originó el descabezamiento del paleorío Grande, lo cual provocó que este se dividiera en dos brazos, que son denominados con el mismo nombre, uno drena al NW y el otro al SE a partir de donde se ubica la traza de esta falla (Fig. 4). Ambos ríos muestran actualmente un desplazamiento dextral de $\sim 0,5 \mathrm{~km}$. El río Grande, que actualmente drena al SE, invirtió su sentido de flujo, tal como lo evidencian algunos afluentes con curso al W y el cañón antecedente del río Grande, de curso al NW, donde cruza la fila montañosa que separa el valle de Nicoya del de Santa Cruz (Figs. 4 y 12b).

Al S de Nicoya, la falla Caimital origina dentro de un valle una divisoria local, donde el río Caimital, afluente del Nosara, drena al SW hasta desembocar en el oceáno Pacífico, mientras el Potrero, afluente del río Grande, drena al 


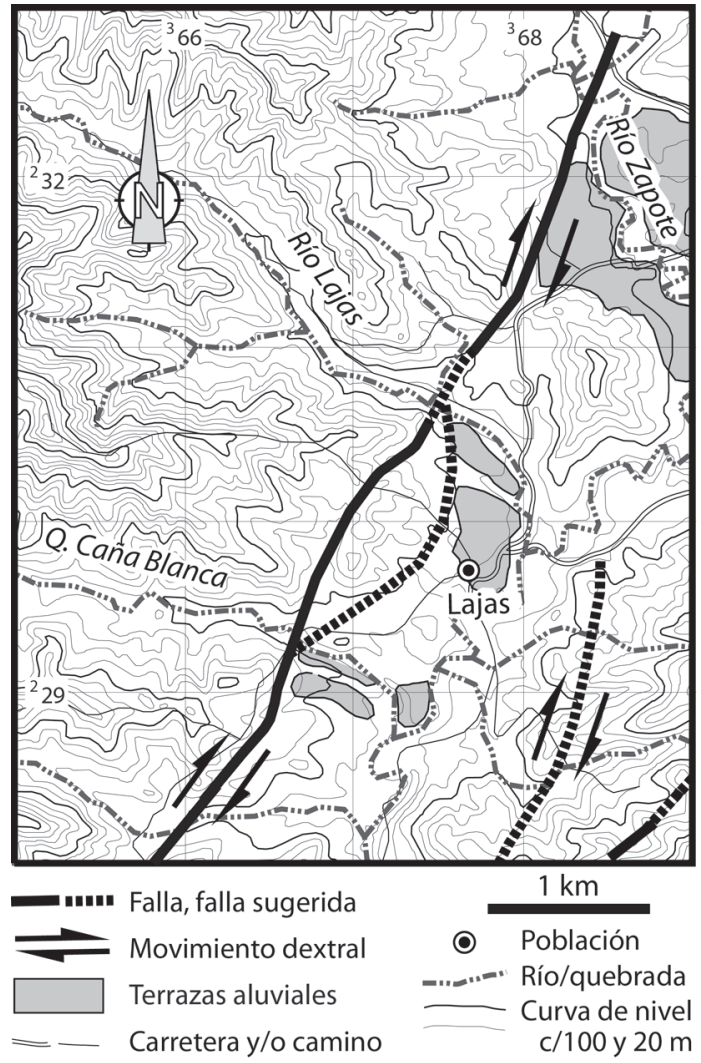

Fig. 10: Detalle del trazo de la falla Guastomatal al cruzar las divisorias y afluentes de la margen derecha del río Quirimán. Depósitos de terrazas aluviales sobre la margen derecha aguas abajo asociadas con los ríos Zapote y Lajas y a la quebrada Caña Blanca sugieren antiguos desvíos a la derecha de los drenajes. Ubicación en figura 4.

NE, desembocando en el golfo de Nicoya (Fig. 4). Al S de la localidad de Caimital, la falla se destaca por un prominente escarpe facetado al E, en el lado E de la fila Cerro Azul, que alcanza su máxima altura al $\mathrm{W}$ de la localidad de Lajas (Figs. 4,14 y 15). Lo anterior evidencia una componente de levantamiento en su lado W. Como veremos posteriormente, de acuerdo con nuestro modelo tectónico se interpreta como de tipo inverso. La superficie Cerro Azul sugiere estar desplazada, porque del lado E de la falla en la localidad de San Rafael se ubica a $\sim 400 \mathrm{~m}$ de altura, mientras que del lado levantado de la falla esta tiene $\sim 600 \mathrm{~m}$ de altura (Fig. 15). Al cruzar el río Nosara, el escarpe de falla origina un valle antecedente estrangulado aguas abajo, mientras que aguas arriba de la falla hay una valle represado, donde se presenta una importante depositación aluvial (Fig. 15). El río Nosara muestra un desvío derecho de $\sim 0,4 \mathrm{~km}$. Al $\mathrm{S}$ de San Juan Bosco, la falla se divide en dos trazas que definen un lomo de falla de rumbo NNW, cuyas trazas siguen las nacientes de los ríos Brujo y Lajas (Fig. 15). Al S del lomo de falla, la falla se ramifica en varias trazas, una sigue el pie del escarpe y otra se ubica cerca del valle del río Lajas, terminando ambas contra la falla Mora (Fig. 4).

\section{Fallas sinestrales Arado y Nosara}

La falla Arado incluye varias trazas de rumbo E-W a NE, las cuales muestran geoformas bien conservadas (Figs. 4, 16 y 17). La falla Arado termina al W contra el sistema de falla Los Chanchos (Fig. 7). Esta terminación W está limitada al N por trazas de rumbo E-W mostrando diversas geoformas sugestivas de movimiento izquierdo (Fig. 7 y cuadro 1), mientras que al $\mathrm{S}$ se cartografió una falla de rumbo NE, donde el lado $\mathrm{N}$ desciende, sugiriendo una falla con componente normal (Fig. 7). Esta última falla limita una zona deprimida anómala de $\sim 1 \mathrm{~km}^{2}$, localizada dentro una zona montañosa, en la margen $\mathrm{S}$ del río Tabaco, la cual se denomina depresión Tabaco y se interpreta es una zona transtensiva (Figs. 7 y 8). En el lado E la falla Arado se divide en dos brazos, el del lado $\mathrm{W}$ tiene rumbo NE y componentes normal e izquierda (Figs. 16 y 17) y el del lado $S$ presenta un rumbo ENE y un movimiento sinestral-normal, definiéndose entre estos el pull-apart de Arado (Fig. 17), donde se localiza una cuenca aluvial drenada por los ríos Diriá y Enmedio. Depósitos de abanicos aluviales asociados con estos ríos son observados en las zonas de transición entre el frente montañoso y la zona aluvial. Las dos trazas que limitan el pull-apart de Arado terminan al E contra la falla Enmedio (Fig. 4). 


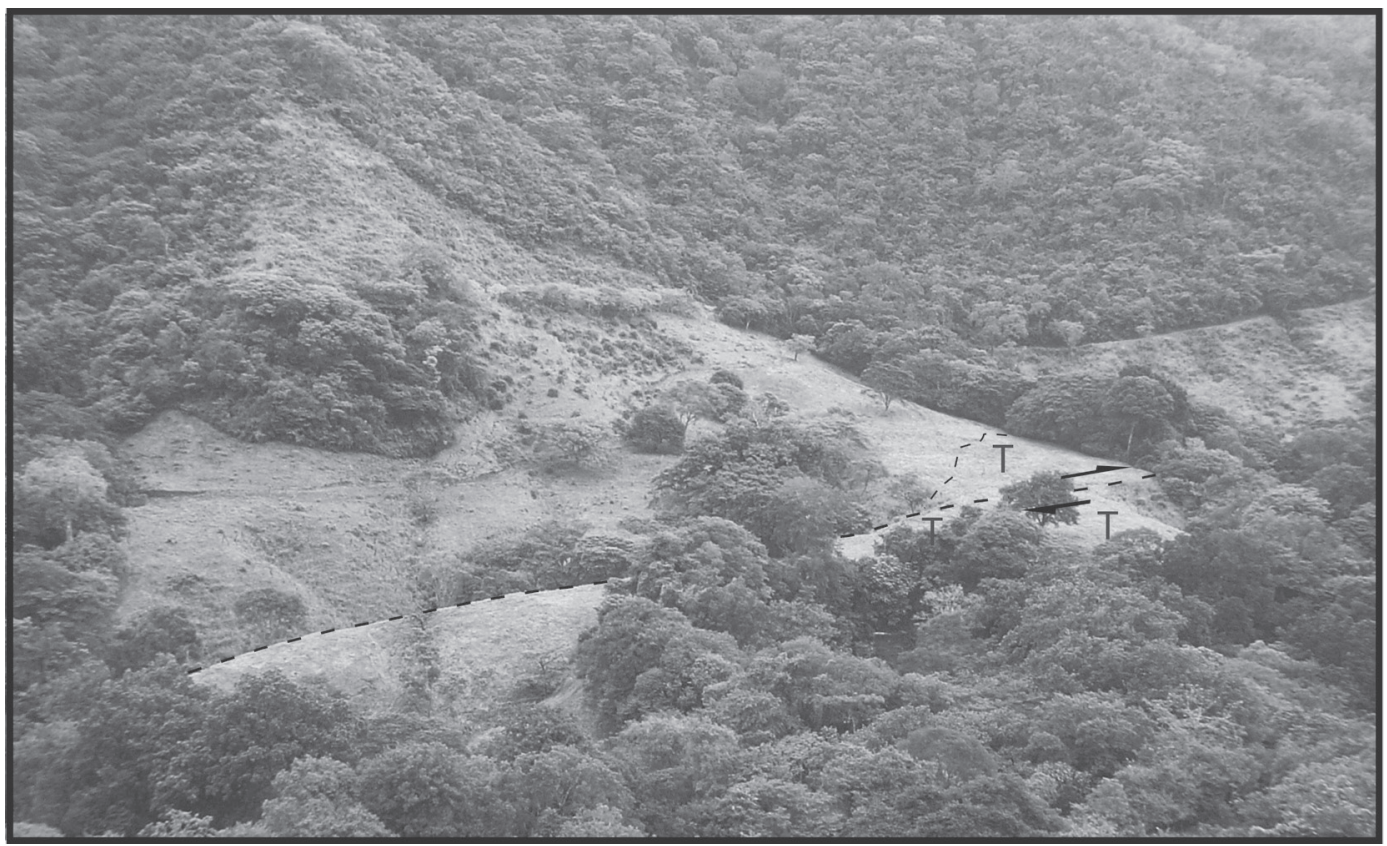

Fig. 11: Vista al WNW de la falla Quirimán donde se une con la falla Belén, mostrando desvío derecho de terraza aluvial asociada con la quebrada Honda, aguas arriba de su confluencia con el río Quirimán.
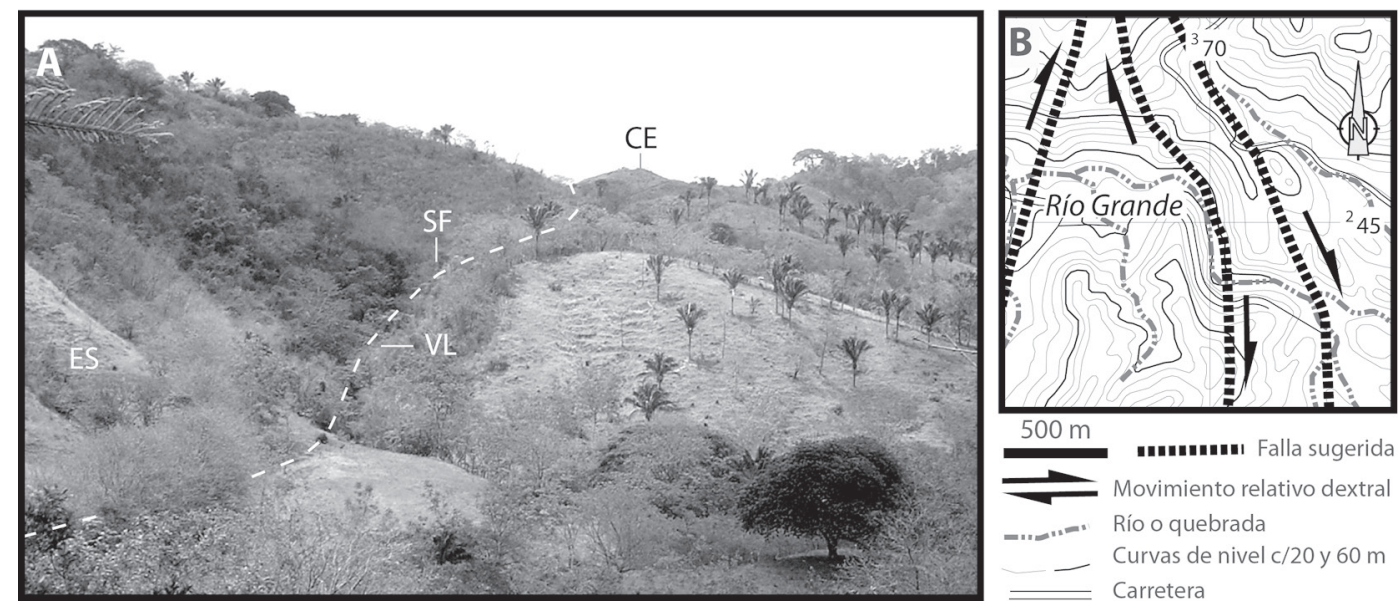

Fig. 12: Muestra características morfotectónicas de la falla Belén. A: Vista al NNW del trazo de la falla al desviar varias estribaciones sobre la margen derecha del río Platanillo, al SSE de Maquenco. CE, SF, VL y ES son respectivamente contraescarpe, silla de falla, valle lineal y escarpe de falla. B. Detalle del desvío derecho de $\sim 0,5 \mathrm{~km}$ del cañón antecedente del río Grande. Ubicación en figura 4. 


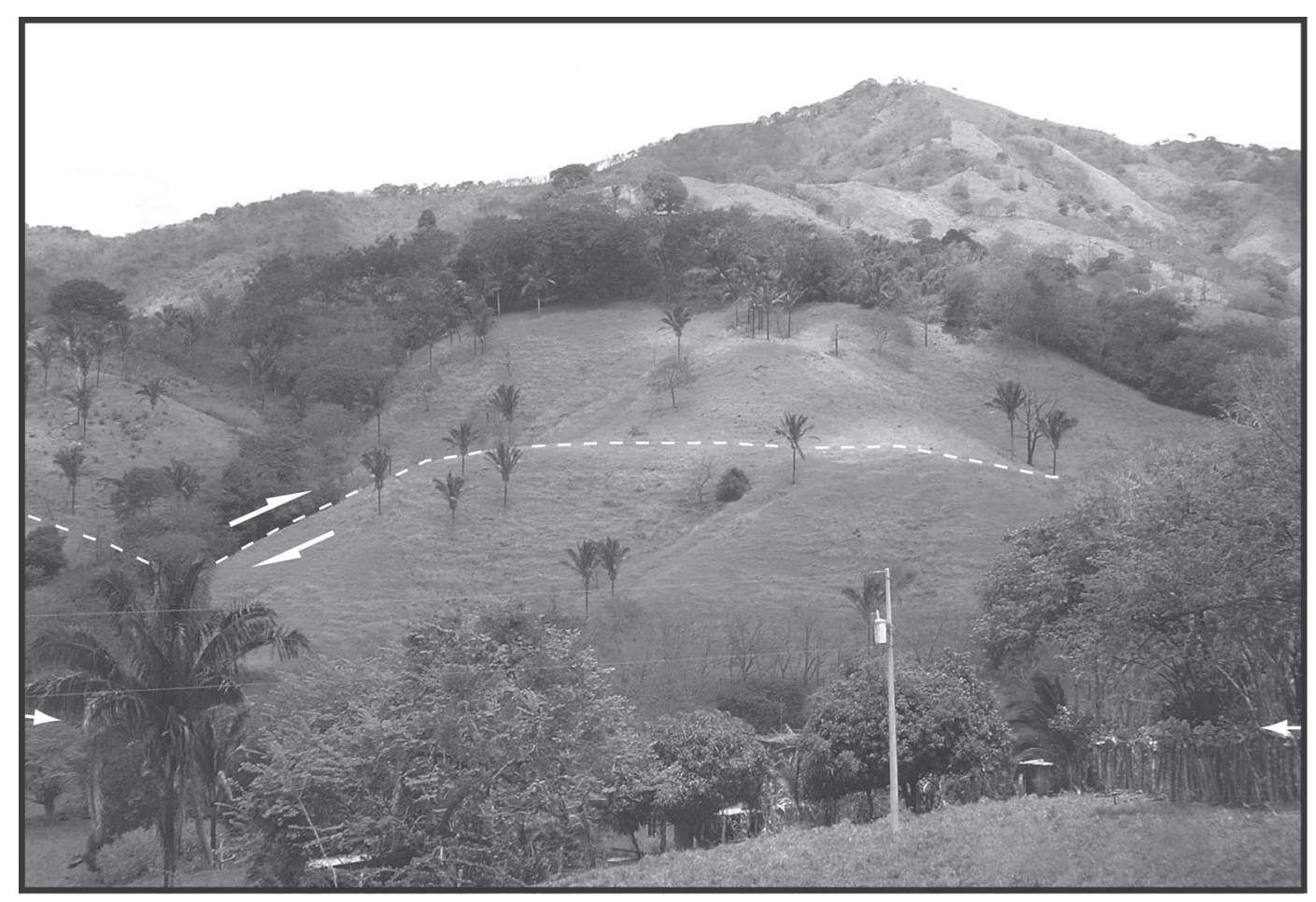

Fig. 13: Vista al W del escarpe de la falla Crucivallejo indicada por flechas. Se sugieren posibles desvíos derechos de facetas y de drenaje (flechas lo indican) a lo largo de traza trasera (a trazos). Margen derecha del río Crucivallejo.

La falla Nosara se inicia al W en playa Nosara a lo largo de dos fallas de rumbo entre E-W y ENE, donde las del lado $\mathrm{S}$ y $\mathrm{N}$ tienen escarpes facetados al $\mathrm{N}$ y al $\mathrm{S}$, respectivamente, limitando una zona deprimida que se ha rellenado con aluviones recientes depositados por el río Nosara y sus afluentes (Fig. 4). Esta depresión se interpreta es una cuenca de tracción o pull-apart, que se denomina Nosara, cuyo ancho disminuye al E, hasta que las dos fallas que la limitan se unen en un trazo simple en el cañón del río Seco. Al E la falla Nosara termina contra la falla Enmedio. El ramal E del sistema de falla Los Chanchos termina contra el ramal $\mathrm{N}$ del pull-apart de Nosara (Fig. 4). Asimismo, se considera que al continuar al W el ramal $\mathrm{N}$ de la falla Nosara en la zona marina, debe terminar contra la rama $\mathrm{W}$ del sistema de falla Los Chanchos (ver tema "Relación entre las fallas neotectónicas y la transrotación" en el capítulo de Discusión).

\section{Subdominio translacional-contraccional}

En la región central de la península de Nicoya hay tres bloques limitados por fallas dextrales de rumbo cercano al N-S, dentro de los cuales hay fallas sinestrales ENE, e inversas con una posible componente sinestral. Lo anterior resulta en movimientos combinados translacionales al $\mathrm{N} \mathrm{y}$ 

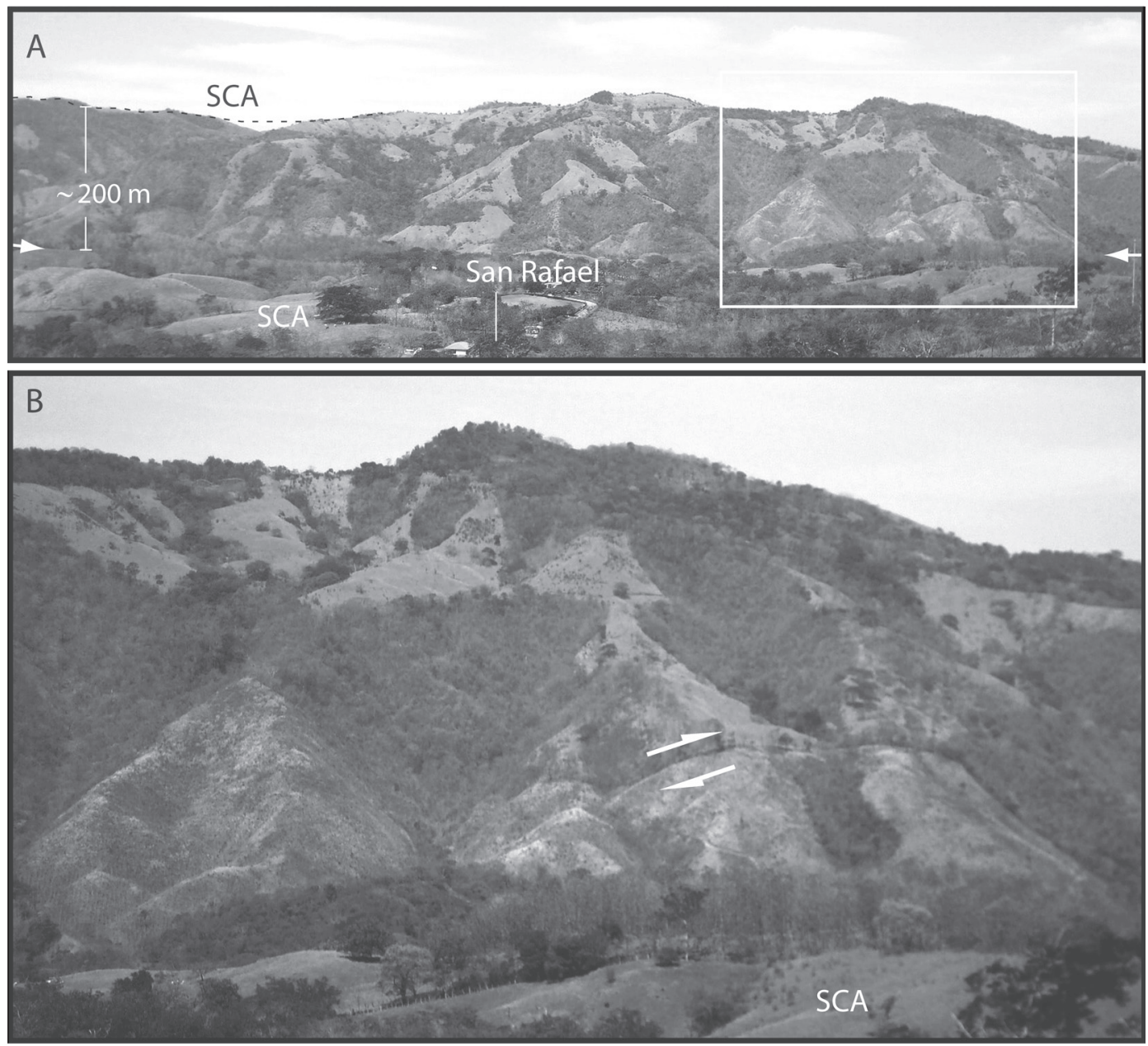

Fig. 14: Morfotectónica de la falla Caimital. A: Vista al W del escarpe de falla facetado al E, al S del río Nosara. En primer plano se observa el remanente de la superficie Cerro Azul (SCA) donde se asienta San Rafael ( $400 \mathrm{~m}$ de altura) (Ver Fig. 15). La parte superior del escarpe en el lado N está a $\sim 700 \mathrm{~m}$. En el lado izquierdo, la SCA está a unos $600 \mathrm{~m}$ sugiriendo un levantamiento vertical de unos $200 \mathrm{~m}$ de la misma. B: Detalle del escarpe de falla (ubicación en A) mostrando facetamiento triangular y una traza secundaria ubicada cerca del pie del escarpe que origina desvío de divisorias y drenajes (indicada con flechas).

contraccionales E-W. Los bloques se encuentran limitados entre los sistemas de fallas dextrales Belén y Carmona-Juan de León, entre la última falla y la falla Lepanto y el que se ubica entre la última falla y la ubicada al E. El límite de este subdominio al $\mathrm{S}$ es difuso pero se localiza al $\mathrm{N}$ de la falla Cedro (Figs. 5 y 6). A continuación se describen las principales fallas de este sub-dominio. 


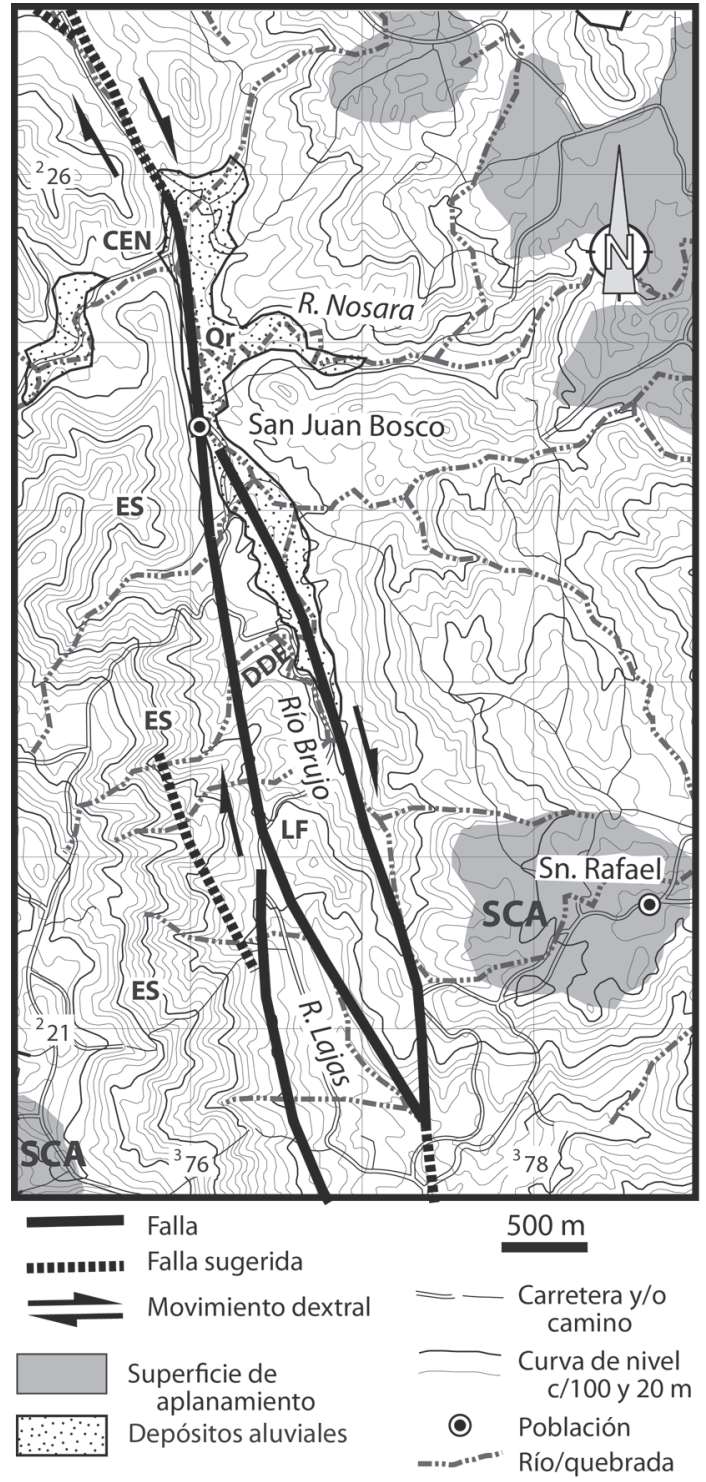

Fig. 15: Morfotectónica de la falla Caimital mostrando el desvío derecho del río Nosara y el cuaternario represado (Qr) aguas arriba del trazo de falla. Aguas abajo de la falla, el río tiene un cauce encañonado (CEN). Asimismo se observa el lomo de falla (LF) y el escarpe de falla (ES). Del lado E de la falla a $400 \mathrm{~m}$ de altura se ubica un remanente erosional de la superficie Cerro Azul en la localidad de San Rafael. En la esquina SW y del lado W de la falla, el mismo remanente se ubica entre 600 y $500 \mathrm{~m}$ sugiriendo un levantamiento vertical de $\sim 200 \mathrm{~m}$. DDE es drenaje descabezado. Ubicación en figura 4.

\section{Fallas dextrales}

La falla Carmona, de rumbo N-S, se caracteriza por un trazo lineal al cruzar colinas y filas (Fig. 5). Sin embargo, al cruzar las zonas aluviales, esteros y la zona de inundación del río Tempisque, su trazo pierde expresión, siendo inferido. Al N, fuera del área de estudio, continúa con la falla Bagaces (Montero \& Alvarado, 1988), donde corta depósitos de ignimbrita pliopleistocenos (Denyer \& Alvarado, 2007), lo cual demuestra su naturaleza neotectónica. Del lado $\mathrm{S}$ del río Tempisque, sugiere provocar desvíos derechos en el sector $\mathrm{N}$ del cerro La Cueva y en los bordes $\mathrm{N}$ y S de los cerros Coyolar (Fig. 18). Al S, al cruzar el cerro Copal sugiere desvíos derechos en las curvas de nivel y define entre dos trazas una zona relativamente deprimida limitada por escarpes facetados al $\mathrm{E}$ en su lado $\mathrm{W}$ y al $\mathrm{W}$ en su lado E. Los anteriores indicadores geomórficos sugieren un movimiento derecho en esta falla. Continuando al S limita el sector E de los cerros de Jesús (Fig. 5). Un par de salitrales se localizan cerca de esta falla.

La falla se continúa con dos relevos a la izquierda, del lado E de la localidad de Carmona (Fig. 5). Al relevo localizado más al E y de mayor longitud se le denomina falla Juan de León. Esta falla corta las estribaciones $\mathrm{E}$ de la fila Balsa, mostrando morfologías bien conservadas, tales como son abanicos desplazados, quebradas desviadas, adaptadas y descabezadas, entre otros (Fig. 19), lo cual sugiere actividad reciente. Al S parece terminar contra la falla Cedro (Fig. 5).

La falla Río de Oro localizada al W de Carmona, tiene un rumbo N-S y una expresión morfotectónica bastante prominente. Al N termina contra una serie de fallas E-W y al S sugiere terminar contra la falla Mora, aunque no se descarta que se continúe más al S (Fig. 5). Esta falla muestra desvíos derechos en filas y quebradas, los cuales son más evidentes al $\mathrm{N}$ del río Ora.

La falla Lepanto se inicia al $\mathrm{N}$ desviando al $\mathrm{S}$ el sector $\mathrm{E}$ de isla Venado (Fig. 6A). Al entrar a la península, al $\mathrm{N}$ de Lepanto, sugiere desvíos 


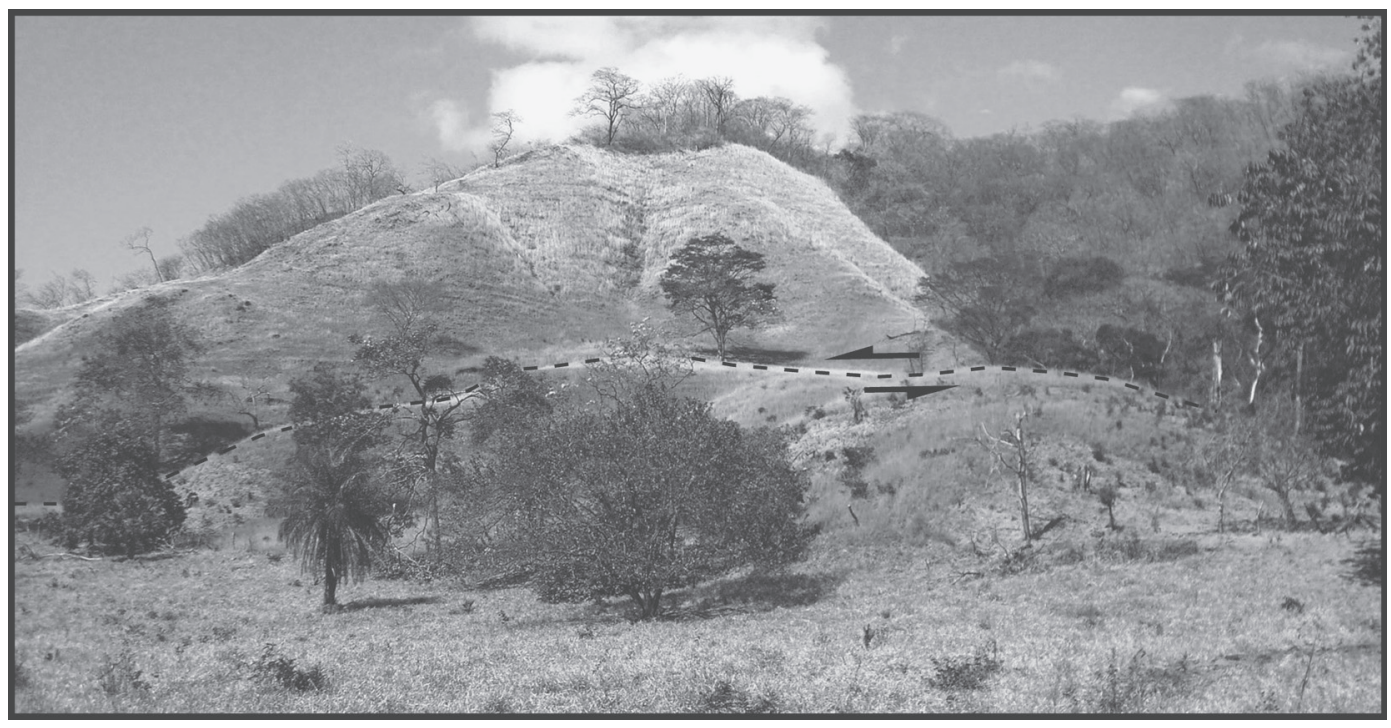

Fig. 16: Vista al W de una traza de la falla Arado en el sector de la cuenca de tracción Arado, mostrando el desvío izquierdo de una loma y un escarpe facetado al E sugiriendo una componente de levantamiento del lado W.

derechos de la costa y en el frente montañoso inverso. Al S de Lepanto, entre las localidades de Ilusión y Montaña Grande limita una zona deprimida dentro de una zona montañosa de unos $6 \mathrm{~km}^{2}$, denominada depresión Montaña Grande, que es drenada por el río Lepanto y sus afluentes y está limitada por un escarpe de falla normal en su ramal W (Figs. 20 y 21). El anterior tramo de la falla define una zona de transtensión. Al S, la traza E sugiere desviar a la falla Cedro hacia la derecha $\sim 0,3 \mathrm{~km}$, mientras la traza $\mathrm{W}$ la desvía a la derecha unos $0,4 \mathrm{~km}$ (Fig. 22). Más al S, las trazas W y E de la zona transtensiva se unen en las nacientes del río Arío (Fig. 6B). Su terminación al $\mathrm{S}$ es inferida.

Del lado oriental del golfo de Nicoya, se ha reconocido la falla Miramar. Es una falla poco estudiada de un rumbo N-S (Fig. 2). Se caracteriza por mostrar varias evidencias morfotectónicas (Cuadro 1). En este estudio se incorpora porque es importante como posible límite al E del bloque limitado al $\mathrm{W}$ por la falla dextral Lepanto (ver adelante tema "Relación entre las fallas neotectónicas y la transrotación").

\section{Fallas inversas}

En la región central-E de la península se han interpretado una serie de fallas de rumbos entre E-W a NW, con escarpes facetados al S y al N, los cuales se interpretan como fallas inversas con una posible componente sinestral. La interpretación de desplazamiento en las anteriores fallas se infiere con base en sus características morfotectónicas y en su posición espacial con respecto al campo local de esfuerzos (ver "Relación entre las fallas neotectónicas y la transrotación" en la discusión). A continuación se describen las principales. La falla Morote de un rumbo entre E-W y NW, fue originalmente reconocida por Dengo (1962), para la traza localizada en el flanco SW de los cerros de Jesús, y hacia el NW interactuaba con otras fallas de igual rumbo, como la Mansión y la Nacaome (Dengo, 1962). Posteriormente fue redefinida y los diferentes trazos se unificaron bajo el nombre de falla Morote (Flores et al., 2003). Al NW y SE termina abruptamente contra las fallas Belén y Carmona, respectivamente (Fig. 5). Muestra varias trazas con rumbo oscilante entre WNW a NW, limitadas 


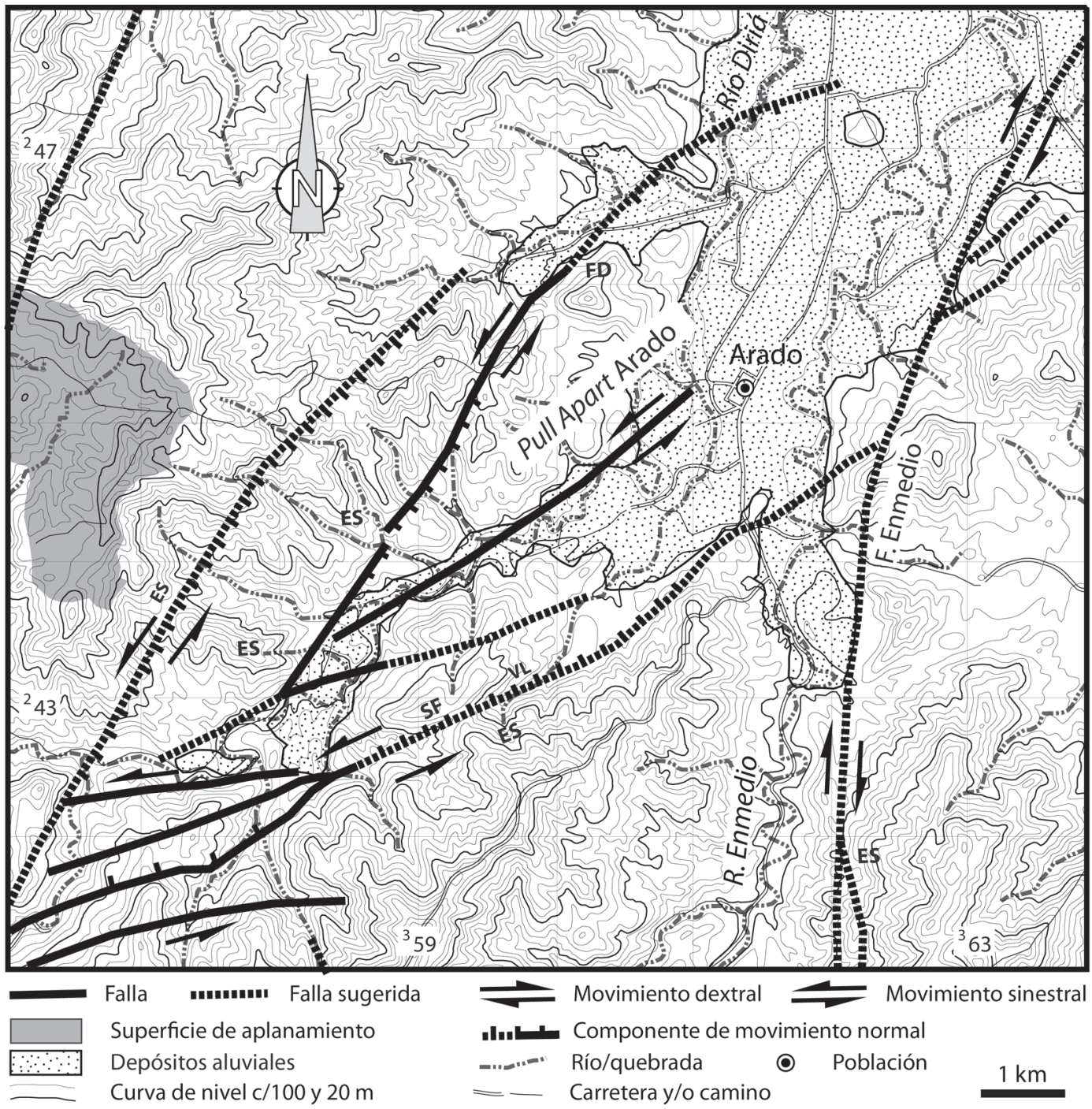

Fig. 17: Muestra el pull-apart Arado, donde termina al E con la falla dextral Enmedio. Ubicación en figura 4. ES, VL, SF y FD son respectivamente escarpe de falla, valle lineal, silla de falla y fila desviada. Ubicación en figura 4.

por escarpes facetados predominantemente al SW. Asimismo, en el sector central-W de la falla y al NE de los escarpes se ha determinado una superficie de aplanamiento levantada y basculada al NE. Lo anterior indica que el plano de falla principal se inclina al NE (Fig.5). Sin embargo, en el sector E de la falla, los cerros de Jesús muestran escarpes facetados al NE y SW (Figs. 5 y 23). En el tajo Calera, ubicado al E de la ciudad de Nicoya (sitio 1 en Fig. 5), las calizas de la Formación Barra Honda (Paleoceno Superior) cabalgan al W sobre la formación Curú (Cretácico Superior-Paleoceno Inferior). En afloramientos observados en la localidad de Obispo (sitio 2, Fig. 5), se interpretó la presencia de fallas inversas inclinadas hacia el $\mathrm{NE}$, en rocas paleógenas.

La sugerencia de un movimiento inverso en la falla Morote aparece desde Dengo (1962). Por otro lado, Flores \& Denyer (2003) la muestran con un movimiento sinestral. En este estudio consideramos que la falla es de movimiento predominante inverso en su sector central-W 


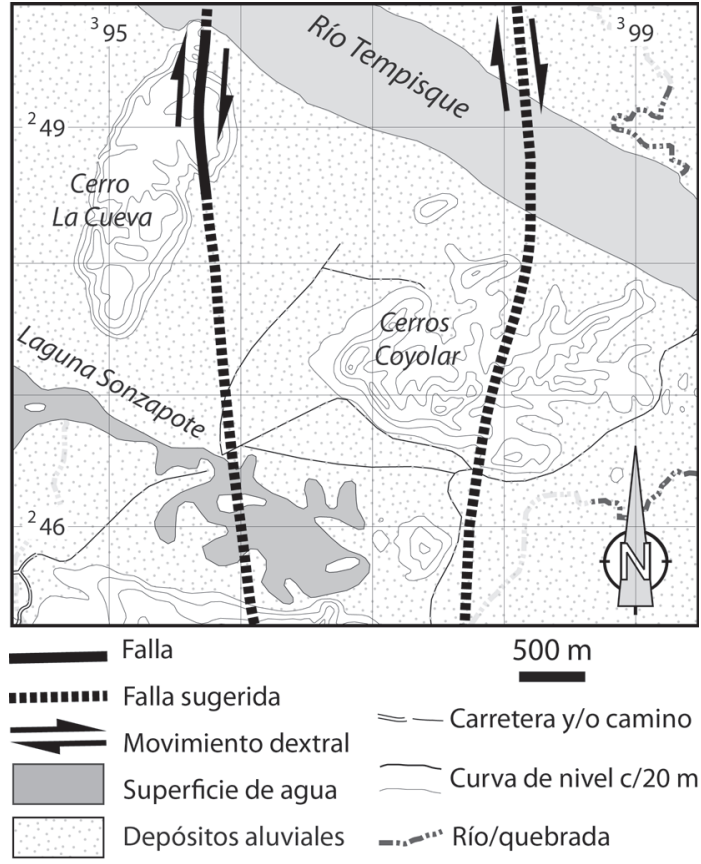

Fig. 18: Al cruzar al $\mathrm{S}$ el río Tempisque, la falla Carmona sugiere originar desvíos a la derecha en el lado $\mathrm{N}$ y S del cerro La Cueva y los cerros Coyolar. Ubicación en figura 5.

a oblicuo inverso-sinestral en su sector E, con base en la expresión morfológica de la falla, la distribución espacial de las diversas trazas sugiriendo varios frentes de levantamiento, las observaciones en afloramientos realizadas durante el trabajo de campo y con base en el modelo de deformación neotectónico, que explica las diversas estructuras neotectónicas de la península de Nicoya (ver adelante).
Al N de la falla Morote y del lado W de las lomas Palos Negros, también se presentan escarpes facetados al SW, donde los más internos alcanzan alturas hasta de $100 \mathrm{~m}$ y el más externo unos 40 $\mathrm{m}$. Estos escarpes se asocian con dos a tres frentes de fallamiento inverso, siendo el SW el más externo y reciente (Fig. 5). Flores \& Denyer (2003) interpretan un eje anticlinal a lo largo de la parte alta de las lomas. Los cerros de Barra Honda ubicados al E de las lomas anteriores no muestran plegamiento o fallamiento inverso.

Al S de la falla Morote se localiza el sistema de falla inverso Cacao, tal como fue reconocido y denominado inicialmente por Dengo (1962) para una falla de trazo similar. Incluye numerosas trazas con rumbos entre E-W y WNW, el cual termina al W y al E contra las fallas dextrales Caimital y Carmona, respectivamente (Fig. 5). En el sector W, la falla Cacao muestra un escarpe facetado al S de unos 100-140 m de alto (Fig. 24). La falla desplaza una superficie de aplanamiento donde se ubica la población de Hojancha, rotando al NE el bloque superior donde se asienta la localidad de Matambú (Figs. 5 y 24). Al E y al ESE de Hojancha se continúa este sistema de falla, con rumbos entre WNW y E-W y escarpes facetados al S, desplazando diversos segmentos de la superficie Cerro Azul (Fig. 5). Denyer \& Flores (2003) habían reconocido fallas inversas en esta zona. En el sector E del sistema de falla Cacao se interpretan un par de trazas con rumbo ENE y componente sinestral (Fig. 5).

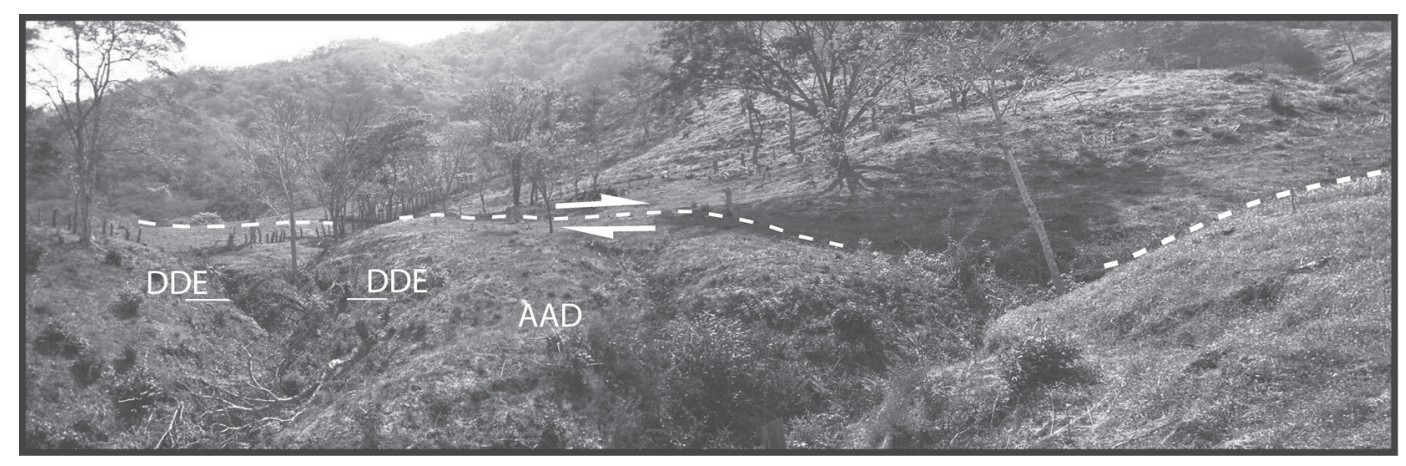

Fig. 19: Vista al W de la traza de falla Juan de León al cruzar las estribaciones de la margen izquierda de la quebrada Balsa. Se sugieren quebradas descabezadas (DDE) y un abanico aluvial desplazado (AAD) a la derecha, donde se entallan las quebradas. 
Cuadro 1

Características de las fallas neotectónicas de la península de Nicoya

\begin{tabular}{|c|c|c|c|c|c|c|}
\hline Nombre falla & $\begin{array}{l}\text { Long. } \\
(\mathrm{km})\end{array}$ & Rumbo & Tipo Despl. & $\begin{array}{l}\text { Bloque } \\
\text { sube }\end{array}$ & Relación con otras fallas & $\begin{array}{c}\text { Evidencias } \\
\text { morfotectónicas y } \\
\text { estructurales }\end{array}$ \\
\hline Los Chanchos & $>30 \mathrm{~km}$ & $\begin{array}{l}\text { Variable entre } \\
\text { NNE a NNW }\end{array}$ & $\begin{array}{l}\mathrm{DD},(\mathrm{TC}, \\
\mathrm{TT})\end{array}$ & & $\begin{array}{l}\text { Al NE se uniría con F. } \\
\text { Belén }\end{array}$ & $\begin{array}{l}\text { VL, ES, CE, DD, } \\
\text { DA, SF, QR,QD, } \\
\text { LO } \\
\text { VL, VF, DD, DA, } \\
\text { SF }\end{array}$ \\
\hline Enmedio & $>45 \mathrm{~km}$ & N-S a NNE & DD & & $\begin{array}{l}\text { Al NE se uniría con } \mathrm{F} \text {. } \\
\text { Belén }\end{array}$ & $\begin{array}{l}\text { VL, ES, CE, SF, } \\
\text { DD, DA, DDI }\end{array}$ \\
\hline Guastomatal & $\sim 25 \mathrm{~km}$ & N-S a NNE & $\mathrm{DD}(\mathrm{TT})$ & & $\begin{array}{l}\text { Termina al S y al } \mathrm{N} \text { contra } \\
\text { las } \mathrm{F} \text {. En medio y Belén, } \\
\text { respectivamente }\end{array}$ & $\begin{array}{l}\text { VL, ES, CE, SF, } \\
\text { DD, DA, DDI, } \\
\text { QD, BF }\end{array}$ \\
\hline Quirimán & $\sim 30 \mathrm{~km}$ & N-S a NNE & $\mathrm{DD}(\mathrm{TT})$ & & $\begin{array}{l}\text { Termina al N contra F. } \\
\text { Belén }\end{array}$ & $\begin{array}{l}\text { VL, DD, DA, SF, } \\
\text { BF, FD, QD }\end{array}$ \\
\hline Belén & $>70 \mathrm{~km}$ & $\mathrm{~N}-\mathrm{S}$ & DD & & & $\begin{array}{l}\text { VL, ES, CE, DD, } \\
\text { DA, SF, BF, QR, } \\
\text { LO } \\
\text { CV, DDE }\end{array}$ \\
\hline Crucivallejo & $>20 \mathrm{~km}$ & NNE & $\mathrm{DD}(\mathrm{TT})$ & & $\begin{array}{l}\text { Termina al } \mathrm{N} \text { contra } \mathrm{F} \text {. } \\
\text { Belén }\end{array}$ & ES, CE, VL, DD \\
\hline Caimital & $\sim 35 \mathrm{~km}$ & NNW & $\mathrm{DD}(\mathrm{TC})$ & W & $\begin{array}{l}\text { Termina al NNW contra F. } \\
\text { Belén y al SSE contra la } \\
\text { F. Mora }\end{array}$ & $\begin{array}{l}\text { ES, CE, LF, QR, } \\
\text { VL, DDI, DD, } \\
\text { DDE, BF }\end{array}$ \\
\hline $\begin{array}{l}\text { Veintisiete de } \\
\text { Abril }\end{array}$ & $\sim 20 \mathrm{~km}$ & NE & $\mathrm{DN}$ & $\mathrm{S}$ & Ramal F. Los Chanchos & $\mathrm{ES}, \mathrm{CE}, \mathrm{VL}, \mathrm{SF}$ \\
\hline Arado & $\sim 15 \mathrm{~km}$ & E-W a ENE & DS & & $\begin{array}{l}\text { Termina al W y E contra F. } \\
\text { Los Chanchos y Enmedio } \\
\text { respectivamente }\end{array}$ & $\begin{array}{l}\text { VL, ES, CE, DD, } \\
\text { DA, SF, QR, LO, } \\
\text { DDI }\end{array}$ \\
\hline Nosara & $\sim 13 \mathrm{~km}$ & E-W a ENE & DS & & $\begin{array}{l}\text { Termina al E contra falla } \\
\text { Enmedio y al W contra } \\
\text { falla Los Chanchos }\end{array}$ & $\begin{array}{l}\text { ES facetados al N y } \\
\text { S, DD, DA, VL }\end{array}$ \\
\hline Carmona & $\sim 30 \mathrm{~km}$ & $\mathrm{~N}-\mathrm{S}$ & DD & & $\begin{array}{l}\text { Se continúa al } \mathrm{N} \text { con } \mathrm{F} \text {. } \\
\text { Bagaces }\end{array}$ & $\begin{array}{l}\text { VL, ES facetados al } \\
\text { E Y W, SF }\end{array}$ \\
\hline Juan de León & $\sim 15 \mathrm{~km}$ & NNE & DD & & $\begin{array}{l}\text { Ramal de F. Carmona. Al } \\
\text { S termina contra F. Cedro }\end{array}$ & $\begin{array}{l}\text { AAD, DD, DA, } \\
\text { DDE, SF, ES, FD }\end{array}$ \\
\hline Río de Oro & $\sim 12 \mathrm{~km}$ & $\mathrm{~N}-\mathrm{S}$ & DD & & $\begin{array}{l}\text { Al N y S termina contra } \\
\text { F. inversas y Mora respec- } \\
\text { tivamente }\end{array}$ & $\mathrm{DD}, \mathrm{FD}$ \\
\hline Bongo & $>25 \mathrm{~km}$ & NNW a NNE & $\mathrm{DD}(\mathrm{TT})$ & & $\begin{array}{l}\text { Al N termina contra } \mathrm{F} \text {. } \\
\text { Cedro }\end{array}$ & $\begin{array}{l}\text { ES, FD, SF, DDI, } \\
\text { DD, VL, QR }\end{array}$ \\
\hline Lepanto & $>28 \mathrm{~km}$ & NNE & $\mathrm{DD}(\mathrm{TT})$ & & & $\mathrm{EF}, \mathrm{FD}, \mathrm{DC}$ \\
\hline Miramar & $>15 \mathrm{~km}$ & $\mathrm{~N}-\mathrm{S}$ & DD & & & VL, EF, CE, QD \\
\hline
\end{tabular}


Cuadro 1 (continuación)

\begin{tabular}{|c|c|c|c|c|c|c|}
\hline Nombre falla & $\begin{array}{l}\text { Long. } \\
(\mathrm{km})\end{array}$ & Rumbo & Tipo Despl. & $\begin{array}{l}\text { Bloque } \\
\text { sube }\end{array}$ & Relación con otras fallas & $\begin{array}{c}\text { Evidencias } \\
\text { morfotectónicas y } \\
\text { estructurales }\end{array}$ \\
\hline Morote & $\sim 33 \mathrm{~km}$ & NW & DI (DS) & $\begin{array}{l}\mathrm{NE} \\
(\mathrm{SW})\end{array}$ & $\begin{array}{l}\text { Al W y E termina contra F. } \\
\text { Belén y Carmona respec- } \\
\text { tivamente }\end{array}$ & $\begin{array}{l}\text { ES facetados al SW } \\
\text { y NE (cerros de } \\
\text { Jesús). Trazas de } \\
\text { falla observadas en } \\
\text { afloramiento }\end{array}$ \\
\hline Palos Negros & $\sim 14 \mathrm{~km}$ & NW & DI (DS) & $\mathrm{NE}$ & $\begin{array}{l}\text { Al W termina contra } \mathrm{F} \text {. } \\
\text { Caimital }\end{array}$ & ES facetado al SW \\
\hline Cacao & $\sim 25 \mathrm{~km}$ & E-W a ENE & DI (DS) & $\mathrm{N}$ & $\begin{array}{l}\text { Al W y E termina contra } \\
\text { F. Caimital y Carmona } \\
\text { respectivamente }\end{array}$ & ES facetado al S \\
\hline Gigante & $\sim 35 \mathrm{~km}$ & E-W a ENE & DI (DS) & $\mathrm{N}(\mathrm{S})$ & $\begin{array}{l}\text { Al W termina contra F. } \\
\text { Juan de León }\end{array}$ & $\begin{array}{l}\text { ES facetado al S } \\
\text { (N) }\end{array}$ \\
\hline Mora & $>32 \mathrm{~km}$ & ENE & DS & & $\begin{array}{l}\text { Al E termina contra F. } \\
\text { Juan de León }\end{array}$ & $\begin{array}{l}\text { VL, ES, CE, DD, } \\
\text { DA, SF }\end{array}$ \\
\hline Dominica & $\sim 20 \mathrm{~km}$ & ENE & DS (DI) & & $\begin{array}{l}\text { Al W se ramifica de F. } \\
\text { Guarial }\end{array}$ & $\begin{array}{l}\text { VL, ES, CE, DD, } \\
\text { DDI, QR, SF }\end{array}$ \\
\hline Cedro & & ENE a WNW & DS (DI) & & & $\begin{array}{l}\text { VL, ES, CE, DD, } \\
\text { DA, LF, DDE, DDI }\end{array}$ \\
\hline Sonzapote & $\sim 14 \mathrm{~km}$ & ENE & DS & & $\begin{array}{l}\text { Al W termina contra F. } \\
\text { Lepanto }\end{array}$ & $\begin{array}{l}\mathrm{DD}, \mathrm{DA}, \mathrm{SF}, \mathrm{VL}, \\
\mathrm{FD}, \mathrm{DDI}\end{array}$ \\
\hline Arío & $>40 \mathrm{~km}$ & ENE a NE & DS & & $\begin{array}{l}\text { Al W termina contra F. } \\
\text { Bongo }\end{array}$ & $\begin{array}{l}\text { ES, CE, SF, DD, } \\
\text { DA, VL }\end{array}$ \\
\hline Cóbano & $>16 \mathrm{~km}$ & E-W & DS & & $\begin{array}{l}\text { Al W termina contra F. } \\
\text { Arío }\end{array}$ & $\begin{array}{l}\text { Es, CE, SF, VL, } \\
\text { QR?. Fallas con } \\
\text { comp. normal } \\
\text { desplazan terrazas } \\
\text { aluviales y Fm } \\
\text { Montezuma }\end{array}$ \\
\hline Pénjamo & $\sim 10 \mathrm{~km}$ & E-W & DI & $\mathrm{N}$ & & $\begin{array}{l}\text { ES facetados al } \\
\mathrm{S}, \mathrm{QR}\end{array}$ \\
\hline San Isidro & & E-W & DI & $\mathrm{N}$ & & ES facetado al S \\
\hline Montezuma & $>12 \mathrm{~km}$ & ENE & DI (DS) & & & $\begin{array}{l}\text { ES, DD, DA. Falla } \\
\text { con comp. inversa- } \\
\text { sinestral desplaza } \\
\text { la Fm. Montezuma } \\
\text { sobre Complejo de } \\
\text { Nicoya }\end{array}$ \\
\hline
\end{tabular}

Explicación de cuadro: En la columna, tipo de desplazamiento, DD, DI, DS, TC y TT son respectivamente fallas de desplazamiento dextral, inverso, sinestral, transpresiva y transtensiva. Cuando se encuentran entre paréntesis se indica que son componentes locales de movimiento. En la última columna, las evidencias morfotectónicas son VL: valle lineal, VF: valle de falla, ES: escarpe de falla, CE: contraescarpe, DD: drenaje desviado, DA: drenaje adaptado, SF: silla de falla, BF: berma de falla, QR: Cuaternario represado, QD: Cuaternario desplazado, LO: lomo de obturación, CV: copa de vino, DDE: drenaje descabezado, DDI: desvío de divisoria, LF: lomo de falla, AAD: abanico aluvial desplazado, FD: fila desviada, DC: desvío de costa. 


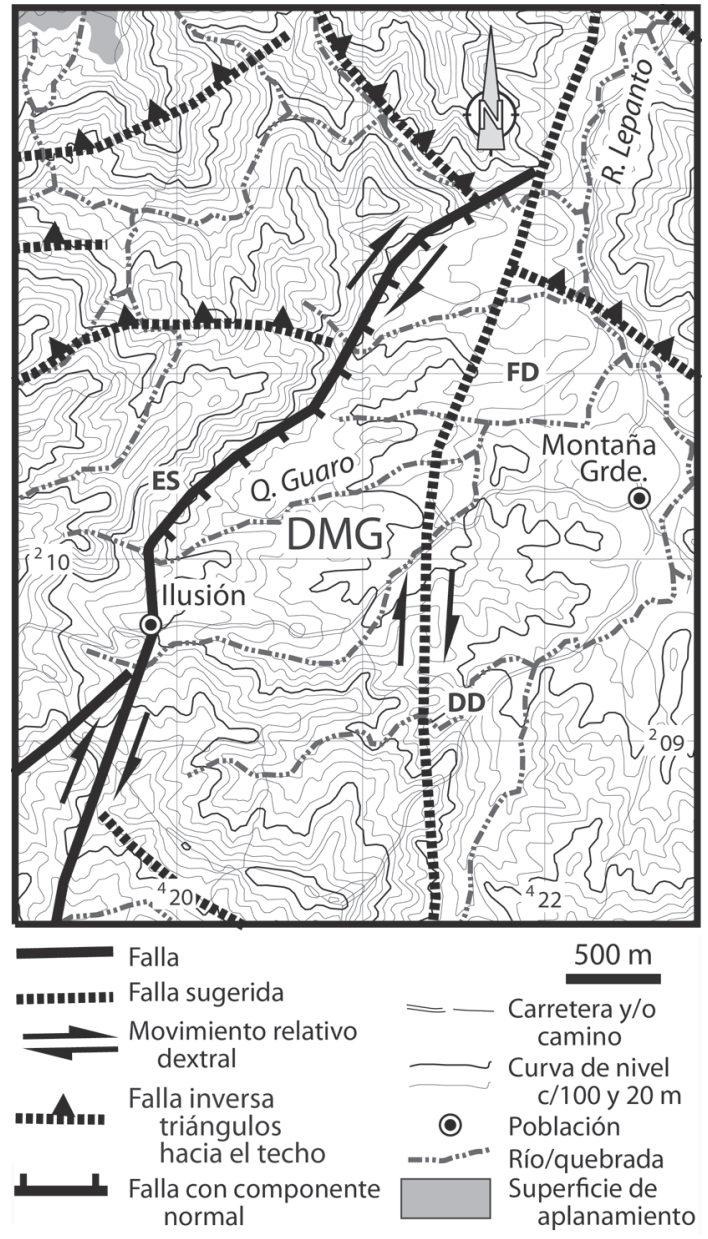

Fig.20: Detalle de las trazas de la falla Lepanto dentro de la depresión de Montaña Grande (DMG). La traza W tiene una componente transtensiva, cuya componente normal se expresa con un escarpe de falla facetado al E, al pie del cual se ha originado una zona deprimida anómala en el curso medio del río Lepanto. ES, FD y DD son respectivamente escarpe de falla, fila desviada y drenaje desviado. Ubicación en figura $6 \mathrm{~A}$.

Sobre el borde montañoso costero del S del golfo de Nicoya, entre el WSW de las localidad de Jicaral y al W de la de Río Grande hay varias fallas de rumbos entre E-W y WNW, con escarpes facetados principalmente al S (Fig. 6A). También hay escarpes facetados al $\mathrm{N}$, especialmente del lado $\mathrm{N}$ del borde montañoso costero entre el $\mathrm{W}$ de Jicaral y el E de Lepanto (Figs. 6A y 25). Algunos de los escarpes que limitan estas fallas son bastante rectilíneos y continuos por varios kilómetros. Este sistema de falla provoca el levantamiento de esta parte de la península tanto con respecto a la llanura aluvial que esta al NW de Jicaral, así como del lado $\mathrm{N}$ de la península con respecto al golfo, entre Jicaral, Lepanto y al E de esta última localidad. Denyer et al. (2003) y Denyer \& Alvarado (2007) muestran las fallas Gigante y Punta Gigante, como fallas paleotectónicas de movimiento inverso y buzantes al S en esta zona. La última estaría sobrecorriendo la Formación Curú, de origen turbidítica. Se considera que las anteriores fallas, forman un sistema de fallas inversas con una posible componente sinestral, que se denomina Gigante, el cual deforma y desplaza la superficie Cerro Azul, atestiguando su naturaleza neotectónica. Este sistema de falla inverso se muestra desviado a la derecha al cruzar al E la falla dextral Lepanto (Fig. 6A).

\section{Fallas sinestrales}

Las fallas principales, de acuerdo con su extensión, continuidad y posibles desplazamientos acumulados, son las fallas Mora, Dominica y Sonzapote (Figs. 5 y 6). La falla Mora de rumbo ENE se extiende por más de $30 \mathrm{~km}$, entre Puerto Carrillo, en el flanco SW de la península, hasta terminar al E contra la falla Juan de León (Fig. 5). Al S de Puerto Carrillo entra en el mar y se desconoce cómo interactúa con la falla dextral Belén, mientras que al NE de Puerto Carrillo, la falla dextral Caimital termina contra la falla Mora. Sobre las estribaciones de la margen izquierda del río Mora, se distingue por una serie de contraescarpes alineados. Al cruzar la fila Mora, la falla pierde prominencia y se subdivide en varias trazas (Fig. 5). El ramal S muestra valles lineales, origina desvíos izquierdos tanto al cruzar el río Bejuco, como los bordes del valle (Fig. 26A). Al cruzar la superficie Cerro Azul sugiere desvíos izquierdos de la misma, como ocurre en el sector de Bajo Mora, donde también se observan desvíos en quebradas (Fig. 26B).

La falla Dominica tiene un rumbo variable, ENE en su sector W, donde muestra un trazo continuo y simple, mientras que al E se subdivide en varias trazas y tiene un rumbo que varía entre E-W y ENE, mostrando una 


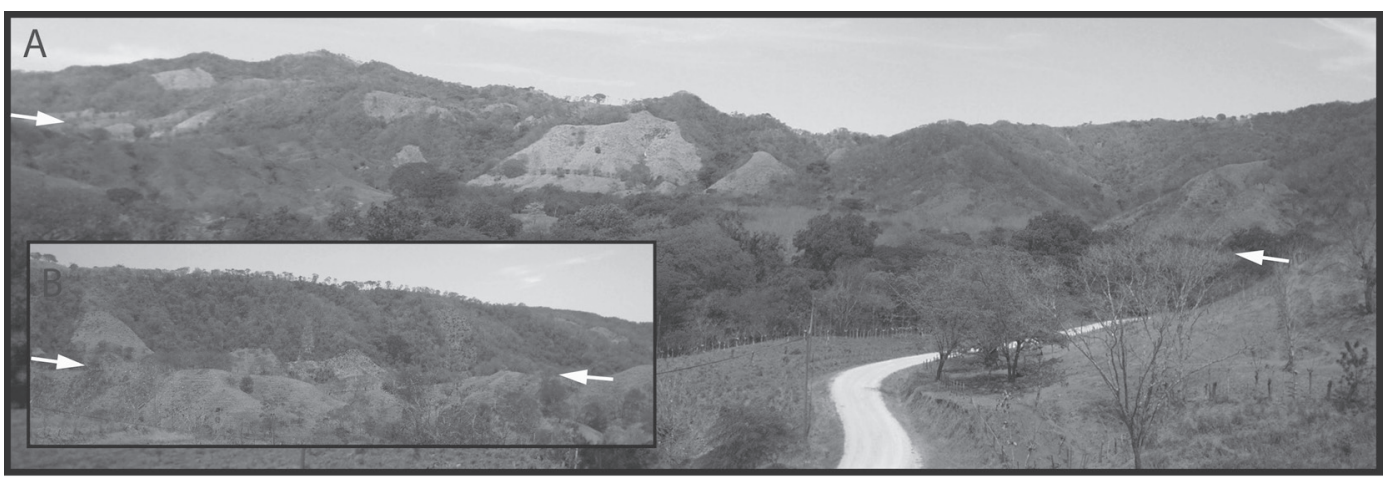

Fig. 21A: Vista al W de la depresión de Montaña Grande (DMG) en primer plano limitada al W por la traza de falla W de la falla Lepanto, que muestra un escarpe de falla facetado al E. B: Vista al $\mathrm{N}$ del escarpe de falla facetado al W y bastante juvenil cerca de la localidad de Ilusión. El salto vertical es de unos $140 \mathrm{~m}$.

componente inversa (Fig. 6). Al W termina contra la falla Cedro, mientras que al E termina contra la falla dextral Lepanto. Muestra desvíos izquierdos en quebradas y ríos, divisorias y remanentes de la superficie Cerro Azul (Fig. 27). Por ejemplo, al cruzar el cerro Picuda, hay un claro desvío izquierdo de la divisoria. En la quebrada Tigra origina un desvío izquierdo, un valle represado aguas arriba con depositación aluvial y encañonado aguas abajo del cruce de la falla. Al cruzar al E el valle de la quebrada Níspero desvía a la izquierda los bordes W y E de un remanente de la superficie Cerro Azul y de las divisorias de las filas (Fig. 27). Al NNE de la localidad de Unión pasa por sillas de falla.

La falla Sonzapote limita al W con la falla Lepanto y se extiende al E hasta alcanzar el sistema de falla inverso Gigante (Fig. 5). Es el límite, tanto al E como al $\mathrm{W}$ de varias fallas inversas del sistema Gigante.

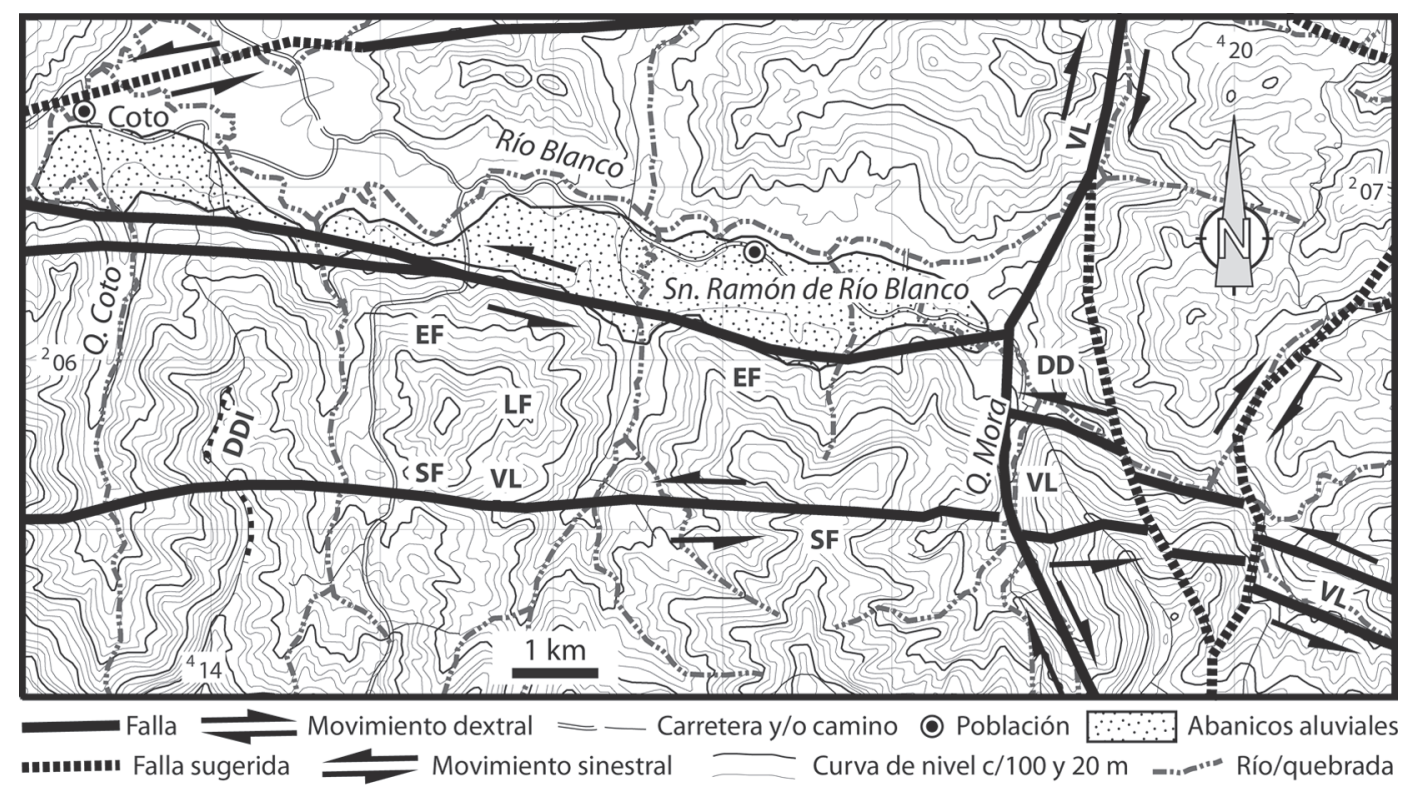

Fig.22: Sector central-E del lomo de falla (LF) de la falla Cedro en su intersección con la falla Lepanto. EF, SF, VL, DD y DDI son respectivamente escarpe de falla, silla de falla, valle lineal, drenaje desviado y divisoria desplazada. Ubicación en figura 6A. 

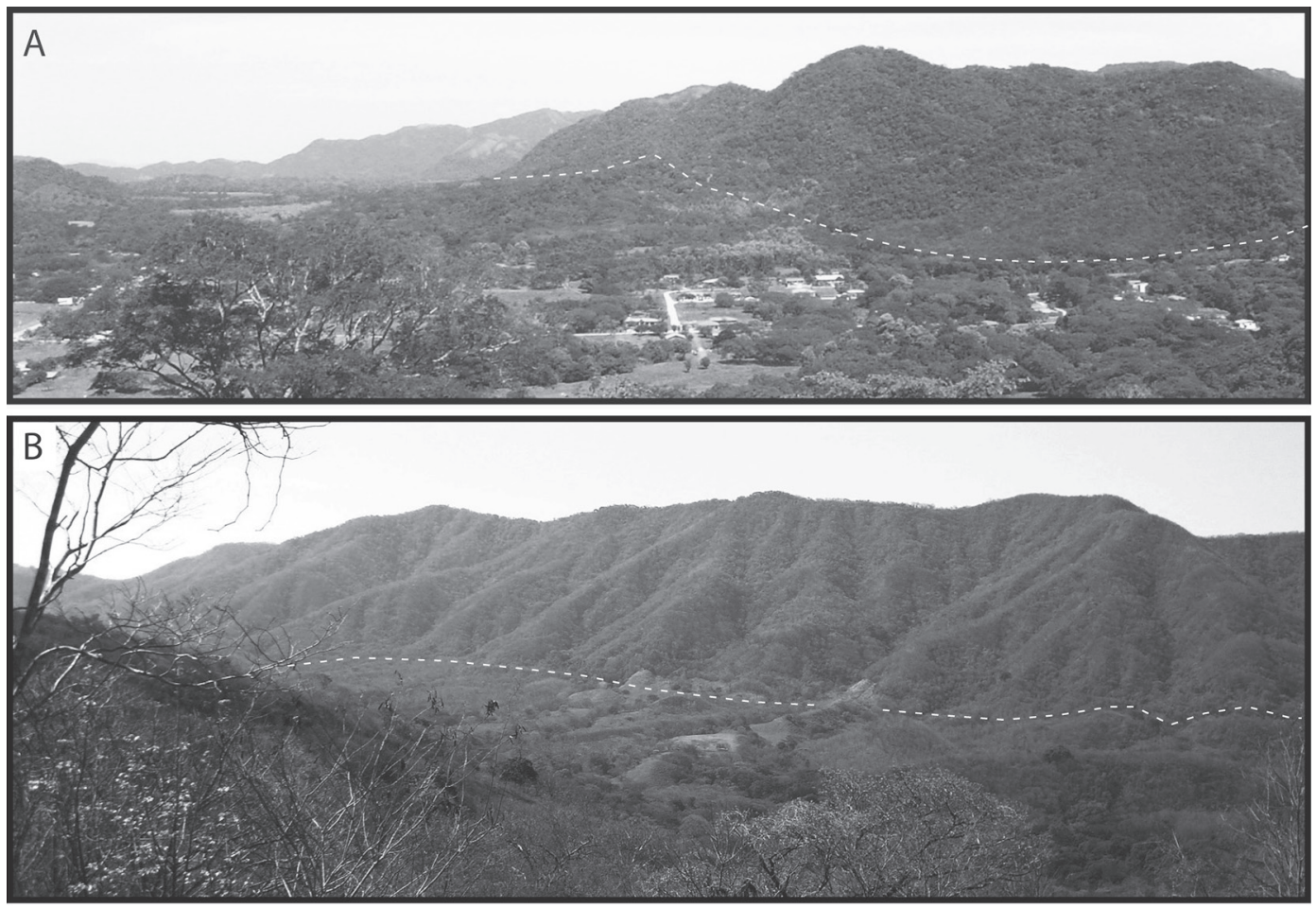

Fig. 23A: Vista hacia el NNW desde el cerro Calera del escarpe de falla de la falla Morote facetado al W. En primer plano se observa la depresión donde se asienta Nicoya. B: Vista al NW del escarpe de falla facetado al W de la falla Morote en el sector de los cerros de Jesús.

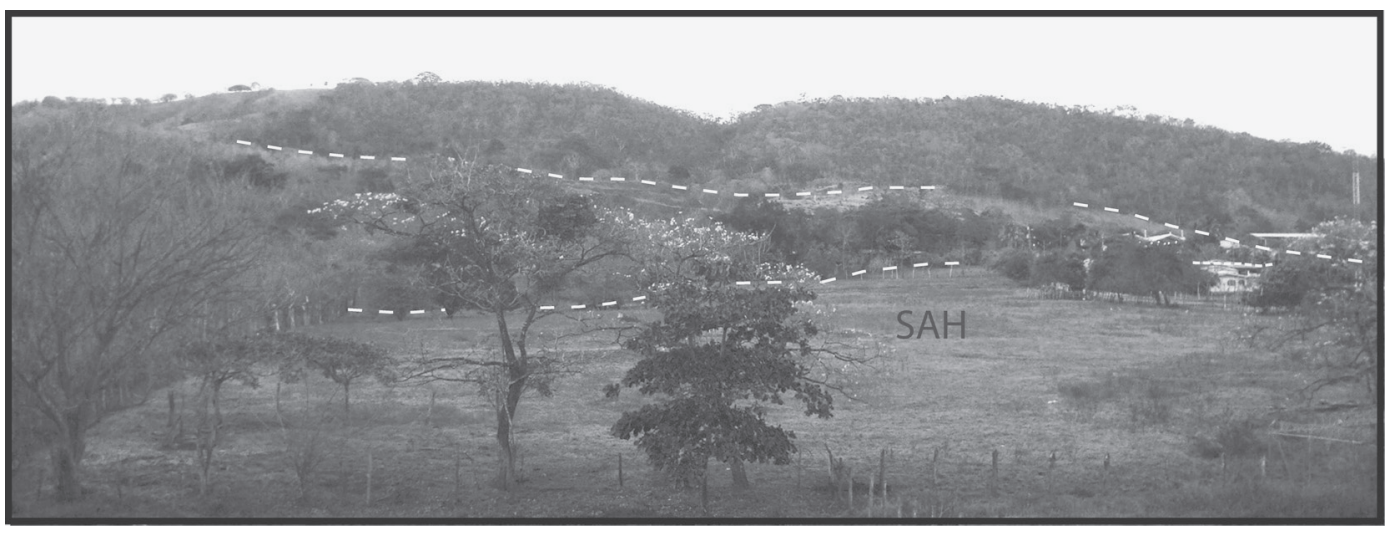

Fig. 24: Vista al $\mathrm{N}$ del escarpe de falla facetado al $\mathrm{S}$ de la falla Cacao, mostrando una traza inferior y otra superior. En primer plano se observa la superficie de aplanamiento donde se asienta Hojancha (SAH). 


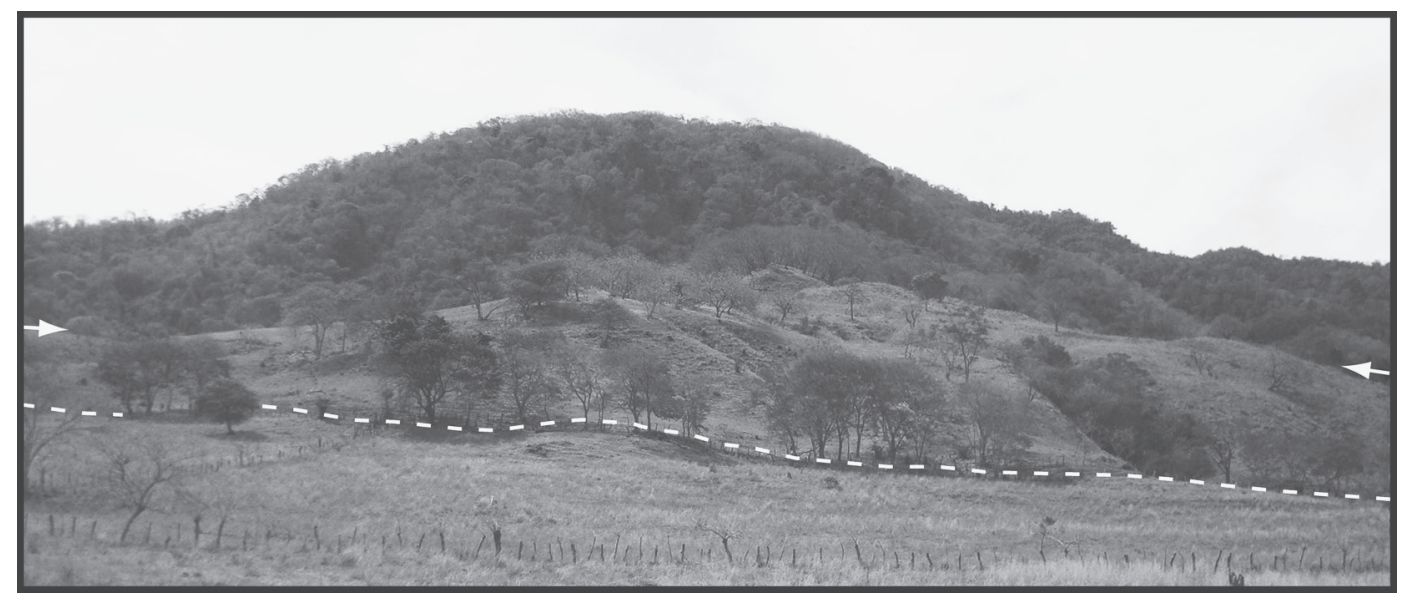

Fig.25: Al E de Jicaral se tiene una vista al S de un escarpe de falla inferior (línea a trazos) y otro superior (indicado por flechas), ambos facetados al N, asociados con el sistema de falla Gigante. En el nivel inferior se observa del lado derecho una quebrada encañonada al salir del escarpe sugiriendo levantamiento neotectónico.

\section{DOMINIO MERIDIONAL DE LA PENÍNSULA DE NICOYA}

La falla Cedro se considera el extremo $\mathrm{N}$ del dominio meridional de la península, en el cual predominan las fallas de rumbo, tanto dextrales como sinestrales (Fig. 6B). En el extremo S también hay fallas oblicuas sinestrales-inversas a inversas de rumbo promedio E-W y pliegues con trazas axiales NNE en el bloque cabalgante.

\section{Fallas dextrales}

El nombre de falla Bongo fue originalmente usado por Dengo (1962) para una traza similar a la del lado E de este trabajo. Esta falla tiene un rumbo entre NNW a NNE extendiéndose al $\mathrm{N}$ a lo largo de dos ramales hasta la falla Cedro, a la cual no parece cruzar o desplazar (Fig. 6). El ramal W, que incluye varias trazas, se localiza a lo largo del valle superior y medio del río Bongo, el cual se ensancha al S y muestra una importante depositación aluvial (Fig. 28). El mismo se encuentra limitado por zonas escarpadas al $\mathrm{W}$ y al $\mathrm{E}$, que se interpreta definen el pull-apart Bongo. El ramal E se localiza a lo largo del valle del río Frío. Ambas ramas se unen al $\mathrm{W}$ del cerro Villalta y originan un desvío a la derecha en el río Arío de $\sim 0,8 \mathrm{~km}$ (Fig. 28). Aguas arriba de donde el río atraviesa la falla, el curso es meándrico y hay un cuaternario represado. Lo anterior concuerda con el desplazamiento dextral inferido para la falla.

Al cruzar al S la superficie de aplanamiento de Cóbano se divide en un par de trazas que limitan una nueva zona de transtensión (Fig. 6). La traza W se interpreta origina un desvío derecho en una fila de $\sim 0,4 \mathrm{~km}$ sobre el valle de la margen izquierda del río Manzanillo. Al S ambas trazas salen al mar al NW de playa Santa Teresa.

\section{Fallas sinestrales}

El nombre de falla Cedro fue usado por Dengo (1962) para una falla de trazo similar a la mostrada en este estudio en sus tramos central y E. Se inicia al W cerca de playa San Miguel en la costa pacífica y se extiende hasta playa Lorenza, en el lado oriental (Fig. 6B). La extensión W de la falla se infiere con base en dos evidencias. La primera es un desvío izquierdo de las curvas de nivel que definen el pie de los cerros Millal al $\mathrm{N}$ y Jabilla al S. La segunda son posibles desvíos izquierdos en el río Jabillo y en una quebrada contigua al E, cerca del valle del río Millal. En su 

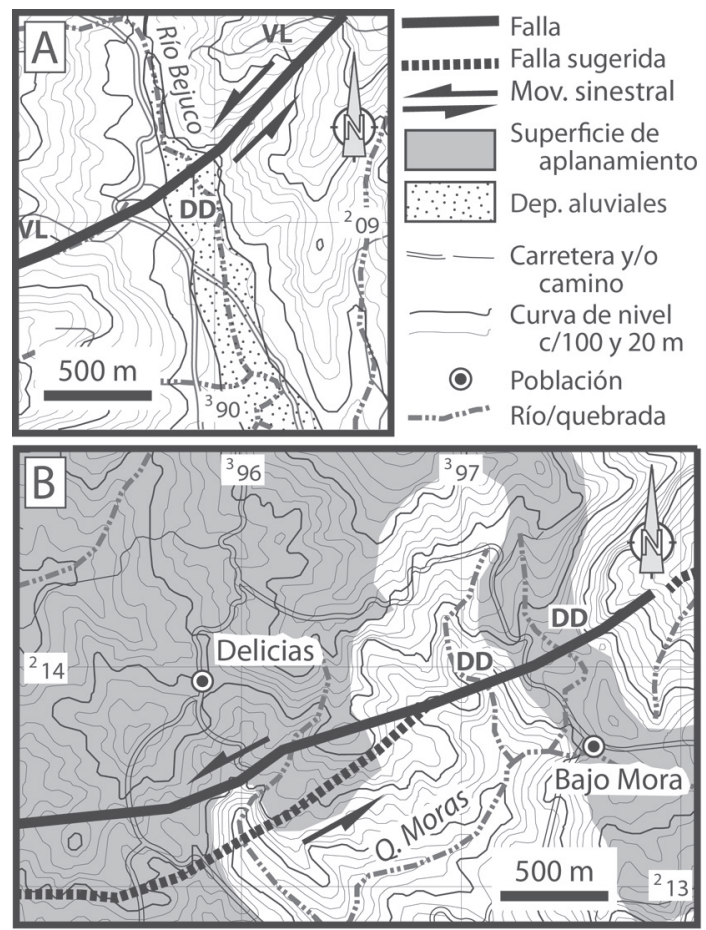

Fig.26: Muestra ejemplos de la morfotectónica de la falla Mora (ubicaciones en figura 5). A: Falla Mora al cruzar el río Bejuco. VL y DD son respectivamente valle lineal y drenaje desviado. B: Al cruzar el remanente erosional Cerro Azul muestra desvíos izquierdos en la misma y en afluentes de la quebrada Moras (DD).

parte central la falla muestra una doble traza que limita un lomo de falla, lo cual indica la naturaleza transpresiva de la falla en este sector. La traza $\mathrm{N}$ del lomo de falla se evidencia por un prominente escarpe facetado al $\mathrm{N}$, el cual se observa al cruzar la fila Zapote y sobre la margen izquierda del río Blanco (Figs. 6B y 22). Algunas quebradas que drenan este escarpe muestran cambios de pendiente bruscos en el perfil de equilibrio, incluyendo cascadas. Asimismo, al pie del escarpe de falla se encuentran varios abanicos aluviales coalescentes, que han desplazado el río Blanco sobre la margen $\mathrm{N}$ de su valle. La traza $\mathrm{S}$ del lomo de falla la definen principalmente valles lineales de rumbo E-W, divisorias desplazadas y un escarpe discontinuo facetado al $\mathrm{S}$, el cual se observa más prominente en su sector central entre las quebradas Coto y Mora (Fig. 22).

En el curso superior de los ríos Blanco y Guarial, la falla Cedro es desviada a la derecha por la falla Lepanto y luego se continúa al E a lo largo de dos trazas de falla subparalelas separadas entre 200 y 300 m, que limitan la fila Bonita (Figs. 6B y 22). Al E ambas trazas se separan definiendo una incipiente transtensión. La traza $\mathrm{S}$ de la falla sigue localmente el río Guarial y sale al golfo de Nicoya cerca de playa Lorenza. La traza $\mathrm{N}$ cruza varias estribaciones de la margen derecha del río Grande y alcanza la traza S cerca de playa Lorenza (Fig. 6B).

La falla Arío se inicia al E de la falla dextral Bongo (Fig. 6B). Al E tiene un rumbo NE cortando las estribaciones NW de la fila Pando, donde muestra sillas de falla, escarpes y contraescarpes, y quebradas desviadas o adaptadas. Más al NE remonta las cabeceras del río Seco a lo largo de valles lineales, donde limita el sector S de la superficie de Cerro Azul en el remanente de Once Estrellas. Al E cruza los cerros Las Vueltas y lue-

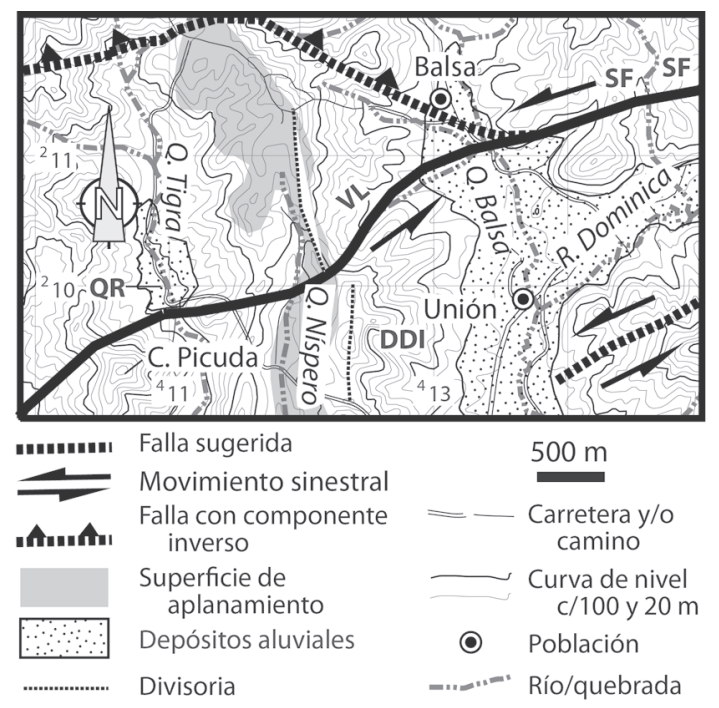

Fig.27: Morfotectónica de la falla Dominica cerca de la localidad de la Unión. Se observan desvíos izquierdos en la quebrada Tigra y un cuaternario represado (QR) aguas arriba del cruce de la falla y en las divisorias en ambos lados de la quebrada Nispero y en la fila Picuda. VL, DDI y SF son, respectivamente, valle lineal, divisoria desviada y silla de falla. Ubicación en figura $6 \mathrm{~A}$. 

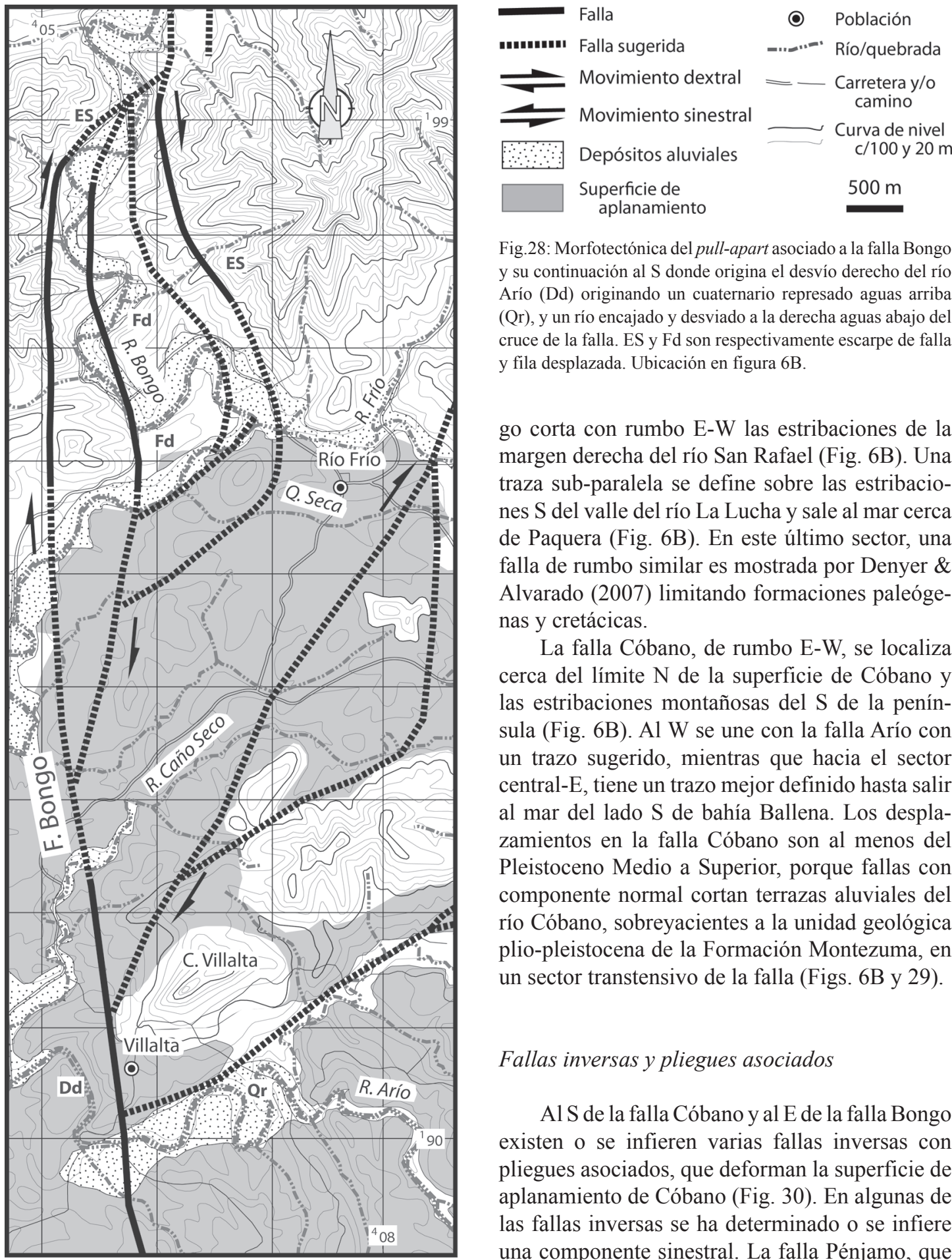

Fig.28: Morfotectónica del pull-apart asociado a la falla Bongo y su continuación al $\mathrm{S}$ donde origina el desvío derecho del río Arío (Dd) originando un cuaternario represado aguas arriba (Qr), y un río encajado y desviado a la derecha aguas abajo del cruce de la falla. ES y Fd son respectivamente escarpe de falla y fila desplazada. Ubicación en figura $6 \mathrm{~B}$.

go corta con rumbo E-W las estribaciones de la margen derecha del río San Rafael (Fig. 6B). Una traza sub-paralela se define sobre las estribaciones $\mathrm{S}$ del valle del río La Lucha y sale al mar cerca de Paquera (Fig. 6B). En este último sector, una falla de rumbo similar es mostrada por Denyer \& Alvarado (2007) limitando formaciones paleógenas y cretácicas.

La falla Cóbano, de rumbo E-W, se localiza cerca del límite $\mathrm{N}$ de la superficie de Cóbano y las estribaciones montañosas del $\mathrm{S}$ de la península (Fig. 6B). Al W se une con la falla Arío con un trazo sugerido, mientras que hacia el sector central-E, tiene un trazo mejor definido hasta salir al mar del lado S de bahía Ballena. Los desplazamientos en la falla Cóbano son al menos del Pleistoceno Medio a Superior, porque fallas con componente normal cortan terrazas aluviales del río Cóbano, sobreyacientes a la unidad geológica plio-pleistocena de la Formación Montezuma, en un sector transtensivo de la falla (Figs. 6B y 29).

\section{Fallas inversas y pliegues asociados}

Al S de la falla Cóbano y al E de la falla Bongo existen o se infieren varias fallas inversas con pliegues asociados, que deforman la superficie de aplanamiento de Cóbano (Fig. 30). En algunas de las fallas inversas se ha determinado o se infiere una componente sinestral. La falla Pénjamo, que 


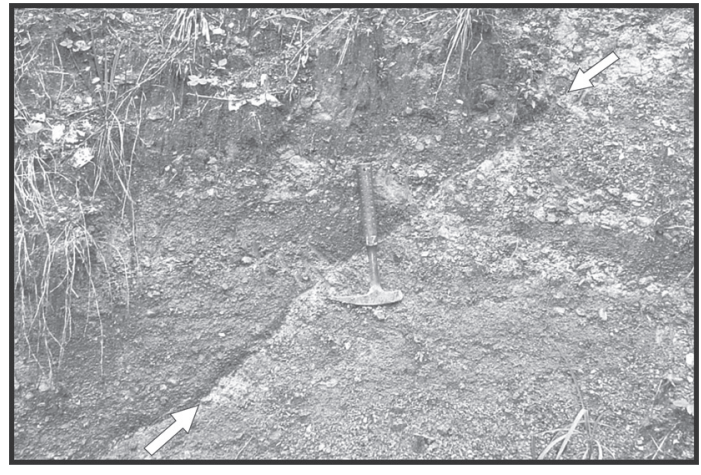

Fig.29: Falla con componente normal (indicada por flechas blancas) cortando depósitos de terrazas aluviales sobreyaciendo a la Formación Montezuma (sitio 1 en figura 6B).

incluye dos trazas de rumbo oscilante cercano al E-W, muestra escarpes facetados al S y representa el límite al $\mathrm{S}$ de la anterior superficie (Fig. 30). La traza frontal tiene un escarpe hasta de $80 \mathrm{~m}$ de alto y la trasera tiene una altura similar. Un pliegue anticlinal desarrollado en turbiditas de la Formación Arío con un flanco delantero fuertemente buzante y el trasero de buzamiento más suave se localiza en la zona del escarpe trasero. Un depósito aluvial, que se interpreta como un cuaternario represado, se localiza al pie del escarpe trasero a lo largo de un afluente del río Enmedio y en el sector aguas arriba del anterior río (Fig. 30).

La falla inversa San Isidro, de rumbo cercano al E-W, se localiza unos $2 \mathrm{~km}$ al $\mathrm{N}$ de la falla Pénjamo (Fig. 30). Se identifica por un escarpe facetado al $\mathrm{S}$ de unos $40 \mathrm{~m}$ de alto. Una naciente del río Lajas se localiza al pie de esta falla en su sector central.

Un drenaje divergente al NW y al SE a partir de colinas de rumbo cercano al $\mathrm{N} 40^{\circ} \mathrm{E}$ sugiere un plegamiento anticlinal al NE de la falla Pénjamo y el cual se continuaría al NE de la falla San Isidro (Fig. 30).

Al ENE de la falla San Isidro se localiza la falla Montezuma con un trazo sinuoso y un escarpe facetado al S de hasta $60 \mathrm{~m}$ de alto (Fig. 30). Un poco al $\mathrm{N}$ de la falla anterior se encuentra un nuevo escarpe de falla de rumbo WNW, que sigue valles lineales. Al N de la falla Montezuma se infiere un pliegue anticlinal con una traza axial de rumbo $\mathrm{N} 35^{\circ} \mathrm{E}$, el cual se muestra desplazado unos $0,15 \mathrm{~km}$ en sentido sinestral, al cruzar el escarpe de falla ubicado al N. Este plegamiento se infiere por mostrar una morfología similar a lo indicado previamente para el pliegue sugerido al $\mathrm{N}$ la falla Pénjamo. La falla Montezuma sobrecorre el Complejo de Nicoya sobre la Formación Montezuma a lo largo de una falla inversa con una componente sinestral, en dos afloramientos (ubicación sitios 1 y 2 en Fig. 30).

\section{SISMICIDAD SUPERFICIAL}

Los sismos superficiales $(0-15 \mathrm{~km})$ fueron obtenidos a partir de cuatro fuentes diferentes de datos (Fig. 31): 1. La base de la Red Sismológica Nacional (RSN, ICE-UCR) para el período 19922004. La cual fue depurada eliminándose aquellos eventos mal localizados que no eran de la zona de estudio y relocalizándose los eventos de magnitudes $\mathrm{Md} \geq 3,0$, con un mínimo de 5 lecturas en al menos 4 estaciones, entre las cuales debían estar las estaciones localizadas dentro de la península JCR o VCR con lecturas de P y S. 2. La base de la Red Sismológica Nacional (RSN, ICE-UCR) para el período 2005-2010. Incluye eventos de magnitudes $\mathrm{Md} \geq 3,0$, con un mínimo de 5 lecturas en al menos 4 estaciones. 3. Los sismos localizados en la península de Nicoya entre diciembre de 1999 y junio del 2001 por Newman et al. (2006) y 4. Los sismos superficiales localizados por una red temporal instalada en el lado interno del golfo de Nicoya entre marzo de 1996 y enero de 1998 (Montero et al., 1998). Asimismo, se compararon las bases de datos 1, 3 y 4 para eliminar eventos duplicados y se escogieron las mejores soluciones hipocentrales.

La ocurrencia de temblores superficiales, localizados en la placa cabalgante sugiere que algunas fallas de la península de Nicoya pueden estar activas (Fig. 31). Las cuatro fuentes de datos muestran una importante sismicidad superficial en diferentes sectores de la península. Es notable un alineamiento de temblores en la extensión marina de la falla Bongo. Sin embargo, en esta zona la sismicidad puede ser explicada por la interacción del levantamiento de Fisher a lo largo del margen convergente. También se observa una alta concentración sísmica en la zona donde las fallas Caimital, Río de Oro y Mora con- 


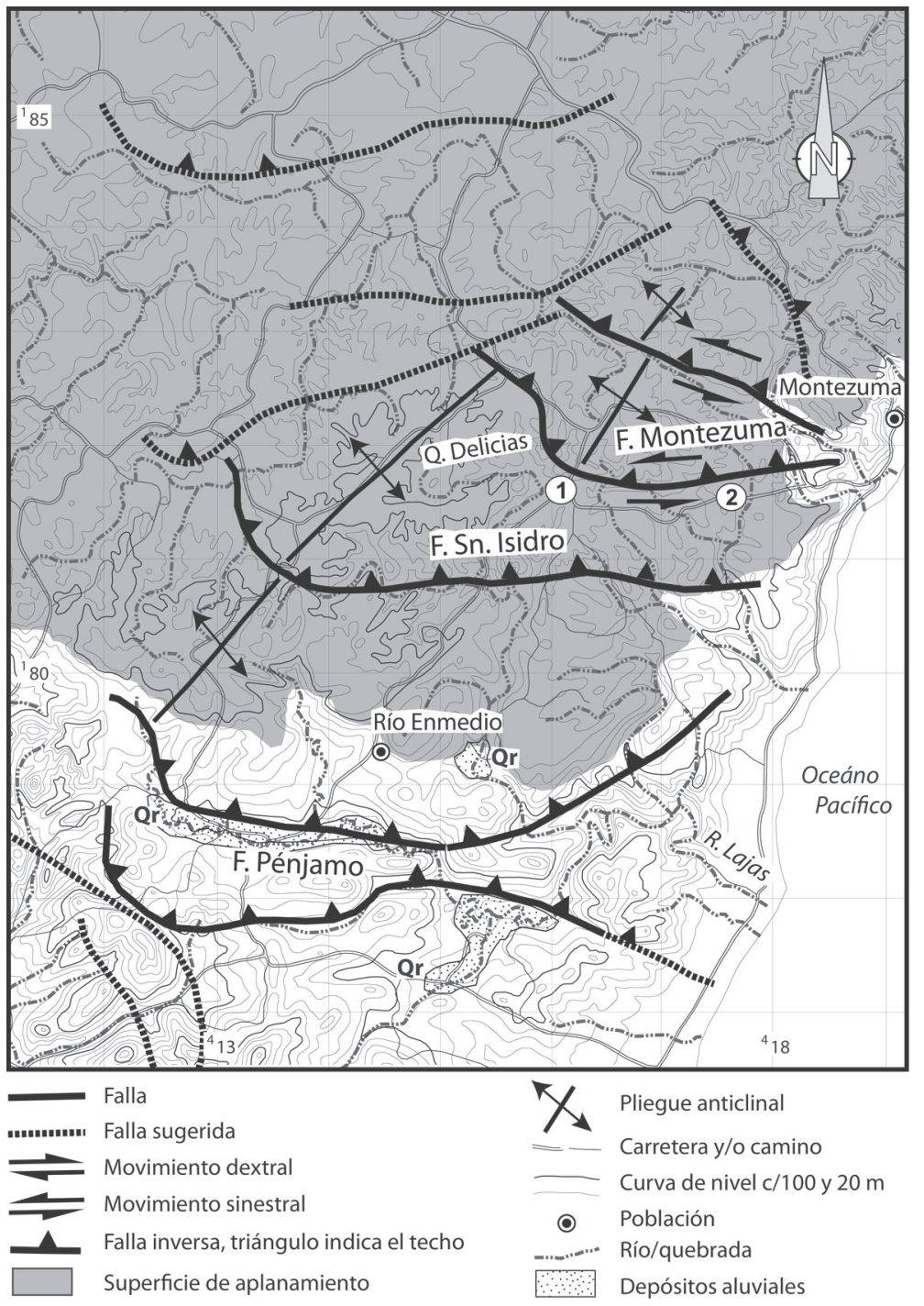

Fig.30: Muestra la neotectónica del sector S de la península evidenciando el sistema de fallas oblicuas sinestrales-inversas a inversas, que desplazan la superficie de aplanamiento de Cóbano. Qr es el cuaternario represado asociado a la falla Pénjamo. Ubicación en figura $6 \mathrm{~B}$.

fluyen. Entre los sismos que se han localizado en esta última área, ocurrió un enjambre de temblores en noviembre del 2007, con varios sismos sentidos con intensidades entre III y IV en la escala Mercalli Modificada (Boletín Red Sismológica Nacional, 2007). Asimismo, hay sismos que siguen las trazas de las fallas dextrales Belén, Caimital y Carmona, aunque estos se muestran más dispersos. Entre las fallas con componente inversa, las fallas Morote y Cacao son las que muestran más sismicidad alinea- da. Hansen et al. (2006) localizó un enjambre de temblores en el sector de la traza de la falla Morote donde esta pasa al sector $\mathrm{W}$ de los cerros de Jesús, a una profundidad cercana a los $15 \mathrm{~km}$ (S. Hansen, com. esc., 2011). El mecanismo focal compuesto de Hansen et al. (2006) para este enjambre tiene un plano nodal de rumbo NNW y movimiento dextral bastante puro y el otro es de rumbo ENE y movimiento sinestral bastante puro (Fig. 31), los cuales son totalmente compatibles con el rumbo y el tipo de des- 


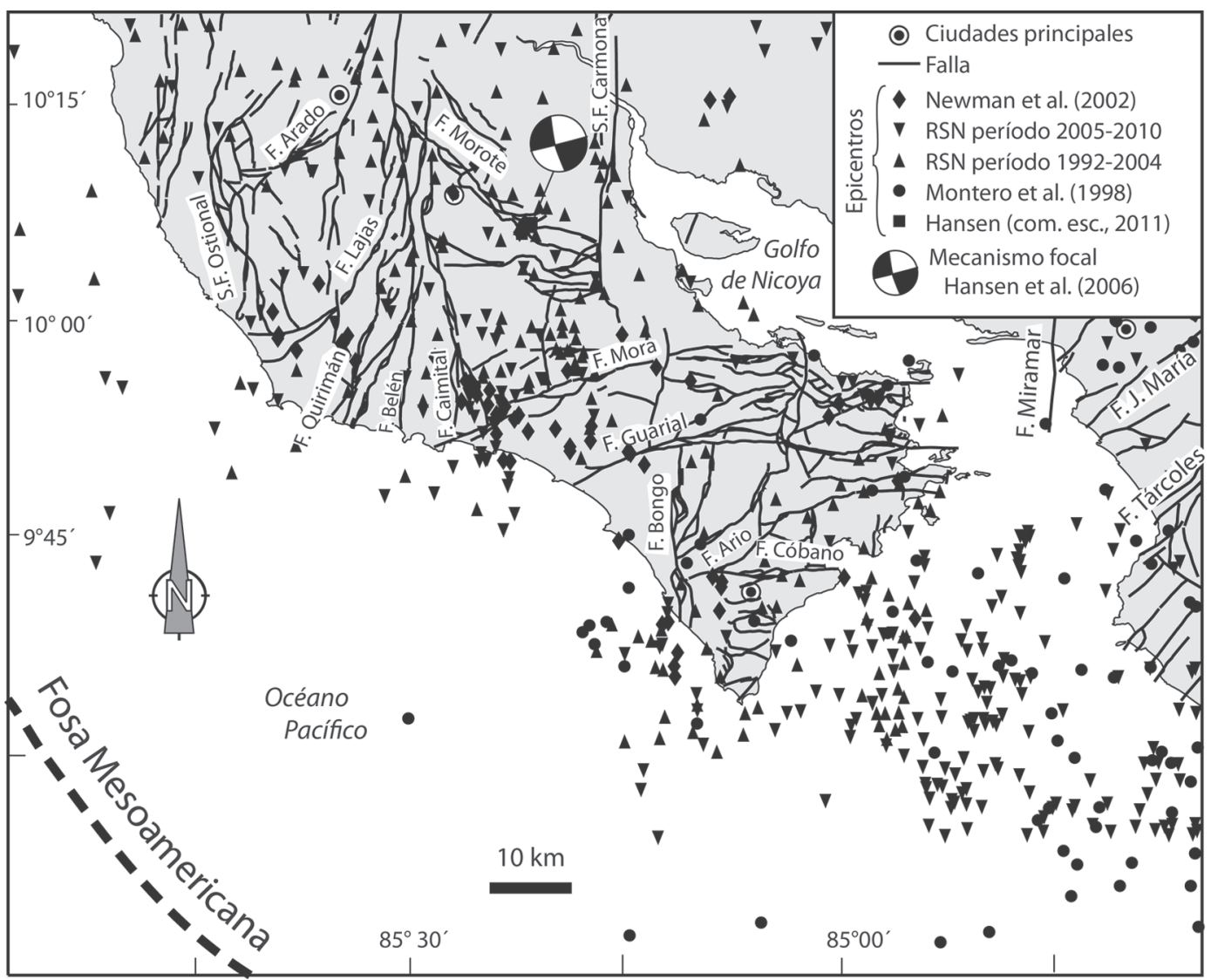

Fig.31: Sismicidad superficial (0-15 km) de la península de Nicoya y del golfo de Nicoya integrando cuatro fuentes de datos epicentrales según se explica en el texto. Las fallas Belén, Caimital, Carmona, Mora y Bongo en su extensión marina sugieren actividad sísmica. El mecanismo focal obtenido para un enjambre de temblores localizado cerca de la falla Morote por Hansen et al. (2006) es concordante con el sistema de fallas dextrales y sinestrales encontrado en este estudio.

plazamiento de las fallas neotectónicas que hemos determinado en la península de Nicoya. Hansen et al. (2006) consideraron que el plano nodal de rumbo NNW y movimiento dextral correspondía con el plano de falla, el cual acomodaría desplazamiento paralelo a la fosa Mesoamericana. Contrario a Hansen et al. (2006), en este estudio se interpreta que el plano nodal ENE y movimiento sinestral corresponde con el plano de ruptura, el cual acomoda desplazamiento y rotación a lo largo de una falla secundaria asociada con la falla inversa-sinestral Morote. Es de observar que trazas de falla asociadas con la falla Morote, con rumbo entre E-W y ENE, se han identificado en el sector donde ocurrió el enjambre de temblores reportado por Hansen et al. (2006), al W de los cerros de Jesús (Figs. 5 y 31).

\section{DISCUSIÓN}

Deformación neotectónica del centro-S de la península de Nicoya y su relación con la indentación tectónica asociada con la cordillera submarina del Coco

Consideramos que el sistema de fallas neotectónicas de la península de Nicoya está relacionado con el escape tectónico del NW de Costa Rica, debido a la indentación del antearco conforme los levantamientos de Fisher y del Coco (la zona comprendida entre ambos en adelante se le denomina simplemente cordillera del Coco), se subducen bajo el centro-S de Costa Rica (Montero, 1994; LaFemina et al., 2009). Para efectos de nuestro mo- 


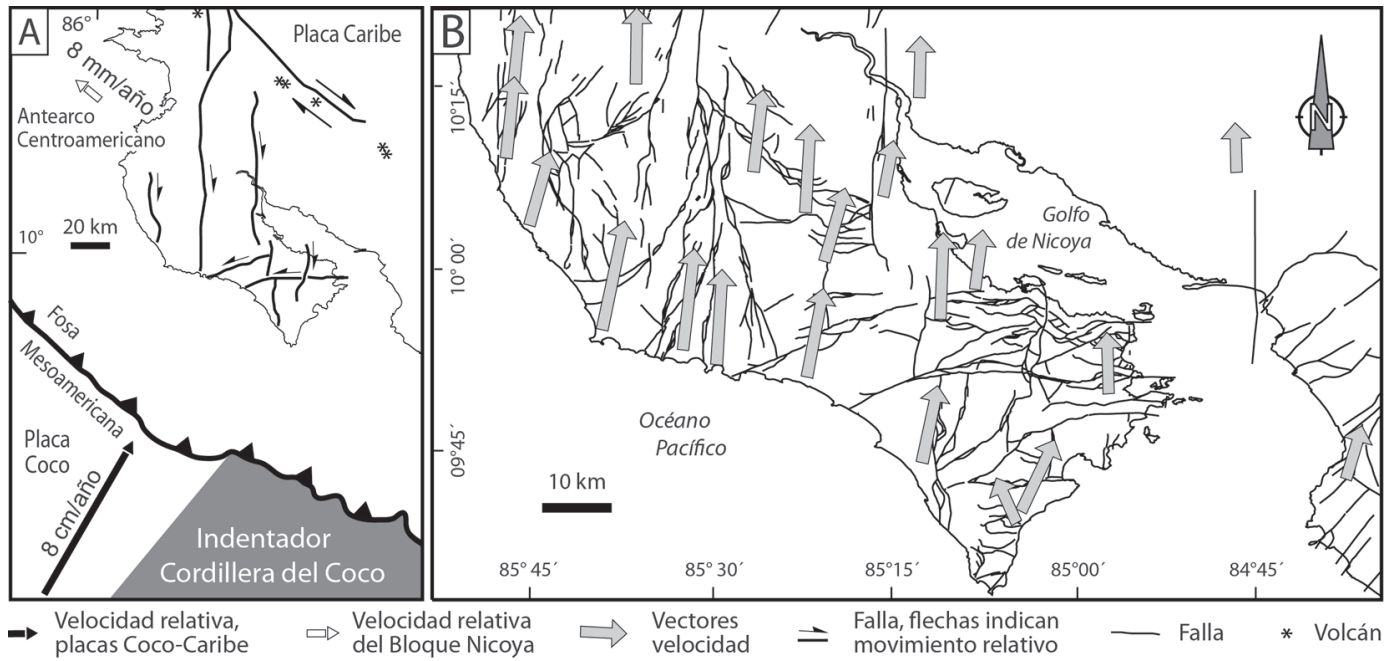

Fig.32A: Modelo tectónico donde el levantamiento del Coco indenta el antearco de la península de Nicoya y provoca el escape tectónico al N a lo largo de las fallas dextrales N-S. Se muestra la velocidad de movimiento relativo Coco-Caribe (flecha negra) y del bloque del Antearco Centroamericano (flecha en blanco, de acuerdo con LaFemina et al., 2009). B: Muestra las velocidades determinadas de datos GPS reportadas por LaFemina et al. (2009) para la península de Nicoya, las cuales se relacionan con el movimiento interplaca Coco-Caribe al $\mathrm{N} 20^{\circ} \mathrm{E}$ y con el escape tectónico del sliver del antearco centroamericano, principalmente a lo largo de las fallas dextrales N-S.

delo partimos de que se inició hace unos $5 \mathrm{Ma}(\mathrm{de}$ Boer et el., 1995; Gräfe, 1998; Gräfe et al., 2002). LaFemina et al. (2009) propusieron un modelo de elementos finitos para la colisión de la cordillera submarina del Coco con el centro-S de Costa Rica y observaron que el mismo explica bien los vectores de velocidad GPS obtenidos en el centro-NW de Costa Rica y en particular el movimiento del bloque o sliver del antearco centroamericano paralelo a la fosa Mesoamericana, tanto en Costa Rica como en Nicaragua (Fig. 32B). Debe indicarse que en el margen convergente de Nicaragua, el acoplamiento interplaca es débil y por tanto, no puede ser explicado solamente por la convergencia oblicua (Turner et al., 2007; Correa-Mora et al., 2009).

Las velocidades obtenidas a partir de los datos de las estaciones GPS de la península de Nicoya (LaFemina et al., 2009; Fig. 32B) son el resultado principalmente del movimiento interplaca CocoCaribe de $8 \mathrm{~cm} /$ año al $\mathrm{N} 20^{\circ} \mathrm{E}$ (DeMets et al., 2010) y en menor medida por causa del escape tectónico del sliver del antearco centroamericano, que LaFemina et al. (2009) estiman es alrededor de $8 \mathrm{~mm} /$ año al NW. Se considera que el movimiento de escape tectónico en la península de Nicoya se divide (slip partitioning) entre las diversas fallas neotectónicas determinadas en este estudio, donde predomina el movimiento al N-S, a lo largo de las fallas dextrales de ese rumbo, que son las más largas y que se continúan al $\mathrm{N}$ fuera del área del presente estudio (Fig. 32A). (Fig. 32).

Por lo tanto, nuestros resultados son concordantes con los datos GPS y la interpretación de LaFemina et al. (2009). Es decir, nuestro arreglo de fallas neotectónicas es explicado por un escape tectónico asociado con la colisión del levantamiento del Coco, como fue propuesto originalmente por Montero (1994).

\section{Relación entre las fallas neotectónicas y la transrotación}

La rotación de juegos de fallas de desplazamiento de rumbo y de los bloques entre estas alrededor de ejes verticales es un modo de deformación que ha sido reconocido desde los trabajos de Freund $(1970,1971)$ y Garfunkel (1970). En la península de Nicoya existen varias características que evidencian que el mecanismo de transrotación 


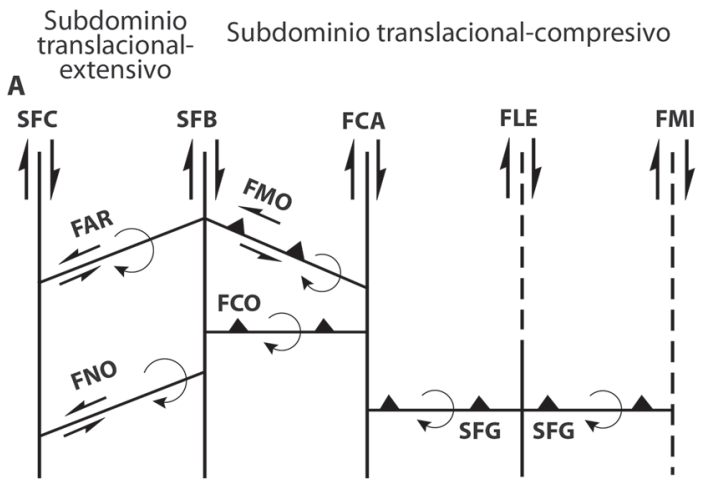

B
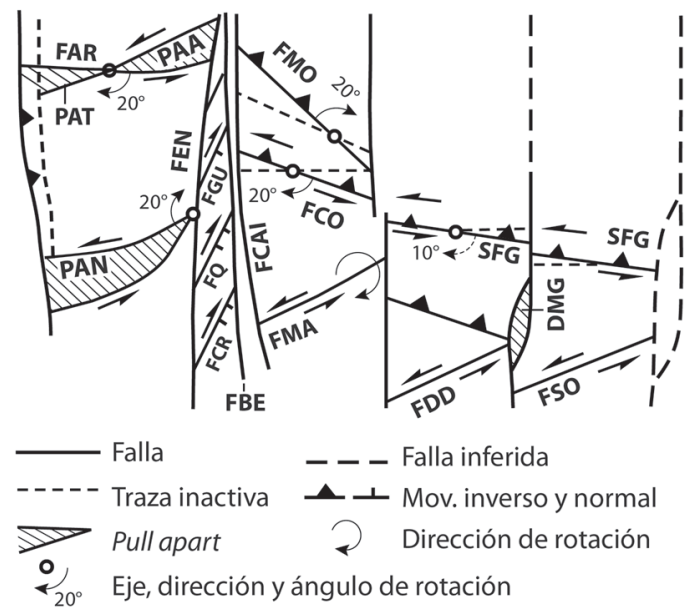

Fig. 33: Modelo esquemático de escape tectónico y transrotación propuesto para el sector central-N de la península. En $\mathrm{A}$, a $5 \mathrm{Ma}$, se parte de un ancho inicial igual entre las zonas de cizalla limitadas por las fallas dextrales, el cual cambia en B (en algún momento en el Pleistoceno Superior) al ocurrir la transrotación y el movimiento translacional al N. SFC, SFB, FCA, FLE, FMI, FAR, FNO, FMO, FCO y SFG son respectivamente los sistemas de fallas Los Chanchos y Belén, las fallas Carmona, Lepanto, Miramar, Arado, Nosara, Morote, Cacao y el sistema de falla Gigante. En A se tienen sus posiciones iniciales, las cuales luego se modifican en $\mathrm{B}$ al ocurrir la rotación $\varphi$ entre $20^{\circ}$ (los dos bloques del W) y $10^{\circ}$ (los dos bloques del E) alrededor de un eje vertical y se forman los pull-apart Tabaco (PAT), Arado (PAA) y Nosara (PAN). La depresión de Montaña Grande (DMG) se forma al ocurrir un salto a la derecha en la falla Lepanto, lo cual acorta el bloque del lado W de la falla. opera dentro de la región como son: la relación espacial entre los diferentes tipos de fallas reconocidas, sus orientaciones, la forma como terminan unas contra otras y las características de deslizamiento determinadas o inferidas en las diferentes fallas (Cuadro 1).

Nuestro estudio ha permitido reconocer un dominio translacional al $\mathrm{N}$, con varios bloques limitados por fallas dextrales, dentro de los cuales consideramos que opera la transrotación. Este dominio se define claramente al $\mathrm{N}$ de la falla Cedro, aunque podría extenderse al $\mathrm{S}$ de esta. El mismo lo hemos dividido en dos subdominios: el translacional-extensivo y el translacional-compresivo.

Se interpreta que existe una transrotación bien definida en el subdominio translacionalextensivo, dentro del bloque limitado por los sistemas de fallas subparalelos y dextrales Los Chanchos y Belén, los cuales controlan el desplazamiento al $\mathrm{N}$ del sector $\mathrm{W}$ de la península (Fig. 4). Dentro de este bloque se han definido las fallas sinestrales Arado y Nosara. El subbloque entre las fallas sinestrales Arado y Nosara está rotando en el sentido de la manecillas del reloj a lo largo de un eje vertical, lo que ha provocado una reorientación de ambas fallas de un rumbo original $\mathrm{N} 60-70^{\circ} \mathrm{E}$ a uno $\mathrm{E}-\mathrm{W}$, formando las cuencas de tracción de Tabaco, Arado y Nosara. El ángulo de rotación, entre $20^{\circ}$ y $30^{\circ}$, se obtuvo a partir de medir el ángulo entre las fallas que limitan las anteriores estructuras transtensivas. La rotación del bloque entre las fallas sinestrales Arado y Nosara aumenta el transporte tectónico entre las fallas dextrales Los Chanchos y Belén, en forma similar al transporte tectónico que se atribuye a las fallas sinestrales comprendidas dentro del sistema de falla transformado San Andrés, California, Estados Unidos (Dickinson, 1996).

Durante el proceso de transrotación, en el sistema de falla dextral Los Chanchos ocurrieron varios ajustes en su geometría, para dar espacio a la rotación de las fallas Arado y Nosara y al bloque comprendido entre estas. De esta manera, queda- 
ron inactivas un par de trazas de falla ubicadas del lado $\mathrm{N}$ del pull-apart Tabaco y al $\mathrm{W}$ del remanente Montaña de la superficie Cerro Azul, que eran originalmente la continuación al $\mathrm{N}$ del sistema de falla Los Chanchos (Fig. 4). Asimismo, al W del pull-apart Tabaco, hay una zona de transpresión en el sistema de falla Los Chanchos, donde ocurre el desplazamiento de unos $3 \mathrm{~km}$ al $\mathrm{W}$ del sector $\mathrm{N}$ de este sistema de falla con respecto a su sector $\mathrm{S}$. Este desplazamiento ocurre precisamente al $\mathrm{W}$ del pull-apart Tabaco, lo cual permitió abrir espacio para el desarrollo de esta estructura transtensiva.

Con respecto a los ajustes geométricos del sistema de falla Los Chanchos hacia su sector $\mathrm{S}$, se considera que conforme se formó el pull-apart de Nosara fueron abandonadas dos trazas, las cuales terminan al S contra la traza de falla E-W del pull-apart Nosara (Fig. 4). Actualmente, el sistema de falla Los Chanchos tiene como traza principal activa la del lado W, que entra en el mar al W de playa Nosara. Asimismo, se considera que la doble traza del sistema de falla Los Chanchos indica que ha ocurrido un desplazamiento de actividad de la traza E a la traza W, para permitir abrir espacio al subbloque que ha rotado entre las fallas sinestrales.

Mientras ocurrían los anteriores ajustes en la geometría del sistema de falla Los Chanchos, a lo largo del sistema de falla Belén ocurrían ajustes similares. El más evidente se da en la geometría de la falla Enmedio. Esta falla muestra un cambio de rumbo de N-S al S de la cuenca de tracción Arado, a NNE del lado E de esta estructura transtensiva. Este cambio de rumbo ha provocado un desplazamiento de la falla Enmedio de unos $3 \mathrm{~km}$ al E, al considerar los sectores al $\mathrm{N}$ y al $\mathrm{S}$ del pullapart (Fig. 4). En la zona del pull-apart Nosara, no se observan ajustes en la geometría de la falla Enmedio, debido a que el eje de rotación vertical a lo largo del cual se abre el pull-apart se ubica en donde la falla Nosara termina contra la falla Enmedio, por lo cual no son requeridos cambios en la geometría de esta última falla, contrario a lo que ocurre en el pull-apart de Tabaco y Arado, cuyo eje de rotación se localiza entre ambas cuencas de tracción.

Un aspecto que resalta en el sistema de falla Belén es que varias de sus trazas de falla de rumbo NNE, tienen una componente de falla normal, como son las fallas Guastomatal, Quirimán y Crucivallejo. Estas fallas muestran una extensión que ha favorecido la rotación de las fallas Arado y Nosara y del subbloque entre ambas, y además, han favorecido el transporte tectónico al $\mathrm{N}$ del bloque entre las fallas Los Chanchos y Belén.

Con respecto al subdominio translacionalcompresional, este comprende tres bloques separados por fallas dextrales subparalelas, que son los siguientes:

1. Entre los sistemas de Belén y Carmona.

2. Entre las fallas Carmona y Lepanto

3. Entre la falla Lepanto hasta posiblemente la falla Miramar (Figs. 2, 5 y 6).

Dentro de los anteriores bloques existen una serie de fallas sinestrales a inversas. Así, dentro del primer bloque se han encontrado las fallas con componente inversa Palos Negros, Morote y Cacao, las cuales parecen tener una componente sinestral. Asimismo, la falla sinestral Mora, se localiza dentro de este bloque. Dentro del segundo bloque se presentan la falla sinestral Dominica y el sistema inverso Gigante. El último parece también presentar una componente sinestral. En el tercer bloque se ubicarían la falla sinestral Sonzapote y la continuación al E del sistema de falla inverso Gigante, pero desplazado al S, en el sector al E de la falla Lepanto.

Las fallas localizadas dentro de cada uno de los diferentes bloques del subdominio translacional-compresional y sus desplazamientos sugeridos, son explicadas por los esfuerzos horizontales compresivos de rumbo NE, que actúan dentro de cada uno de los bloques, debido a los esfuerzos de cizalla simple aplicados en los límites de los mismos. Dentro de los anteriores 
bloques, las observaciones que sugieren transrotación son las siguientes:

1. Las fallas sinestrales no muestran una fase transtensiva, como si se observa en las fa1las Arado y Nosara. Además, las fallas sinestrales Dominica y Sonzapote parecen cortar o desplazar las fallas inversas, lo que sugiere que son más recientes que las inversas. Lo anterior se interpreta como que los sectores $\mathrm{S}$ de los bloques, donde se encuentran las fallas sinestrales, están en un estadio inicial de transrotación (Figs. 5 y 6). Esto incluye los sectores de los bloques donde se ubica el sistema de falla inverso Gigante, el cual sugiere una leve rotación (alrededor de $10^{\circ}$ ?) en algunas de sus trazas, dado que muestran cambios de rumbo de E-W a WNW, aunque las mismas podrían explicarse también por los cambios de rumbos que son típicos de este tipo de fallas debido a su bajo grado de buzamiento.

2. En concordancia con el punto anterior, la falla sinestral Mora, se localiza en un sector del bloque donde la distancia entre las fallas dextrales N-S (Caimital y Carmona) es mayor ( 22-26 km), comparado con el sector N ( 20-23 km) (Fig. 5). Esto refuerza la interpretación de que este sector $\mathrm{S}$ del bloque está en estado inicial de transrotación. Con respecto al ancho del sector $\mathrm{S}$ del bloque debe resaltarse que la falla Caimital (al SW del bloque) tiene una componente de levantamiento en su lado $\mathrm{W}$, lo que implica que en este sector tiene una componente dextral-inversa. Como la falla Carmona se releva a la derecha con la falla Juan de León, este sector S del bloque mantiene un ancho similar al original.

3. En el lado $\mathrm{N}$ del bloque, localizado entre las fallas Caimital y Carmona, se sugiere una reducción de ancho (ver punto anterior), lo que implica rotación. La rotación parece sugerirla el sistema de falla Cacao, el cual tiene trazas de rumbo E-W y WNW (Fig. 5), cerca de la localidad de Hojancha y al E de la misma. Se sugiere que las trazas E-W están inactivas y son anteriores a las WNW. El eje de rotación se debe ubicar en la parte media del sistema de falla y se considera que el ángulo de rotación ha sido alrededor de unos $20^{\circ}$, el cual fue determinado a partir del ángulo desarrollado entre las anteriores trazas. Con respecto a la falla Morote, se considera que la traza del lado $\mathrm{N}$ de los cerros de Jesús se ha desplazado al sector S de estos cerros; mientras que al NW de los cerros de Jesús, la falla Morote muestra varias trazas con rumbos entre E-W y NW. Se estima una rotación para la falla Morote similar al sistema de falla Cacao. La rotación dentro del sector $\mathrm{N}$ del bloque entre las fallas Belén y Carmona sugiere que las fallas Palos Negros, Morote y Cacao deben tener alguna componente de movimiento sinestral a lo largo de ellas, como lo sugiere la interpretación que hicimos del mecanismo focal obtenido de Hansen et al. (2006), que fue discutida previamente. En este sentido, este sistema de falla inverso parece tener alguna similitud con el que se ubica del lado W del big bend en la falla San Andrés, al W del desierto de Mohave (Jackson \& Molnar, 1990).

4. Otra sugerencia de transrotación es la determinación de Flores \& Denyer (2003) de un movimiento izquierdo con una componente inversa en la falla Morote, hecha con base en estrías. En el caso de que este sea el deslizamiento actual de la falla indicaría una rotación actual de la falla, o bien corresponde con uno anterior, en cuyo caso sería una rotación pasada.

\section{Modelo cinemático esquemático}

Un modelo esquemático de evolución de los bloques entre las fallas dextrales Los Chanchos y Belén y entre este último y los bloques ubicados al E se presenta en la figura 33. En la primera fase, que se ubica hace unos $5 \mathrm{Ma}$, inicialmente los bloques estaban separados por un ancho similar (Fig. $33 \mathrm{~A}$ ), aunque en la península varían entre $10 \mathrm{y}$ 25 km (Figs. 2 y 3). Las fallas Arado y Nosara eran sinestrales puras y de rumbo ENE. En los bloques al E, las fallas Palos Negros y Morote, tenían un rumbo más al $\mathrm{W}$ que el actual, mientras el sistema de falla Cacao tenía un rumbo E-W. Las fallas sinestrales Mora, Dominica y Sonzapote no habían iniciado actividad, mientras que el sistema de falla inverso Gigante inicia actividad con un rumbo E-W.

La segunda fase (Fig. 33B) se ubica en el algún momento del Pleistoceno Superior. En esta ocurre desplazamiento dextral dentro del bloque 
limitado por las fallas Los Chanchos y Belén y transrotación dentro del subbloque entre las fallas Arado y Nosara, por lo cual estas fallas rotan unos $20^{\circ}$ y abren los pull-apart Arado, Tabaco y Nosara. Durante la transrotación de este subbloque, el mismo se expande al W y al E, provocando los desplazamientos al $\mathrm{W}$ de las trazas de falla Los Chanchos y el cambio de rumbo en la falla Enmedio de N-S a NNE, al E de la cuenca de tracción Arado. Además, ocurre la extensión del sistema de falla Belén con la formación de las fallas Guastomatal, Quirimán y Crucivallejo, como se describió previamente. En los bloques adyacentes, las fallas Palos Negros, Morote y Cacao han transrotado unos $20^{\circ}$ provocando un cambio de rumbo en las fallas al WNW (fallas Cacao) y al NW (Palos Negros y Morote), acortándose el bloque al $\mathrm{E}$ del sistema de falla Belén, al mismo tiempo que el lado $\mathrm{W}$ del sistema de falla Belén se expande. En el sistema de falla Gigante ocurre una leve rotación (unos $10^{\circ}$ ?). Al final de esta fase se inicia la actividad en las fallas Mora, Dominica y Sonzapote.

El acortamiento E-W de los bloques ocurre de varias formas:

1. Formación de la falla Caimital, al E de la falla Belén.

2. La falla Carmona mantiene su posición en su sector N, pero en el sector S se releva a la izquierda originando la falla Juan de León. Lo anterior provoca disminución de ancho del bloque entre las fallas Caimital y Carmona al N, mientras mantiene el mismo ancho al S.

3. La falla Lepanto origina el pull-apart de Montaña Grande relevándose a la derecha, por lo que durante la transrotación se modifican las distancias dentro del bloque limitado por las fallas dextrales N-S Carmona-Juan de León y Lepanto (Fig.33A y B). La geometría de la falla Miramar es incierta porque se interpreta su traza dentro de la zona marina.

Con base en los anteriores supuestos se estima una tasa de rotación de unos $2^{\circ} / \mathrm{Ma}$ para los bloques del lado $\mathrm{W}$ de la península y de unos $4 \%$ Ma para los bloques comprendidos entre las fallas Los Chanchos-Belén y Belén-Carmona. Los anteriores valores se obtienen al considerar que el proceso tectónico de transrotación se inicia hace unos 5 Ma y que la segunda fase ocurre cerca del tiempo actual (algún momento del Pleistoceno Superior).

¿Qué ocurre en la parte $\mathrm{S}$ de la península? La falla sinestral Cedro parece cortar la península con un rumbo variable $\mathrm{E}-\mathrm{W}$, por lo que el claro transporte tectónico que se observa al $\mathrm{N}$ de la misma, no se observa al S. La falta de claridad en la traza $\mathrm{W}$ de esta falla, al igual que el $\mathrm{S}$ de la falla Juan de León y el $\mathrm{N}$ de la falla Bongo, sugieren varias posibles interacciones entre estas fallas, como puede ser, por un lado, que la falla Bongo se continúe con la Juan de León. Por otro lado, aunque la falla Lepanto sugiere desplazar a la Cedro, ambas se continúan luego de cruzarse entre sí, no pudiéndose determinar sin ambigüedad la terminación al S de la falla Lepanto. La falla sinestral Arío termina al W contra la falla dextral Bongo.

Las anteriores observaciones del sector $\mathrm{S}$ de la península no permiten esclarecer si ocurre un transporte hacia el $\mathrm{N}$, similar al que ocurre al $\mathrm{N}$ de la falla Cedro, o si más bien ocurre transporte al E. Aunque el estudio de las fallas en este sector de la península no ha permitido aclarar la anterior incertidumbre, se considera que el transporte al $\mathrm{N}$ también debe predominar, porque si no existiría una zona de extensión entre el sector central-NW y el $\mathrm{S}$ de la península, lo cual no se observa.

\section{Correlación con el marco geotectónico}

Lo anterior puede estar relacionado con la subducción de la serranía de Fisher y con las diferencias de acoplamiento determinadas a lo largo de la zona interplaca Coco-Caribe en estudios recientes, como se explicará seguidamente. El valor de la pendiente $b$ de la relación frecuencia-magnitud de los sismos ha sido relacionada con el régimen de esfuerzo imperante a lo largo de la falla y la zona adyacente (como es discutido por Ghosh et al., 2008). Se considera que entre menor es el valor $b$, mayor es el esfuerzo imperante. Valores relativamente más bajos en el parámetro $b$ fueron encontrados por Ghosh et al. (2008) bajo la parte central de la península de Nicoya $(0,8$ a 1,7$)$ y más altos bajo la parte $\mathrm{S}(1,7$ a 2,0$)$. Stankova-Pursley et al. (2011) determinaron que el esfuerzo aparente incrementa desde la parte $\mathrm{S}$ hacia la parte $\mathrm{N}$ de 
la península. Ambos resultados son compatibles con un acoplamiento interplaca mayor bajo el sector central de la península, lo cual concuerda con los resultados determinados por Norabuena et al. (2004), con base en el modelado de los datos GPS de la misma zona. En la parte $\mathrm{S}$ de la península, los altos valores de b y un relativamente menor nivel de esfuerzo aparente sugieren un menor acoplamiento en la zona interplaca, en correspondencia con el sector donde se está subduciendo la serranía de Fisher.

De lo anterior se deduce que en la parte $\mathrm{S}$ de la península de Nicoya, las características geométricas de la deformación neotectónica parecen estar controladas por la subducción de la serranía de Fisher, bajo la misma. Al S de la falla Cóbano se presentan fallas inversas, oblicuas inversas-sinestrales y pliegues perpendiculares a las anteriores fallas. Las fallas de movimiento oblicuo inverso-sinestral Pénjamo, San Isidro y Montezuma, tienen un rumbo aproximadamente perpendicular a la dirección de subducción de la serranía de Fisher y los pliegues asociados con rumbos aproximadamente perpendiculares a las fallas anteriores, tienen un rumbo similar a la serranía de Fisher, sugiriendo que los mismos se relacionan con la deformación causada en el antearco externo, por el movimiento de este elemento morfológico hacia el $\mathrm{N} 20^{\circ} \mathrm{E}$.

\section{Fallamiento neotectónico y su relación con la superficie Cerro Azul}

Las evidencias de deformación de los remanentes de la superficie Cerro Azul son de especial importancia en nuestro estudio, porque reflejan movimientos neotectónicos. Hare \& Gardner (1985) definieron la superficie Cerro Azul como una superficie de erosión formada cerca del nivel del mar, durante un período de estabilidad tectónica. Gardner (com. esc., 2011) sugiere que esta superficie se formó en el Mioceno Temprano a Medio, en concordancia con la edad del horizonte BOSS (Base-of-slope sediment horizon or surface) determinado por Vannucchi et al. (2001), en el margen convergente de la placa Caribe, frente a la costa pacífica de la península de Nicoya. Una vez formada la superficie Cerro Azul, esta fue levantada en forma discontinua y diferenciada, lo que llevó a su erosión y fragmentación en seis bloques principales (Fig. 3). Hare \& Gardner (1985) plantearon que durante ese proceso, la superficie se deformó originándose un semi-domo fallado, el cual se hunde al SE, desde el bloque Esperanza hasta el remanente de Once Estrellas, en el sector $\mathrm{SE}$ de la península. Según estos autores, la deformación frágil se concentró en el sector NW de la superficie con el desarrollo de dos fallas principales con componente normal y levantamiento relativo en el lado SE, que denominaron LimonesCañas y Montaña y que separan respectivamente los fragmentos de Carrera Buena y Montaña y al último del bloque Esperanza.

De acuerdo con nuestro estudio, el sistema de falla Los Chanchos tiene un cambio de rumbo al $\mathrm{NW}$, en el sector $\mathrm{N}$ del bloque Montaña, originando un relevo transtensivo, expresado mediante la falla oblicua dextral-normal Veintisiete de Abril, con un escarpe facetado al NW, lo cual explica el levantamiento vertical relativo del remanente Montaña con respecto al Carrera Buena, que oscila entre un mínimo de 90 m y un máximo de 219 m (Hare \& Gardner, 1985). Por otro lado, entre los remanentes Montaña y Esperanza, hemos identificado la falla Arado. Sin embargo, la geometría y cinemática de esta falla no parecen explicar adecuadamente el levantamiento diferencial vertical máximo entre ambos remanentes de $\sim 275 \mathrm{~m}$ (Hare \& Gardner, 1985), aunque esta falla si corresponde con un elemento estructural importante entre los mismos. De acuerdo con nuestro modelo tectónico, el bloque entre los sistemas de fallas Los Chanchos y Belén está siendo comprimido en el lado $\mathrm{W}$ y levantado por fallas con componente normal en el lado E, lo cual no explica el movimiento diferencial entre los remanentes Montaña y Esperanza. Lo indicado previamente sugiere que algún otro mecanismo tectónico anterior al reconocido en este trabajo debe explicar estos levantamientos de la superficie Cerro Azul desde su formación, en este y otros sectores de la península.

Con respecto a la deformación flexural de la superficie Cerro Azul, la metodología aplicada en nuestro estudio no estuvo dirigida a determinar deformaciones dúctiles como las planteadas por 
Hare \& Gardner (1985). Sin embargo, debemos enfatizar que en concordancia con la geología que predomina en la mayor parte de la península, donde aflora el Complejo de Nicoya, un basamento de naturaleza rígida, hemos determinado en este estudio una deformación que es esencialmente frágil, lo cual se puede deber a que solo estamos reconociendo parte de la deformación acumulada por la superficie Cerro Azul desde su formación y levantamiento.

En este estudio hemos determinado numerosos ejemplos en los cuales los remanentes erosionales de la superficie Cerro Azul están limitados y desplazados por las diferentes fallas reconocidas dentro de la península, indicando su carácter neotectónico. Como veremos adelante con el modelo tectónico que planteamos para explicar el sistema de falla reconocido en la península de Nicoya, consideramos que el origen del mismo es al menos parcialmente posterior al levantamiento que ha llevado a la superficie Cerro Azul a su actual elevación en diferentes sectores de la península.

\section{Las fallas dextrales como vías de salida de volátiles provenientes del manto}

Existen varios manantiales que prácticamente no se secan durante el verano, localmente conocidos como salitrales. Varios de los mismos que fueron ubicados durante el trabajo de campo, se localizan cerca de las trazas de las fallas dextrales N-S, como son las fallas Belén, Caimital y Carmona (Figs. 4 y 5). Hilton et al. (2009a y b) muestran que las relaciones de isotopos de Helio $\left({ }^{3} \mathrm{He} /{ }^{4} \mathrm{He}\right)$ obtenidos de los salitrales de la península de Nicoya indican una proveniencia del manto. Su alineación y correspondencia con algunas de las fallas, son un indicativo de que estas estructuras son las que han servido para que estos volátiles suban a la superficie.

\section{CONCLUSIONES}

En este estudio hemos definido un arreglo de fallas neotectónicas dentro de la península de Nicoya, a partir de interpretaciones morfotectóni- cas complementadas con datos geológicos, y sismológicos. Se han distinguido dos dominios de fallas, donde el primero tiene un movimiento translacional al $\mathrm{N}$ y se localiza en el centro-NW de la península. El mismo se caracteriza por el predominio de bloques limitados por fallas sub-paralelas de desplazamiento dextral de rumbo cercano al N-S, denominados sistemas de fallas Los Chanchos y Belén y las fallas Carmona-Juan de León, Lepanto y posiblemente la falla Miramar. Dentro de los anteriores bloques se interpretan fallas sinestrales ENE a inversas E-W a NW, que incluyen una componente sinestral. El arreglo de fallas anterior es explicado por la transrotación que ocurre dentro de los bloques, al ocurrir los movimientos dextrales en las fallas que limitan los bloques. Se estima que la tasa de rotación en el centro-NW de la península es entre $2^{\circ} / \mathrm{Ma}$ para los dos bloques del lado E y de $4^{\circ}$ /Ma para los dos bloques del lado W. Lo anterior considerando que el proceso tectónico se inicio hace unos $5 \mathrm{Ma}$, a partir de la colisión del levantamiento del Coco con el centro-S de Costa Rica (de Boer et al., 1995; Gräfe, 1998; Gräfe et al, 2002). El segundo dominio se localiza en el sector $\mathrm{S}$ de la península y tiene un arreglo de fallas, donde predominan fallas sinestrales y dextrales, con desplazamientos horizontales de importancia relativa aparentemente similar, indicando traslación al $\mathrm{N}$ y menos probable al $\mathrm{E}$ de este sector de la península. Asimismo, hay un dominio de fallas inversas y pliegues asociados que son subsidiarios a las fallas de rumbo anteriores.

El dominio translacional al $\mathrm{N}$ del centroNW de la península ocurre dentro de una zona donde el acoplamiento interplaca Coco-Caribe es relativamente más fuerte (Ghosh et al., 2008; Stankova-Pursley et al., 2011). El dominio del $\mathrm{S}$ de la península se presenta a lo largo de una zona de acoplamiento interplaca variable, aunque menor que el localizado bajo centro-NW de la península (Ghosh et al., 2008; StankovaPursley et al., 2011).

El arreglo de fallas neotectónicas de la península de Nicoya y la transrotación determinada se explica por la indentación del antearco, debido a la colisión de la cordillera del Coco con el margen convergente del centro-S de Costa Rica. Este provoca el escape tectónico del NW de Costa Rica 
en dirección paralela a la fosa Mesoamericana, tal como fue propuesto originalmente por Montero (1994) y modelado a partir de datos de velocidades GPS por LaFemina et al. (2009). Las velocidades GPS obtenidas para diversas estaciones GPS ubicadas dentro de la península de Nicoya por los anteriores autores (Fig. 32B), se relacionan principalmente con el movimiento interplaca Coco-Caribe de $8 \mathrm{~cm} /$ año al N20 ${ }^{\circ} \mathrm{E}$ (DeMets et al., 2010), pero también tienen una pequeña componente relacionada con el escape tectónico, que se divide (slip partitioning) entrelas diversas fallas dextrales N-S identificadas en nuestro estudio. Lo anterior señala que el escape tectónico de la península y del antearco centroamericano ocurre inicialmente al $\mathrm{N}$ y luego al NW en dirección paralela a la fosa.

\section{AGRADECIMIENTOS}

Nuestro agradecimiento a Luis Diego Morales, quien como Presidente de la Comisión Nacional de Prevención de Riesgos y Atención de Emergencias, nos dio el apoyo financiero para la realización de este proyecto. Los comentarios y sugerencias de Guillermo E. Alvarado fueron de invaluable ayuda, lo que llevó a una mejora sustancial de este escrito. Mario Segnini del CIEDES nos cedió una imagen LANDSAT, que se utilizó en este estudio. Alvaro Aguilar del CENIGA nos facilitó las fotografías y mapas del proyecto TERRA. La Red Sismológica Nacional aportó los epicentros de sismos de profundidad menor a $15 \mathrm{~km}$. Carlos Ramírez nos ayudó con la ubicación de algunos salitrales. Carlos Vargas, Elena Badilla y Luis Obando colaboraron en el uso del SIG. Daniel Soto realizó parte del filtrado de datos sismológicos. Lidier Esquivel y Julio Madrigal de la CNE apoyaron el proyecto. Parte de estos resultados se incorporaron dentro del proyecto con la Dirección de Geología del MINAET, sobre la geología de la península de Nicoya, donde se agradece la colaboración de José Francisco Castro.

Esta investigación originalmente formó parte de las actividades del proyecto de investigación 113-
A5-162 de la Escuela Centroamericana de Geología de la UCR. Posteriormente, se realizaron las actividades finales como parte de los proyectos $830-\mathrm{B} 0$ 242 y 830-B1-101 del Centro de Investigaciones en Ciencias Geológicas de la UCR.

\section{REFERENCIAS}

ARROYO, I., 2001: Sismicidad y neotectónica en la región de influencia del proyecto Boruca. Hacia una mejor definición sismogénica del sureste de Costa Rica.- 162 págs. Univ. de Costa Rica, San José [Tesis Lic.].

BARCKHAUSEN, U., RANERO, C.R., VON HUENE, R., CANDE, S.C. \& ROESER, H., 2001: Revised tectonic boundaries in the Cocos Plate off Costa Rica: Implications for the segmentation of the convergent margin and for plate tectonic models.- J. Geophys. Res. 106: 19207-19220.

BOLETÍN RED SISMOLÓGICA NACIONAL (RSN: UCR-ICE), 2007: Resumen de la actividad sísmica en Costa Rica durante el mes de noviembre 2007.- 3 págs. Univ. de Costa Rica, San José.

CHINCHILLA, A.L., 1988: Geologie und struktur des ophiolth-komplexes der NicoyaHalbinsel (NW-Costa Rica).- 135 págs. Univ. de Tübingen, Alemania.

COLLOT, J.Y., DANIEL, J. \& BURNE, R.V., 1985: Recent tectonics associated with the subduction/collision of the d'Entrecasteaux zone in the Central New Hebrides Arc.Tectonophysics, 112: 325-356.

CORREA-MORA, F., DEMETS, C., ALVARADO, D., TURNER, H.L., MATTIOLI, G., HERNANDEZ, D., PULLINGER, C., RODRIGUEZ, M. \& TENORIO, C.., 2009: GPS-derived coupling estimates for the Central American subduction zone and volcanic arc-faults: 
El Salvador, Honduras and Nicaragua.Geophys. J. Intern., 179: 1279-1291.

DEBOER, J.Z., DRUMMOND, M.S., BORDELON, M.J., DEFANT, M.J., BELLON, H. \& MAURY, R.C., 1995, Cenozoic magmatic phases of the Costa Rican island arc (Cordillera de Talamanca.- En: MANN., P. (ed.): Geologic and Tectonic Development of the Caribbean Plate Boundary in Southern Central America.- Geol. Soc. Amer. Spec. Paper, 295: 35-55.

DEMETS, C., GORDON, R. \& ARGUS, D., 2010: Geologically current plate motions.Geophys. Journ. Intern, 181: 1-80.

DENGO, G., 1962: Estudio geológico de la región de Guanacaste, Costa Rica.- 112 págs. IGN, San José.

DENYER, P. \& ALVARADO, G., 2007: Mapa geológico de Costa Rica.- Escala 1:400 000, Librería Francesa, San José.

DENYER, P. \& FLORES, K., 2003: Mapa geológico de la hoja Matambú.- Escala 1:100 000, Rev. Geol. Amér. Central, 28.

DENYER, P. \& GAZEL, E., 2009: The Costa Rican Jurassic to Miocene oceanic complexes: Origin, tectonics and relations.- J. South Amer. Earth Sci., 28: 429-442.

DENYER, P., MONTERO, W. \& ALVARADO, G., 2003: Atlas tectónico de Costa Rica.81 págs. Editorial Universidad de Costa Rica, San José.

DENYER, P., MONTERO, W. \& FLORES, K., 2005: Apuntes sobre la geología de las hojas Golfo y Berrugate.- Rev. Geól. Amér. Central. 32: 99-108

DICKINSON, W.R., 1996: Kinematics of Transrotacional Tectonism in the California
Transverse Ranges and Its Contribution to Cumulative Slip Along the San Andreas Transform Fault System.- Geol. Soc. Amer. Spec. Paper, 305: 1-46.

FISHER, D. M., GARDNER, T. W., MARSHALL, J. \& MONTERO, W., 1994: Kinematics associated with the late Cenozoic deformation in Central Costa Rica: Western boundary of the Panama microplate.- Geol. 22: 263-266.

FISHER, D.M., GARDNER, T.W., MARSHALL, J., SAK, P.B. \& PROTTI, M., 1998: Effect of subducting seafloor roughness on forearc kinematics, Pacific Coast, Costa Rica.Geology, 26: 467-470.

FLORES, K. \& DENYER, P., 2003: Mapa geológico de la hoja Talolinga.- Escala 1: 100 000, Rev. Geol. Amér. Centr., 28.

FLORES, K., DENYER, P. \& AGUILAR, T., 2003: Nueva propuesta estratigráfica: geología de las hojas Matambú y Talolinga Guanacaste, Costa Rica.- Rev. Geol. Amér. Central. 28: 131-138.

FREUND, R., 1970: Rotation of strike slip faults in Sistan.- Southeast Iran J. Geol., 78: 188-200.

FREUND, R., 1971: The Hope fault, a strike slip fault in New Zealand.- New Zealand Geol. Surv. Bull. 86:1-49.

GARDNER, T.H., VERDONCK, D., PINTER, N.M., SLINGERLAND, R., FURLONG, K.P., BULLARD, T.H. \& WELLS, S.G., 1992: Quaternary Uplift astride the aseismic Cocos Ridge, Pacific coast, Costa Rica.Geol. Soc. Amer. Bull. 104: 219-232.

GARDNER, T., MARSHALL, J., MERRITS, D., BEE, B., BURGETTE, R., BURTON, E., COOKE, J., KEHRWALD, N., PROTTI, M., FISHER, D. \& SAK, P., 2001: Holocene forearc block rotation in respon- 
se to seamount subduction, southeastern Península de Nicoya, Costa Rica.- Geol. 29: 151-154.

GARFUNKEL, Z., 1970: The tectonics of the western margins of the Southern Arava.- 204 págs. Univ. Hebrew, Israel [Tésis Ph. D].

GHOSH, A, NEWMAN, A, THOMAS, A. \& FARMER, G., 2008: Interface locking along the subduction megathrust from $b-$ value mapping near Nicoya Peninsula, Costa Rica.- Geophys. Res. Letters. 35, DOI:10.1029/2007GL031617.

GRÄFE, K., 1998, Exhumation and thermal evolution of the Cordillera de Talamanca (Costa Rica): constrains from fission track analysis, 40Ar-39Ar and 40Rb-39Sr chronology.- 113 pp. Univ. of Tübingen, Germany [Thesis Ph.D].

GRÄFE, K., FRISCH, W., VILLA, I.M. \& MESCHEDE, M., 2002, Geodynamic evolution of southern Costa Rica related to low-angle subduction of the Cocos Ridge: constrains from thermochronology.Tectonophysics, 348: 187-204.

GURSKY, M. 1988: Análisis tectónico de la Península de Nicoya (Costa Rica) y su significado para el desarrollo estructural-geodinámico de América Central meridional.- Rev. Geol. Amér. Central, 8: 19-75.

HANSEN, S.E., SCHWARTZ, S.Y., DESHON, H.R. \& GONZÁLEZ, V., 2006: Earthquake Relocation and Focal Mechanism Determination Using Waveform Cross Correlation, Nicoya Peninsula, Costa Rica.- Bull. Seismol. Soc. Amer. 96: 10031011, DOI: $10.1785 / 0120050129$.

HARE, P.W. \& GARDNER, T. W., 1985: Geomorphic indicators of vertical neotectonism along convergent plate margins, Nicoya Peninsula, Costa Rica.- En:
HACK, J. \& MORISAWA, M., (eds.).Tectonic Geomorphology: Proceedings, 15th Geomorphology Symposia series, Binghamton, New York: 76-104

HILTON, D., FISCHER, T.P., RAMÍREZ, C., FUERI, E., BARRY, P.H., MONTERO, W. \& DENYER, P., 2009a, Helium isotopes in the seismogenic zone of Costa Rica.DINGUE Noble Gas Workshop, Nancy, France. [2 págs. sin numeración].

HILTON, D.R., FÜRI, E., FISCHER, T.P., RAMÍREZ, C., TRYON, M., BARRY, P.H., BROWN, K.M., MONTERO, W. \& DENYER, P., 2009b, Helium and $\mathrm{CO}_{2}$ characteristics of the submarine and subaerial fluids of the Costa Rica forearc.- Goldschmidt Conference, Davos, Switzerland. [1 pág. sin numeración].

JACKSON, J. \& MOLNAR, P., 1990: Active faulting and block rotations in the western Transverse Ranges, California.- J. Geophys. Res., 95: 22073-22087.

KOLARSKY, R., MANN, P., \& MONTERO, W., 1995: Forearc deformation related to the subduction of the Cocos ridge, southeastern Costa Rica.- En MANN., P. (ed.): Geologic and Tectonic Development of the Caribbean Plate Boundary in Southern Central America.- Geol. Soc. Amer. Spec. Paper, 295: 235-262.

LAFEMINA, P., DIXON, T.H., GOVERS, R., NORABUENA, E., TURNER, H., SABALLOS, A., MATTIOLI, G., PROTTI, M., \& STRAUCH, W., 2009: Fore-arc motion and Cocos Ridge collision in Central America.- Geochem. Geophys. Geosyst., 10, DOI:10.1029/2008GC002181.

MACMILLAN, I., GANS, P.B., \& ALVARADO, G., 2004: Middle Miocene to present plate tectonic history of the southern Central American Volcanic Arc.- Tectonophysics, 392: 325-348. 
MARSHALL, J. \& ANDERSON, R., 1995: Quaternary uplift and seismic cycle deformation, Península de Nicoya, Costa Rica.Geol. Soc. Amer. Bull., 107: 463-473.

MONTERO, W., 1994: Neotectonics and related stress distribution in a subduction-collisional zone: Costa Rica.- En: SEYFRIED, H. \& HELLMANN, W. (eds.): Geology of an Evolving Island Arc, The Isthmus of Southern Nicaragua, Costa Rica and Western Panamá.- Profil, 7: 125-141.

MONTERO, W., \& ALVARADO, G., 1988: Los terremotos de Bagaces de 1935 y 1941: Neotectonismo transversal a la Cordillera Volcánica del Guanacaste.- Ciencia y Tecnología, 12: 69-87.

MONTERO, W., FERNÁNDEZ, M., ROJAS, W., BRENES, L. \& REDONDO, C., 1998: Sismicidad y sismotectónica de la región central de Costa Rica.- 34 págs. Univ. de Costa Rica, San José [Inf. Interno].

NEWMAN, A.V., SCHWARTZ, S.Y., GONZALEZ, V., DESHON, H.R., PROTTI, J.M. \& DORMAN, L.M., 2002: Along-strike variations in the seismogenic zone below Nicoya Peninsula, Costa Rica.- Geophys. Res. Lett., 29(20), DOI: 10.1029/2002GL015409.

NORABUENA, E., DIXON, T., SCHWARTZ, S., DESHON, H., NEWMAN, A., PROTTI, M., GONZALEZ, V., DORMAN,L., FLUEH, E., LUNDGREN, P., POLLITZ, F., \& SAMPSON, D., 2004: Geodetic and seismic constraints on some seismogenic zone processes in Costa Rica.- J. Geophys. Res., 109, DOI:10.1029/2003JB002931.

PROTTI, M., GÜENDEL, F. \& MCNALLY, K., 1995: Correlation between the age of the subducting Cocos plate and the geometry of the Wadati-Benioff zone under Nicaragua-Costa Rica.- En:
MANN, P. (ed.): Geologic and Tectonic Development of the Caribbean Plate Boundary in Southern Central America.Geol. Soc. Amer. Spec. Paper 295: 309326.

RANERO, C.R. \& VON HUENE, R., 2000: Subduction erosion along the Middle America convergent margin.- Nature, 404: 748-752.

SANDOVAL, L.F, SÁENZ, R., ACUÑA, J., CASTRO, J.F., GÓMEZ, M., LÓPEZ, A., MEDEROS, B., MONGE, A., VARGAS, J., FERNÁNDEZ, T., ULATE, R. \& RAMÍREZ, C., 1982: Mapa Geológico de Costa Rica.- Escala 1:200 000, IGN, San José.

SAK, P., FISHER, D., GARDNER, T., MARSHALL, J. \& LAFEMINA, P., 2009: Rough crust subduction, forearc kinematics, and Quaternary uplift rates, Costa Rican segment of the Middle America Trench.- Geologic. Soc. Amer. 121: 992 1012, DOI: 10.1130/B26237.1

STANKOVA-PURSLEY, J., BILEK, S., PHILIPPS, W.S., \& NEWMAN, A., 2011: Along strike variations of earthquake apparent stress at the Nicoya Peninsula, Costa Rica, subduction zone.Geochem. Geophys. Geosyst. 12(8), DOI: 10.1029/2011GC003558.

TAYLOR, F.W., MANN, P., BEVIS, M., EDWARDS, R., CHENG, H., CUTLER, K., GRAY, S., BURR, G., BECK, J., PHILLIPS, D., CABIOCH, G. \& RECY, J., 2005: Rapid forearc uplift and subsidence caused by impinging bathymetric features: Examples from the New Hebrides and Solomon arcs.- Tectonics, 24, DOI: 10.1029/2004TC001650.

TURNER, H.L., LAFEMINA, P., SEVALLOS, A., MATTIOLI, G.S., JANSMA, P.E., \& DIXON, T., 2007: Kinematics of 
the Nicaraguan forearc from GPS geodesy.- Geophys. Res. Letters, 34, DOI: 10.1029/2006GL027586.

USGS, 2004: Shuttle Radar Topography Mission, 1 Arc Second scene SRTM.Global Land Cover Facility, Universidad de Maryland. http://www.glcf.umd.edu/ data/srtm/.

VANNUCCHI, P., SCHOLL, D., MESCHEDE, M. \& MCDOUGALL-REID, K., 2001: Tectonic erosion and consequent collapse of the Pacific margin of Costa Rica: Combined implications from ODP Leg 170, seismic offshore data, and regional geology of Nicoya Peninsula.- Tectonics, 20: 649-668.

VON HUENE, R., BIALAS, J., EMEIS, K., FLUH, E., LEANDRO, C., CROPP, B., CSERNOK, T., FABEL, E., PEREZ., I., FLORES, A., HOFFMANN, J., HOLLER, P., LEON, R., BARRIOS, O., CHAVARRIA, J., JESCHKE, G. \& ESCOBEDO, D., 1995: Morphotectonics of the Pacific margin of Costa Rica.- En: MANN, P. (ed.): Geologic and Tectonic development of the Caribbean plate boundary in Central America.- Geol. Soc. Amer. Spec. Paper: 295: 291-307.

VON HUENE, R., RANERO, C.R. \& WATTS, P. 2004: Tsunamigenic slope failure along the Middle America Trench in two tectonic settings.- Marine Geol. 203: 303-317.

VON HUENE, R., RANERO, C.R., WEINREBE, W. \& HINZ, K., 2000: Quaternary convergent margin tectonics of Costa Rica, segmentation of the Cocos plate and Central America volcanism.- Tectonics, 19: 314-334.

WALTHER, C.H.E., 2003: The crustal structure of the Cocos ridge off Costa Rica.- J. Geophys. Res. 108 (B3), 2136, DOI: 10.1029/2001JB000888.

WELLS, S., BULLARD, T., MENGES, C., DRAKE, P., KARAS, K., KELSON, K., RITTER, J. \& WESLING, J., 1988: Regional variations in tectonic geomorphology along a segmented convergent plate boundary, Pacific coast of Costa Rica.- Geomorphology, 1: 239-265. 